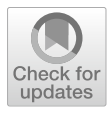

Cite as

Nano-Micro Lett.

(2020) 13:12

Received: 24 July 2020

Accepted: 28 September 2020

Published online: 28 October 2020

(C) The Author(s) 2020

\section{Advanced Anode Materials of Potassium Ion Batteries: from Zero Dimension to Three Dimensions}

\author{
Jiefeng Zheng ${ }^{1}$, Yuanji Wu${ }^{1}$, Yingjuan $\mathrm{Sun}^{1}$, Jianhua Rong ${ }^{1}$, Hongyan $\operatorname{Li}^{1}{ }^{\circledR}{ }^{凶}, \mathrm{Li} \mathrm{Niu}^{2}$
}

\title{
HIGHLIGHTS
}

- This review introduces the recent anode materials of potassium ion batteries classified into $0 \mathrm{D}, 1 \mathrm{D}, 2 \mathrm{D}$, and 3D, mainly including carbon materials, metal-based chalcogenides and metal-based oxides, and alloying materials.

- The advantages, disadvantages, and optimized strategies of different dimensional anode materials are summarized.

- The relationship between different dimensional anode materials in potassium ion batteries and the corresponding electrochemical performances is outlined. And some strategies are proposed to deal with the current disadvantages of potassium ion batteries.

ABSTRACT Potassium ion batteries (PIBs) with the prominent advantages of sufficient reserves and economical cost are attractive candidates of new rechargeable batteries for large-grid electrochemical energy storage systems (EESs). However, there are still some obstacles like large size of $\mathrm{K}^{+}$to commercial PIBs applications. Therefore, rational structural design based on appropriate materials is essential to obtain practical PIBs anode with $\mathrm{K}^{+}$accommodated and fast diffused. Nanostructural design has been considered as one of the effective strategies to solve these issues owing to unique physicochemical properties. Accordingly, quite a few recent anode materials with different dimensions in PIBs have been reported, mainly involving in carbon materials, metal-based chalcogenides (MCs), metal-based oxides (MOs), and alloying materials. Among these anodes, nanostructural carbon materials with shorter ionic transfer path are beneficial for decreasing the resistances of transportation. Besides, MCs, MOs, and alloying materials with nanostructures can effectively alleviate their stress changes. Herein, these materials are classified into 0D, 1D, 2D,

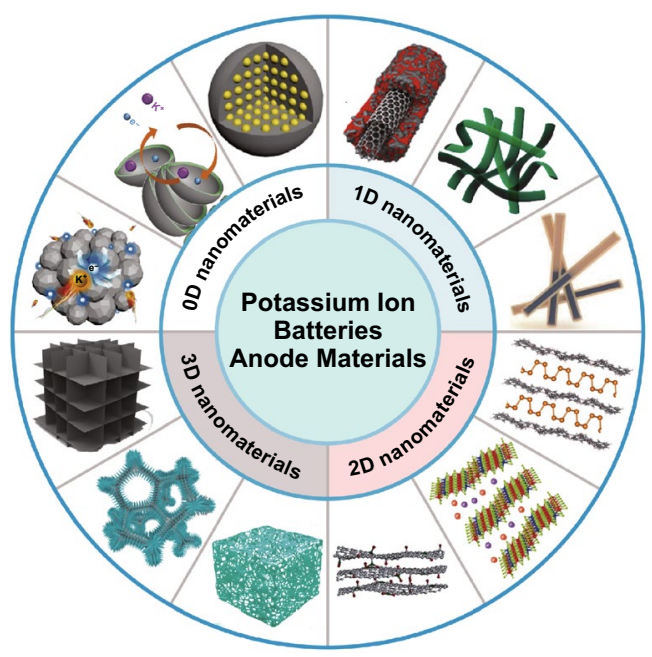
and 3D. Particularly, the relationship between different dimensional structures and the corresponding electrochemical performances has been outlined. Meanwhile, some strategies are proposed to deal with the current disadvantages. Hope that the readers are enlightened from this review to carry out further experiments better.

KEYWORDS Potassium ion batteries; Anode; Structure design; Nanomaterials; Dimensions

Hongyan Li, lihongyan@jnu.edu.cn

1 Department of Materials Science and Engineering, College of Chemistry and Materials Science, Jinan University, Guangzhou 510632, People's Republic of China

2 Center for Advanced Analytical Science, c/o School of Chemistry and Chemical Engineering, Guangzhou University, Guangzhou 510006, People's Republic of China 


\section{Introduction}

In 2004, it was the first time that Ali Eftekhari proposed the prototype of PIBs [1]. Nonetheless, the later stagnation about PIBs researches was ascribed to the safety issues about the $\mathrm{K}$ as well as technologies about other metal ion batteries becoming increasingly popular [2]. Owing to fossil fuels used increasingly as well as the severity of global warming, renewable and sustainable energy sources have been exploiting, including solar, wind, rain, geothermal, tide, and wave energies. Nevertheless, EESs must be considered to solve the intermittent issues of clean energy, which has a great effect on storing and delivering these energy resources [3, 4]. So far, lithium ion batteries (LIBs), as a representative energy storage technology, have been widely explored for portable devices, electrical vehicles, and large-grid EESs because of high energy density and stable cycling lifespan [5]. Unfortunately, there are some barriers for LIBs to develop sustainably, such as challenging lithium $(\mathrm{Li})$ recovery, uneven distribution of $\mathrm{Li}$, and increasing cost [6-8]. Accordingly, it is necessary to search for alternative rechargeable batteries' technologies. Based on cost and resource considerations, scientists have put a lot of effort into developing a series of non-lithium ion batteries, including sodium ion batteries (SIBs) [9], PIBs [10], magnesium ion batteries (MIBs) [11], zinc ion batteries (ZIBs) [12], aluminum ion batteries (AIBs) [13] and so on [14]. Since zinc, magnesium, and aluminum are less active than lithium, they could be used as anode materials for metal ion batteries [15-17]; especially, magnesium and aluminum anodes do not even form dendrites, so their corresponding ion batteries are able to meet the safe requirement $[18,19]$. In addition, commercial LIBs mainly use graphite with a theoretical specific capacity of $372 \mathrm{mAh} \mathrm{g}^{-1}$ as anode material, while the capacities of zinc $\left(820 \mathrm{mAh} \mathrm{g}^{-1}\right)$ [20], magnesium (2205 $\left.\mathrm{mAh} \mathrm{g}^{-1}\right)$, and aluminum $\left(2980 \mathrm{mAh} \mathrm{g}^{-1}\right)$ anodes are much higher than that of graphite [18]. Clearly, each multivalent cation can exchange more than one electron, suggesting that if a host material can store the same number of cations, the capacities of multivalent ion cells are several times that of monovalent ion cells. Therefore, these multivalent ion batteries may have higher energy densities. Furthermore, the ion radii of zinc ions $(0.74 \AA$ ) [12], magnesium ions (0.72 $⿱$ ) [21], and aluminum ions ( $0.535 \AA$ ) [21] are relatively small, having low trends to damage the structure of host material. However, although these multivalent metal ion batteries have various irreplaceable advantages, they also face some intractable problems. First of all, the surface charge density of these multivalent metal ions is relatively high, resulting in greater mutual repulsion between cations and greater interaction between cations and host materials, which is not conducive to high capacity and high rate performance for batteries [22]. Besides, the potentials of $\mathrm{Zn} / \mathrm{Zn}^{2+}$ ( $-0.76 \mathrm{~V}$ vs. SHE) [23], $\mathrm{Mg} / \mathrm{Mg}^{2+}\left(-2.37 \mathrm{~V}\right.$ vs. SHE) [14], $\mathrm{Al} / \mathrm{Al}^{3+}(-1.76 \mathrm{~V}$ vs. SHE) [13] are much higher than that of $\mathrm{Li}^{2} / \mathrm{Li}^{+}(-3.04 \mathrm{~V}$ vs. SHE), indicating that it is difficult for these batteries to obtain high operating voltages. There are many other problems that hinder their development. For instance, the zinc anode is still plagued by dendrites problem [24] and the electrolyte used in MIB is not ideal [14, 25, 26]. Compared with MIBs, ZIBs, and AIBs, both the working principle and the electrode materials and electrolytes used in SIBs and PIBs are similar to those of LIBs, for the reason that sodium, potassium, and lithium have similar physical and chemical properties [27]. It is expected that PIBs and SIBs have fewer obstacles for commercial applications.

PIBs aroused remarkable attentions again in 2015 and increasing researches have been publishing since then (the inset of Fig. 1). Firstly, PIBs possess similar rocking-chair operating principle compared with LIBs, which provides a favorable foundation for the studies of PIBs [28, 29]. Secondly, PIBs with lower price and sufficient resources are suitable for EESs [30]. Thirdly, the standard redox potential versus SHE of $\mathrm{K}^{+} / \mathrm{K}(-2.93 \mathrm{~V})$ is not only even comparable to that of $\mathrm{Li}^{+} / \mathrm{Li}(-3.04 \mathrm{~V})$ but also lower compared with that of $\mathrm{Na}^{+} / \mathrm{Na}(-2.71 \mathrm{~V})$; thus, PIBs are beneficial to produce higher operating voltages [31, 32]. Meanwhile, the lowest potential versus SHE of $\mathrm{K}^{+} / \mathrm{K}(-2.88 \mathrm{~V})$ is compared with that of $\mathrm{Na}^{+} / \mathrm{Na}(-2.56 \mathrm{~V})$ and $\mathrm{Li}^{+} / \mathrm{Li}(-2.79 \mathrm{~V})$ in some non-aqueous electrolytes like propylene carbonate solvent, which makes PIBs benefit from wider potential window to achieve high energy density [2, 33, 34]. Besides, Okoshi et al. indicated that weaker Lewis acidity and low $\mathrm{K}$-ion desolvation energy brought about the smaller Stokes radius of solvated ions and the low interfacial reaction resistance, respectively, which made $\mathrm{K}$ electrolytes possess higher conductivity compared with $\mathrm{Li}$ as well as sodium (Na) electrolytes [35]. In addition, the commercialized graphite has been successfully explored for PIBs anode and the theoretical capacity is around $279 \mathrm{mAh} \mathrm{g}^{-1}$, but it is not suitable 


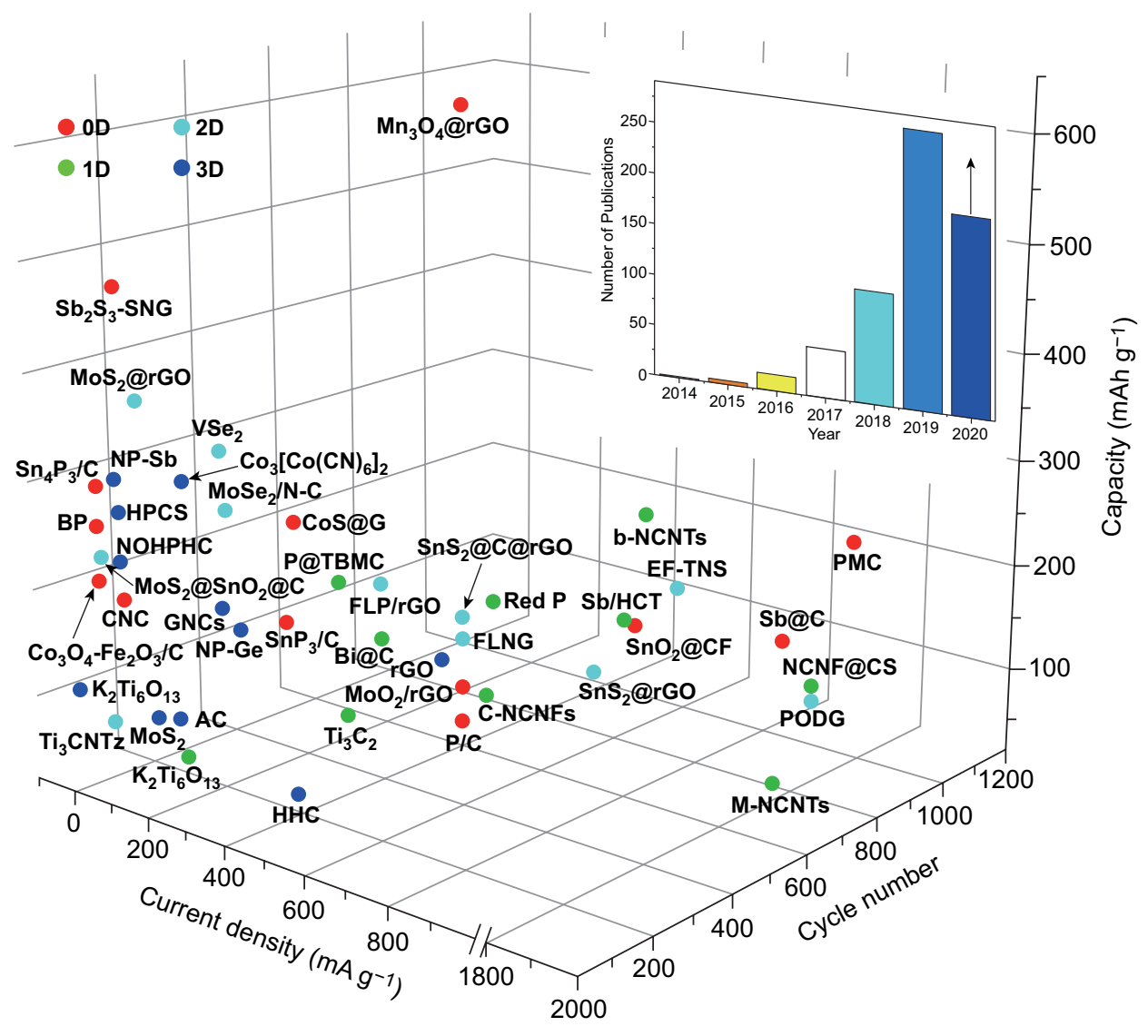

Fig. 1 Cycle capacity of various PIBs anode materials reported recently. $\mathrm{Sb}_{2} \mathrm{~S}_{3}$-SNG [38]; $\mathrm{Co}_{3} \mathrm{O}_{4}-\mathrm{Fe}_{2} \mathrm{O}_{3} / \mathrm{C}$ [39]; black phosphorus $=\mathrm{BP}$ [33]; $\mathrm{Sn}_{4} \mathrm{P}_{3} / \mathrm{C}$ [40]; $\mathrm{CoS} @ \mathrm{G}$ [41]; CNC [42]; PMC [43]; $\mathrm{Sb@C} \mathrm{[44];} \mathrm{P/C} \mathrm{[45];} \mathrm{MoO}_{2} / \mathrm{rGO}$ hollow sphere composites= $\mathrm{MoO}_{2} / \mathrm{rGO}$ [46]; $\mathrm{Mn}_{3} \mathrm{O}_{4} @ \mathrm{rGO}$ [47]; $\mathrm{SnP}_{3} / \mathrm{C}$ [48]; $\mathrm{SnO}_{2}$ nanoparticles anchored on carbon foam= $\mathrm{SnO}_{2} @ \mathrm{CF}$ [49]; P@TBMC [50]; NCNF@CS [51]; alkalized $\mathrm{Ti}_{3} \mathrm{C}_{2}$ MXene nanoribbons $=\mathrm{Ti}_{3} \mathrm{C}_{2}$ [52]; chitin-derived NCNFs =C-NCNFs [53]; bamboo-like NCNTs =b-NCNTs [54]; MOF-derived

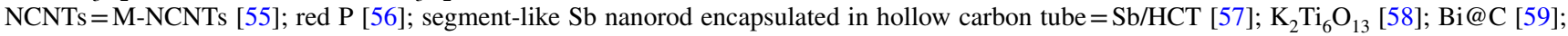
$\mathrm{Ti}_{3} \mathrm{CNTz}$ [60]; $\mathrm{MoS}_{2} @ \mathrm{rGO}$ [61]; $\mathrm{MoS}_{2} @ \mathrm{SnO}_{2} @ \mathrm{C}$ [62]; graphene-like $\mathrm{VSe}_{2}$ nanosheets= VSe $\mathrm{V}_{2}$ [63]; Few-layered SnS ${ }_{2}$ nanosheets supported on $\mathrm{rGO}=\mathrm{SnS}_{2} / \mathrm{rGO}$ [64]; FLNG [65]; PODG [66]; $\mathrm{MoSe}_{2} / \mathrm{N}-\mathrm{C}$ [67]; EF-TNS [68]; FLP/rGO [69]; $\mathrm{MoS}_{2}$ [70]; $\mathrm{K}_{2} \mathrm{Ti}_{6} \mathrm{O}_{13}$ [71]; NP-Sb [72]; NP-Ge [73]; activated carbon $=\mathrm{AC}$ [74]; $\mathrm{Co}_{3}\left[\mathrm{Co}(\mathrm{CN})_{6}\right]_{2}$ [75]; HPCS [76]; N/O co-doped mesoporous carbon octahedrons = NOHPHC [77]; rGO aerogel = rGO [78]; GNCs [79]; honeycomb hard carbon = HHC [80]. And the inset about number of articles obtained from Web of Science on PIBs anode materials and based on the corresponding Topic about potassium ion battery, potassium ion storage, potassium storage, and anode (accessed: July 1, 2020)

for SIBs [28, 29, 31]. Furthermore, the unwanted K-metal deposition on the surface of anode may be hindered due to the insertion potential versus $\mathrm{K}^{+} / \mathrm{K}$ of $\mathrm{K}$-ion $(0.2 \mathrm{~V})$, which is beneficial for improving safety in terms of operation [32]. Moreover, compared with Li metal $\left(180.54{ }^{\circ} \mathrm{C}\right)$ and Na metal $\left(\approx 98{ }^{\circ} \mathrm{C}\right)$, K-metal lower melting point $\left(63.38^{\circ} \mathrm{C}\right)$ makes the dendritic $\mathrm{K}$ melting to provide a secure capability under an appropriate temperature [10, 36, 37]. It is worth mentioning that $\mathrm{Cu}$ foil can be replaced with $\mathrm{Al}$ foil as current collectors in anode electrode of PIBs without forming Al-K alloy, cutting down the batteries' production expenses [29]. Given the above-mentioned advantages, $\mathrm{PIBs}$ are promising alternative batteries for LIBs. To date, the reported PIBs anode materials mainly contain carbon materials (e.g., carbon nanotubes (CNTs), graphene, and graphite), $\mathrm{MCs}$ (e.g., $\mathrm{MoS}_{2}$ and $\mathrm{MoSe}_{2}$ ), MOs (e.g., $\mathrm{MoO}_{2}$ and $\mathrm{SnO}_{2}$ ), and alloying materials (e.g., antimony ( $\mathrm{Sb})$, tin ( $\mathrm{Sn})$, bismuth (Bi), germanium (Ge), and phosphorous (P)) (Fig. 1).

Accordingly, lots of anode materials have been reported, but it is still necessary to well comprehend how to select suitable anode materials so as to make it convenient to search for the related materials. It is known that alkali ion batteries (LIBs, SIBs, and PIBs) have similar electrochemical processes due to their similar features. And then, the 
practical application of alkali ion batteries can be influenced because of the choice of suitable anode materials based on selection principle. Therefore, the selection principle of LIBs, SIBs, and PIBs should be considered about several aspects in detail: (1) The materials can be regarded as anode materials, depending on whether the material can react with alkali ions and the corresponding theoretical capacity; (2) The structural stability and durability should also be considered because the robust structures can better tolerate with the stress variation during long cycles; (3) The operability of the materials is also one of the considered factors, so the materials affected easily by environmental conditions like oxygen should be excluded; (4) The cost of materials also affects the practical application of batteries; (5) The recyclability of electrode materials should be paid more attention to make good use of resources and protect environment. Therefore, based on aforementioned selection principle, the anode materials can be better chosen. However, it does not mean that all anode electrodes used in LIBs can be successfully used in SIBs and PIBs, although LIBs, SIBs, and PIBs have similarities in the energy storage mechanism. For examples, the aforementioned graphite can be used as the commercial LIBs electrode materials but not suitable for $\mathrm{Na}^{+}$. This phenomenon is possibly attributed to two main reasons: (1) Ionic insertion can be affected because of different storage reactions between ions and the corresponding active materials and (2) Different ion radii are necessary to search for related different material accommodating their ionic size, such as $\mathrm{Li}^{+}(0.76 \AA), \mathrm{Na}^{+}(1.02 \AA)$, and $\mathrm{K}^{+}(1.38$ $\AA)$. So some anode materials may be conducive to hold $\mathrm{Li}^{+}$ but not in favor of containing large K-ion.

The aforementioned electrode materials have exhibited distinct electrochemical performances due to their unique features. Meanwhile, it is well known that the materials properties will be affected due to different dimensional structures. Zero-dimensional (0D) nanomaterials can promote ionic adsorption and mitigate stress variation owing to surface effect and small size effect. As 0D nanomaterials, $\mathrm{SnO}_{2}$ nanoparticles anchored on carbon foam not only facilitated electrolyte penetration but also boosted $\mathrm{K}$-ion transport, which realized the cycle capacity of $231.7 \mathrm{mAh} \mathrm{g}^{-1}$ at $1 \mathrm{~A} \mathrm{~g}^{-1}$ after 400 cycles as well as the rate capacity of $143.5 \mathrm{mAh} \mathrm{g}^{-1}$ at $5 \mathrm{~A} \mathrm{~g}^{-1}$ [49]. Furthermore, one-dimensional (1D) nanomaterials with high length-to-diameter ratio are beneficial to enhance the electronic and ionic transfer and provide high mechanical robustness. For example, owing to unique architecture, nitrogen (N)-doped carbon nanofibers (CNFs) as electrode materials in PIBs exhibited outstanding performances, delivering a capacity of $146 \mathrm{mAh} \mathrm{g}^{-1}$ at $2 \mathrm{~A} \mathrm{~g}^{-1}$ after 4000 cycles [81]. In addition, two-dimensional (2D) nanomaterials are also capable of improving ionic adsorption and facilitating ionic diffusion owing to high surface area as well as tunable interlayer spacing. As one of the typical 2D materials, few-layer bismuthene explored for PIBs anode materials could facilitate electrolyte infiltration, boost K-ion transfer, and buffer volumetric expansion in the course of charge and discharge process, so a capacity of more than $200 \mathrm{mAh} \mathrm{g}^{-1}$ was delivered at $20 \mathrm{~A} \mathrm{~g}^{-1}$ over 2500 cycles [82]. As for three-dimensional (3D) nanomaterials, with high mechanical strength and interconnected structures, they can effectively tolerate stress variation and make largely electrode contact with electrolyte as well as promote electronic conductivity. In 2019, 3D reduced graphene oxide (rGO) aerogel was fabricated to enhance $\mathrm{K}$-ion transfer, improving rate performance $\left(92 \mathrm{mAh} \mathrm{g}^{-1}\right.$ at $\left.6.7 \mathrm{C}\right)$ as well as cycle performance (267 $\mathrm{mAh} \mathrm{g}^{-1}$ at $\mathrm{C} / 3$ after 100 cycles) [78].

In this review, $0 \mathrm{D}, 1 \mathrm{D}, 2 \mathrm{D}$, and 3D nanomaterials about the recent developed PIBs anode materials will be introduced (Fig. 2), mainly concentrating on carbon materials, MCs and MOs, and alloying materials. Among them, carbon materials with the advantage of low price are attributed to its abundant sources, which is beneficial for practical applications. In addition, the existing technology can be used to prepare carbon nanomaterials, making the synthesis process convenient. And then, the structures of carbon materials are relatively stable and durable, which helps to keep structural stability and improve the long life of the corresponding electrode during charging and discharging. As for MCs and MOs, they have high capacity and it is easy to synthesize. Besides, alloying materials not only possess high theoretical capacity, such as $\mathrm{Sb}\left(660 \mathrm{mAh} \mathrm{g}^{-1}\right)$ [83] and $\mathrm{Bi}$ (385 $\mathrm{mAh} \mathrm{g}^{-1}$ ) [83], but also can react with K-ion under low potentials $\left(\sim 0.1-0.8 \mathrm{~V}\right.$ vs. $\left.\mathrm{K}^{+} / \mathrm{K}\right)$ [72, 84-88]. Additionally, similar to MCs and MOs, alloying materials can be prepared by some easy synthesis methods, so it is convenient to obtain the corresponding products [2]. According to these advantages, alloying materials can be considered as anode materials of PIBs. Furthermore, the structural design and the corresponding electrochemical performances of different dimensional anode materials will be summarized. To date, the capacities of $0 \mathrm{D}-3 \mathrm{D}$ carbon materials have varied from 200 to $600 \mathrm{mAh} \mathrm{g}^{-1}$. Moreover, MCs and MOs 


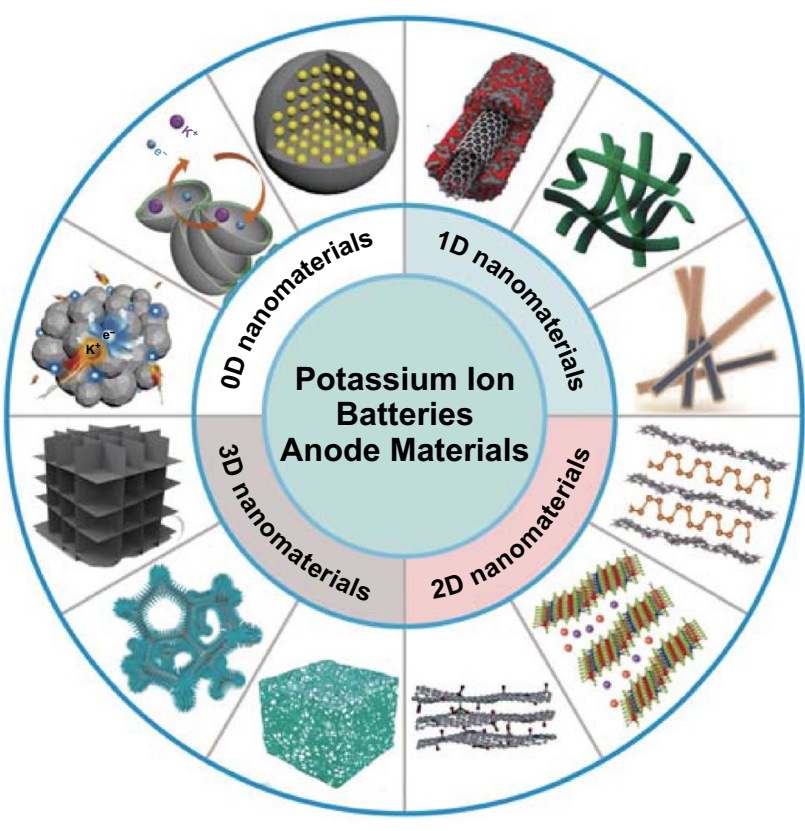

Fig. 2 Schematic diagram of various 0D-3D PIBs anode materials. Reproduced with permission from Ref. [42, 43, 68, 89]. Copyright 2018 (2019), John Wiley and Sons; from Ref. [66, 90, 91]. Copyright 2017 (2019, 2020), Royal Society of Chemistry; from Ref. [50]. Copyright 2018, Elsevier; from Ref. [69, 72, 92, 93]. Copyright 2017 (2018, 2019), American Chemical Society

with 0D-3D structures have delivered the capacities with 50-600 $\mathrm{mAh} \mathrm{g}^{-1}$. In addition, the capacities of 0D-3D alloying materials varied from 300 to $1000 \mathrm{mAh} \mathrm{g}^{-1}$ have been studied [36]. Meanwhile, some practical strategies about solving some challenging issues will be proposed.

\section{Zero-Dimensional Nanomaterials for PIBs}

OD nanomaterials are defined as $1 \mathrm{~nm}$ to $100 \mathrm{~nm}$ in three dimensions. So far, OD nanomaterials have various types, including quantum dots, nanoparticles, nanospheres, nanocages, core-shell structures, and so forth. Typically, these OD nanomaterials have been widely studied in energy storage field due to structural features and properties including surface effect, small size effect, and so on; especially, the small size of $0 \mathrm{D}$ nanomaterials possesses large surface area, providing sufficient sites for ionic adsorption [94, 95]. Additionally, the stable structure plays a crucial role in buffering large volume expansion, like hollow 0D nanomaterials. Therefore, 0D nanomaterials are beneficial for anode materials of PIBs to keep contact with electrolyte and restrict volumetric variation. However, the electrochemical performances will be affected due to 0D nanomaterials with easier self-aggregation. Thus, it is better to be composited with other materials to inhibit aggregation for anode materials. Next, the relationship between 0D nanomaterials and the corresponding electrochemical performances will be elaborated in detail. In addition, the initial Coulombic efficiency (C.E.), rate performances, and cycle properties of recent reported OD anode materials of PIBs are summarized in Table 1.

\subsection{Zero-Dimensional Carbon Materials}

0D carbon materials with shorter ionic diffusion pathway are advantageous to reduce transport resistances. Accordingly, a few studies about nanoparticles have recently been reported so as to improve the electrochemical behavior. Carbon nanoparticles with N/P co-doping and expanded interlayer (NP-CNPs) were fabricated for the PIBs electrode materials [107]. The synergistic effect of nano-size and $\mathrm{P} / \mathrm{N}$-co-doping helped to obtain good electrochemical performances. Then, the NP-CNPs electrode had a capacity of $157 \mathrm{mAh} \mathrm{g}^{-1}$ at $5.0 \mathrm{~A} \mathrm{~g}^{-1}$ (Fig. 3c). In addition, a capacity of $190 \mathrm{mAh} \mathrm{g}^{-1}$ was obtained at $1.0 \mathrm{~A} \mathrm{~g}^{-1}$ after 4000 cycles (Fig. 3d). According to experimental test, the nanoparticles with the expanded interlayer and uniform ultrafine nanoparticles were exhibited (Fig. 3a, b). Obviously, the morphology of nanoparticles and its expanded interlayer could effectively improve the electrochemical performances, which not only provided shorter K-ion transfer path as well as improved electrical conductivity, but also enhanced adsorption capability toward K-ions.

Besides, novel hollow structures may be advantageous for accommodating the volumetric changes compared with solid nanoparticles. For example, graphite has been wildly utilized but still suffered from large volumetric variation during charge and discharge process as PIBs electrode. Although some progress has been achieved in terms of regulating structure including polynanocrystalline graphite, activated carbon, and expanded graphite, it is still challenging to ensure the robust stability of graphite during long cycling process $[74,108-110]$. It is worthwhile that hollow nanocages have gradually been used for electrode materials. Cao et al. [42] synthesized graphitic carbon nanocage (CNC) as anode material for PIBs by taking 
Table 1 Comparison of the state-of-the-art performances of OD anode materials in PIBs

\begin{tabular}{|c|c|c|c|c|}
\hline Materials & Initial C.E. (\%) & $\begin{array}{l}\text { Rate capacity }\left(\mathrm{mAh} \mathrm{g}^{-1}\right) \text { at } \\
\text { the current density }\left(\mathrm{mA} \mathrm{g}^{-1}\right)\end{array}$ & $\begin{array}{l}\text { Cycle capacity }\left(\mathrm{mAh} \mathrm{g}^{-1}\right) \text { at the cur- } \\
\text { rent density }\left(\mathrm{mA} \mathrm{g}^{-1}\right) \text { (cycle number) }\end{array}$ & References \\
\hline $\mathrm{Sb}_{2} \mathrm{~S}_{3}-\mathrm{SNG}$ & 69.7 & 340 at 1000 & 480.078 at $50(100)$ & {$[38]$} \\
\hline $\mathrm{Co}_{3} \mathrm{O}_{4}-\mathrm{Fe}_{2} \mathrm{O}_{3} / \mathrm{C}$ & 54 & - & 220 at $50(50)$ & [39] \\
\hline $\mathrm{BP}$ & 60 & 300 at 2000 & 270 at $50(50)$ & {$[33]$} \\
\hline $\mathrm{Sn}_{4} \mathrm{P}_{3} / \mathrm{C}$ & - & 221.9 at 1000 & 307.2 at $50(50)$ & [40] \\
\hline $\mathrm{Sb} @ \mathrm{C}$ & 75.8 & 127 at 2000 & 160 at $1000(800)$ & [44] \\
\hline $\mathrm{Sb} @ \mathrm{PC}$ & 46.2 & 200 at 2000 & 90 at $500(200)$ & [96] \\
\hline $\mathrm{P} / \mathrm{C}$ & 50.3 & 90 at 500 & 71.5 at $500(500)$ & [45] \\
\hline $\mathrm{ZNP} / \mathrm{C}$ & 58.5 & 46 at 2000 & 145 at $500(300)$ & [97] \\
\hline Sb@NPMC & 50 & 161 at 1000 & 130 at $1000(1500)$ & [98] \\
\hline $\mathrm{MoO}_{2} / \mathrm{rGO}$ & 51.6 & 176.4 at 500 & 104.2 at $500(500)$ & [46] \\
\hline $\mathrm{Co}_{0.85} \mathrm{Se}-\mathrm{QDs} / \mathrm{C}$ & 61.8 & 220 at 2000 & 228 at $1000(500)$ & [99] \\
\hline $\mathrm{S}, \mathrm{N}$ co-doped thin carbon & - & 64 at 4000 & 65 at $2000(900)$ & {$[100]$} \\
\hline $\mathrm{Mn}_{3} \mathrm{O}_{4} @ \mathrm{rGO}$ & 66 & 95 at 10,000 & 635 at $500(500)$ & [47] \\
\hline $\mathrm{Fe}_{\mathrm{x}} \mathrm{O} @ \mathrm{NFLG}$ & 46 & 176 at 5000 & 140 at $5000(5000)$ & [101] \\
\hline Titanium oxynitride nanoparticles/carbon & - & 72 at 1600 & 150 at $200(1250)$ & [102] \\
\hline $\mathrm{SnP}_{3} / \mathrm{C}$ & 58.8 & 221.8 at 1200 & 225 at $500(80)$ & {$[48]$} \\
\hline $\mathrm{SnO}_{2} @ 3 \mathrm{D} \mathrm{PC}$ & 13.99 & 144.6 at 2000 & 270.3 at $100(200)$ & [103] \\
\hline VN-QDs/CM & 72.9 & 152 at 2000 & 215 at $500(500)$ & [104] \\
\hline $\mathrm{Co}_{9} \mathrm{~S}_{8} / \mathrm{N}-\mathrm{C} @ \mathrm{MoS}_{2}$ & 89.1 & 50 at 1000 & 100 at $1000(100)$ & {$[105]$} \\
\hline $\begin{array}{l}\text { Carbon-coated mesoporous } \mathrm{Co}_{9} \mathrm{~S}_{8} \text { nano- } \\
\text { particles supported on } \mathrm{rGO}\end{array}$ & 59.5 & 215.1 at 5000 & 210.8 at $1000(1200)$ & [106] \\
\hline $\mathrm{SnO}_{2} @ \mathrm{CF}$ & 44.43 & 143.5 at 5000 & 231.7 at $1000(400)$ & [49] \\
\hline
\end{tabular}

advantage of Ketjen carbon black. From Fig. 3e, f, it can be clearly seen that the CNC possessed interlinked structural appearance, which benefited fast electronic transfer. As for the electrochemical performances, reversible capacities of the $\mathrm{CNC}$ electrode were $221.5 \mathrm{mAh} \mathrm{g}^{-1}$ as well as $175 \mathrm{mAh} \mathrm{g}^{-1}$ at 0.1 and $35 \mathrm{C}$, respectively (Fig. $3 \mathrm{~g}$ ). As expected, the electrochemical behavior of the obtained electrode was due to its unique structure features. In detail, the cage-like structure kept the stability of structure by reducing the anisotropy and avoiding interlayer slipping. Then, the cage-like hollow interior could retain the structural integrity by accommodating volume changes well in the course of charging and discharging. Similarly to soft carbon, hollow graphitized carbon nanocages (HGCNs) were also synthesized as effective PIBs electrode materials [111]. The authors exhibited that HGCN-1000 (1000 mean the carbonization temperature of $1000{ }^{\circ} \mathrm{C}$ ) with highly graphitized carbon-cage, developed porosity, and hollow structure was endowed robust structural stability and good electrochemical performances. Therefore, the capacity retention of $95.9 \%$ for the HGCN-1000 electrode was achieved at $1 \mathrm{~A} \mathrm{~g}^{-1}$ over 2000 cycles, which identified better cyclic stability.

Based on the above-mentioned examples, 0D carbon materials including nanoparticles and nanocages have been fabricated to effectively enhance the electrochemical performances, devoted to fast ionic transportation and high structural stability. However, compared with LIBs and SIBs, few studies about carbon dots (CDs) applied for anode materials of PIBs have been reported [112-120]. Therefore, it is necessary for further experiments to focus on novel structure for the family of OD carbon anode materials, such as CDs, core-shell structure, and yolk shell structure.

\subsection{Zero-Dimensional MCs and MOs}

MCs and MOs have proved to be a kind of hopeful PIBs electrode materials, but severe volume changes and low electrical conductivity have hindered their development. It is well known that the minimization of materials is conducive to alleviating stress changes, so the preparation of OD MCs 
(a)

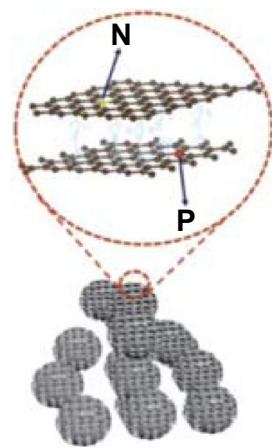

(b)

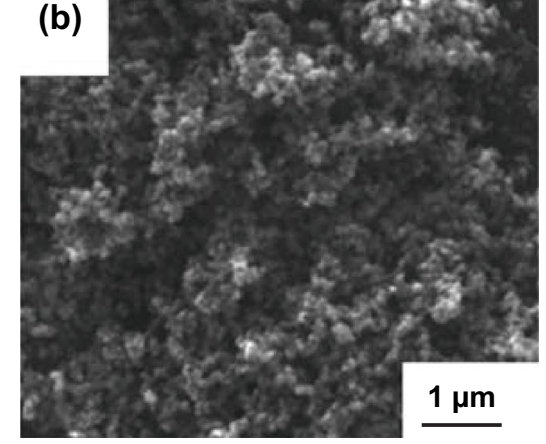

(d)

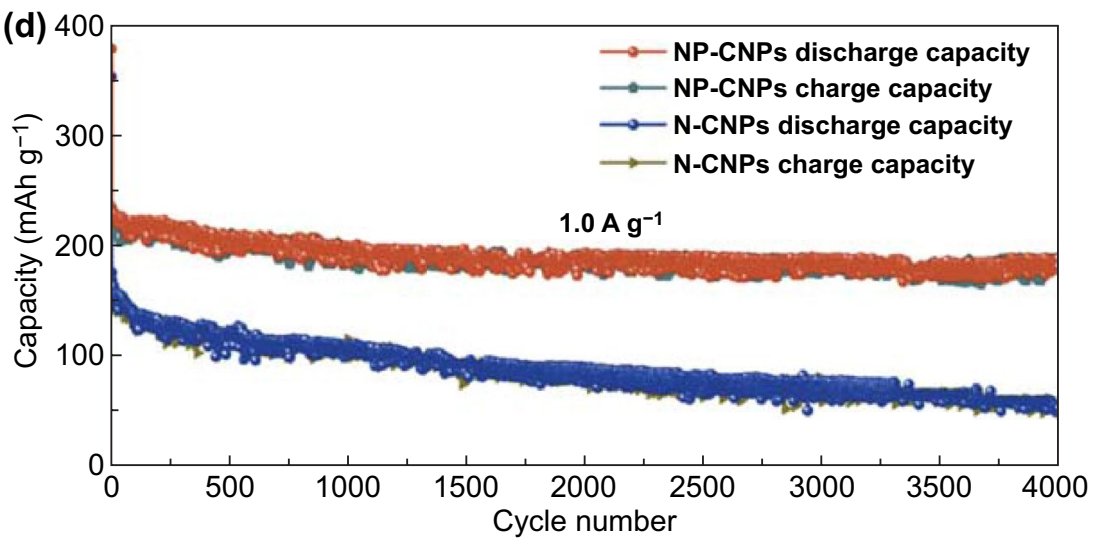

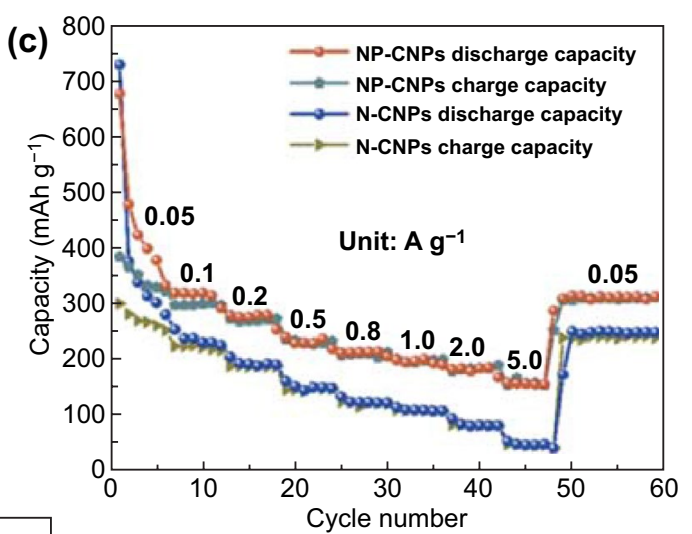

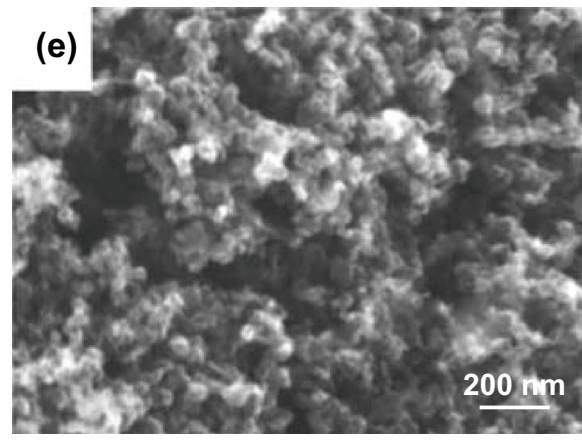

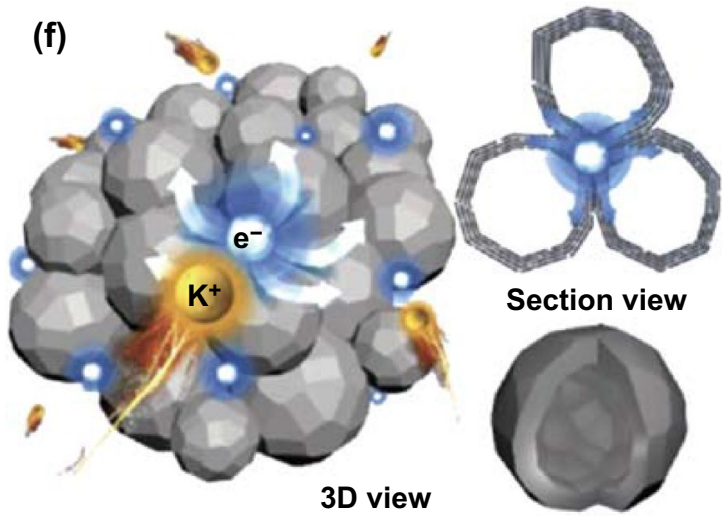

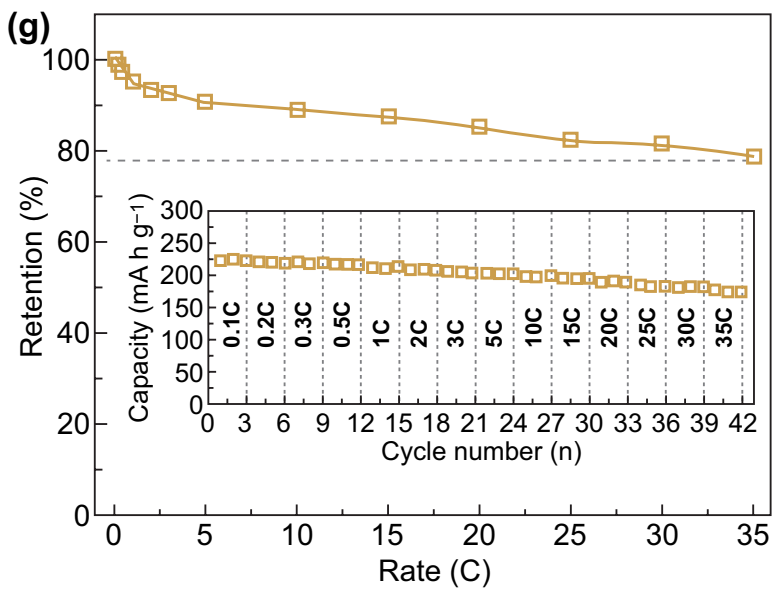

Fig. 3 NP-CNPs' a schematic diagram, b SEM image, $\mathbf{c}$ as well as N-CNPs' rate capacities in the range of $0.05-5.0 \mathrm{~A} \mathrm{~g}^{-1}$, d long cycle capacities at $1.0 \mathrm{~A} \mathrm{~g}^{-1}$ over 4000 cycles. Reproduced with permission from Ref. [107]. Copyright 2019, American Chemical Society. e SEM image of CNC. f Schematic illustration of CNC. $\mathbf{g}$ Discharge capability retention corresponding to rate performance (inset). Reproduced with permission from Ref. [42]. Copyright 2018, John Wiley and Sons

and MOs is an effective method. In order to solve low conductivity and agglomeration problems, MCs and MOs are usually combined with conductive materials.

Quantum dots with quantum confinement are practical architectures for boosting electronic and ionic transportation. A composite about cobalt sulfide compounded with graphene (CoS@G) was synthesized for PIBs (Fig. 4a)
[41]. In this composite, graphene offering landing platform for $\mathrm{CoS}$ quantum dots not only contributed to restraining the agglomeration of $\mathrm{CoS}$ quantum dots, but also improved electronic conductivity. Then, numerous smaller CoS nanoclusters were uniformly dispersed onto the graphene nanosheets, consisting of the interlinked quantum dots (Fig. 4b, c). As illustrated in Fig. 4d, the 

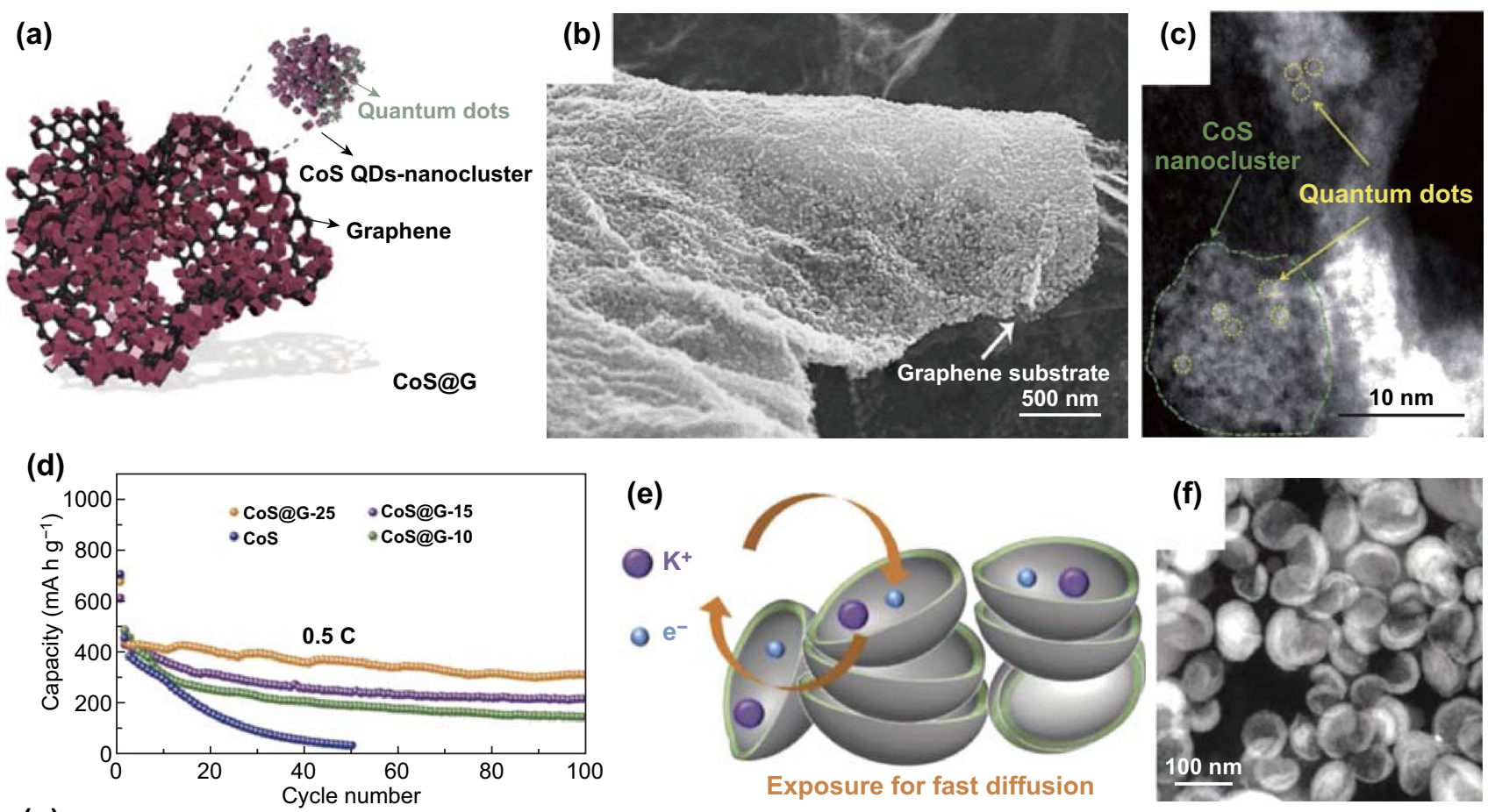

(g)

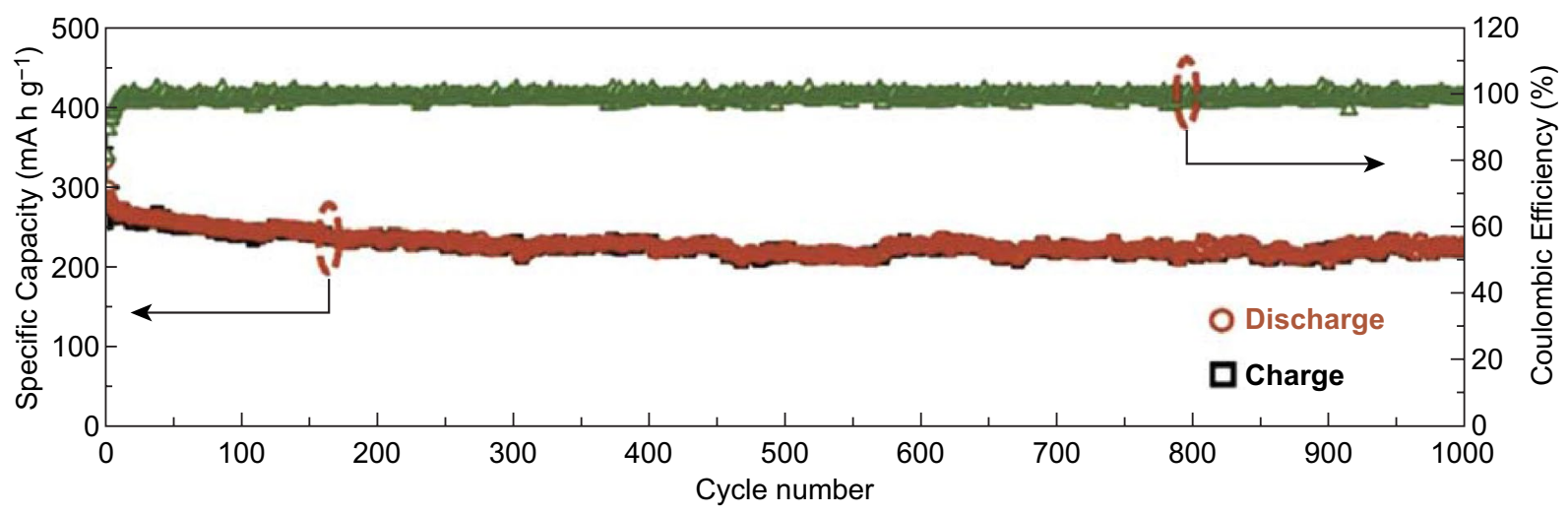

Fig. 4 a Schematic illustration of CoS@G composite. b SEM and c dark field images of the obtained sample. d Cycling capacities of CoS@G25 anode compared with other samples. Reproduced with permission from Ref. [41]. Copyright 2017, John Wiley and Sons. e Schematic diagram of PMC with fast ion and electron diffusing. f HAADF-STEM image of PMC. $\mathbf{g}$ Long-term cycle performance as well as (C.E.) at $1.0 \mathrm{~A} \mathrm{~g}^{-1}$ over 1000 cycles. Reproduced with permission from Ref. [43]. Copyright 2018, John Wiley and Sons

CoS@G-25 (25 means 25\% graphene oxide) electrode delivered the discharge capacity of $310.8 \mathrm{mAh} \mathrm{g}^{-1}$ at $500 \mathrm{~mA} \mathrm{~g}^{-1}$ after 100 cycles. Moreover, the CoS@G-25 electrode's capacities were retained $67.3 \%$ and $56.2 \%$ at $3 \mathrm{C}$ and $4 \mathrm{C}$, respectively. Therefore, it is effective for novel shapes to improve the corresponding electrochemical performances. Coating is also an effective means to prevent agglomeration and buffer volume changes, such as building a core/shell structure. So Wang et al. [43] synthesized $\mathrm{MoSe}_{2} / \mathrm{C}$ composites with pistachio-shucklike morphology (PMC) as PIBs anodes to improve their performances. As shown in Fig. 4e, the packing density of the unique PMC was enhanced via plane-to-plane contact. It could expedite electronic transfer as well as K-ion diffusion and retain the structural stability during the process of potassium/depotassium. Additionally, the PMC exhibited pistachio-shuck-like morphology with the diameter of around 70-90 nm (Fig. 4f). In the electrochemical test, the PMC electrode delivered $226 \mathrm{mAh} \mathrm{g}^{-1}$ at $1.0 \mathrm{~A} \mathrm{~g}^{-1}$ after 1000 cycles (Fig. 4g). The PMC electrode's electrochemical performances were due to the core of $\mathrm{MoSe}_{2}$, the pistachio-shuck-like structure, and thin amorphous carbon 
shell. These structural features could facilitate K-ion transfer and buffered the volume expansion.

Besides, titanium dioxides $\left(\mathrm{TiO}_{2}\right)$ have been utilized in LIBs and SIBs but seldom reported for PIBs. Therefore, in 2019, Fang et al. [121] synthesized a composite about $\mathrm{TiO}_{2}$ nanoparticles anchored on rGO for PIBs. As for this composite, the small size $\mathrm{TiO}_{2}$ could boost $\mathrm{K}$-ion diffusion and the rGO could promote electronic transfer. So its electrochemical performances could be enhanced, which achieved the rate capacity of $107.1 \mathrm{mAh} \mathrm{g}^{-1}$ at $1000 \mathrm{~mA} \mathrm{~g}^{-1}$ and the cycling capacity of $88.4 \mathrm{mAh} \mathrm{g}^{-1}$ at $1000 \mathrm{~mA} \mathrm{~g}^{-1}$ after 1000 cycles. Nevertheless, its electrochemical behavior is necessary to be improved by further experiments.

\subsection{Zero-Dimensional Alloying Materials}

Alloying materials including $\mathrm{Sb}, \mathrm{Sn}, \mathrm{Bi}, \mathrm{Ge}$, as well as $\mathrm{P}$, characterized by high capacity, have been studied for PIBs anode materials [84]. Volume expansion is one of their most obvious shortcomings, and the stress variation can be affected by small size structures. Therefore, it is urgent to design appropriate electrode materials and designing suitable nanostructures is a common modification method.

It was reported that nanoparticles have been widely fabricated as electrode materials to mitigate stress changes. As a typical example, engineering bulk materials to nanoparticles is beneficial to alleviate stress variation. Thus, the network of a carbon sphere enclosed Sb nanoparticles ( $\mathrm{Sb} @ \mathrm{CSN}$ ) as PIBs anode [90]. The schematic diagram of Sb@CSN and its TEM image are shown in Fig. 5a, b, which indicated the Sb nanoparticles were well encapsulated in the carbon sphere with uniform distribution. As for electrochemical performances, the $\mathrm{Sb} @ \mathrm{CSN}$ electrode presented high discharge capacity of $626 \mathrm{mAh} \mathrm{g}^{-1}$ at $200 \mathrm{~mA} \mathrm{~g}^{-1}$ after second cycle (Fig. 5c). In addition, the capacity of $504 \mathrm{mAh} \mathrm{g}^{-1}$ was obtained at $200 \mathrm{~mA} \mathrm{~g}^{-1}$ after 200 cycles (Fig. 5d). The $\mathrm{Sb} @ \mathrm{CSN}$ anode's electrochemical behavior indicated the importance of small size nanoparticles and carbon sphere network, which could buffer volume expansion and promote the transportation of electrons. Similarly, Ge and co-workers [87] also constructed a composite composed of Sb nanoparticles and carbon materials. They encapsulated ultra-small Sb nanocrystals into CNFs for PIBs anode, which achieved $225 \mathrm{mAh} \mathrm{g}^{-1}$ at $1 \mathrm{~A} \mathrm{~g}^{-1}$ after 2000 cycles because ultrasmall Sb nanocrystals and hollow nanochannels not only promoted $\mathrm{K}^{+}$fast diffusion but also buffered strain variation. Compared to carbon spheres, CNFs may have better connectivity and can better make the electrode stable. Additionally, the nanostructural design also has an impact on the electrochemical performances of red P. So tailoring different sizes of red P into 3D carbon could effectively overcome the above-mentioned disadvantages (Fig. 5e) [122]. In this composite, the small size of red $\mathrm{P}$ and $3 \mathrm{D}$ carbon nanosheet framework could reduce the degree of volume expansion; on the other hand, it also could boost the fast electron transportation during charge and discharge process. In addition, red $\mathrm{P}$ without agglomeration was displayed, which indicated that red $\mathrm{P}$ was uniformly dispersed in the 3D carbon nanosheet frameworks (Fig. 5f). Benefit from the structural design, the red P@CN composite anode delivered a charge capacity of $715.2 \mathrm{mAh} \mathrm{g}^{-1}$ and a rate capacity of $323.7 \mathrm{mAh} \mathrm{g}^{-1}$ at $2000 \mathrm{~mA} \mathrm{~g}^{-1}$ (Fig. $5 \mathrm{~g}, \mathrm{~h}$ ). Based on nanoparticles with effective impact, different morphology of $0 \mathrm{D}$ alloying materials should be designed to enhance the electrochemical performances.

\section{One-Dimensional Nanomaterials for PIBs}

1D nanomaterials are defined as high length-to-diameter aspect ratios, including nanotubes, nanorods, nanowires, nanofibers, and nanoribbons. Since CNTs were first discovered by Iijima [123], 1D nanomaterials with similar structures have been widely studied. The structural features of 1D nanomaterials not only include nanoscale and microscale joint effects, but also contain high aspect ratio and oriented growth direction [124]. Therefore, 1D nanomaterials are beneficial for fast transportation of electrons and ions and have an impact on tolerating the stress changes, which was considered as a class of most promising materials for high performances of energy storage systems [125]. Given these mentioned above, 1D nanomaterials can be utilized to boost the diffusion of electrons and ions as well as alleviate the stress variation as PIBs electrode materials. Significant progress has recently been achieved for anode materials with high performances by designing and fabricating 1D nanomaterials. Based on typical 1D nanomaterials, systematic discussion is carried out about the relationship between the related structures and their electrochemical performances. Furthermore, in order to comprehensively comprehend the electrochemical behavior of 1D nanomaterials, the initial 
(a)

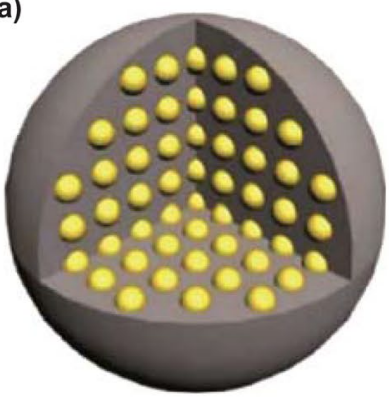

(b)

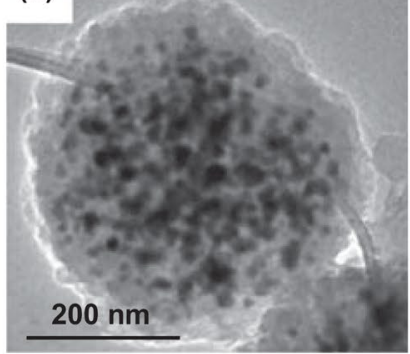

(c)

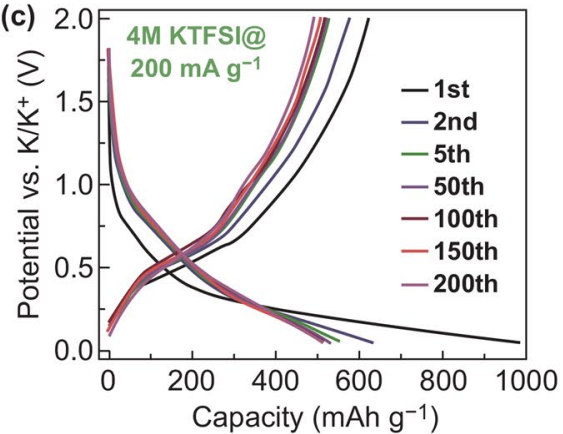

(e)

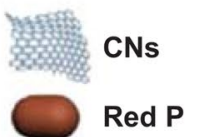

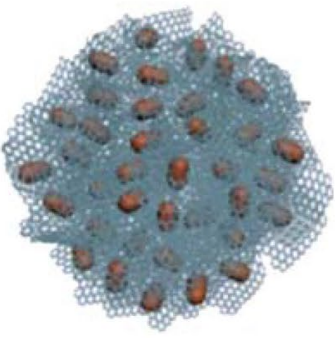

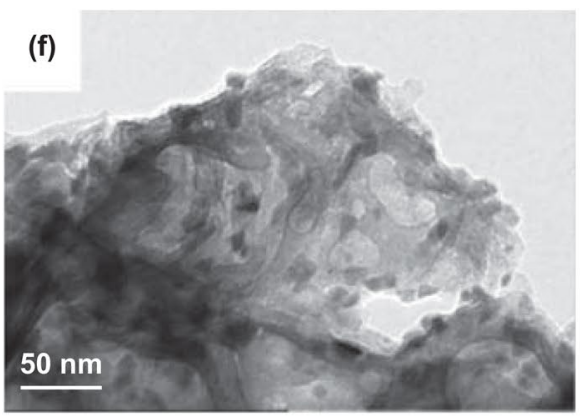

(g)
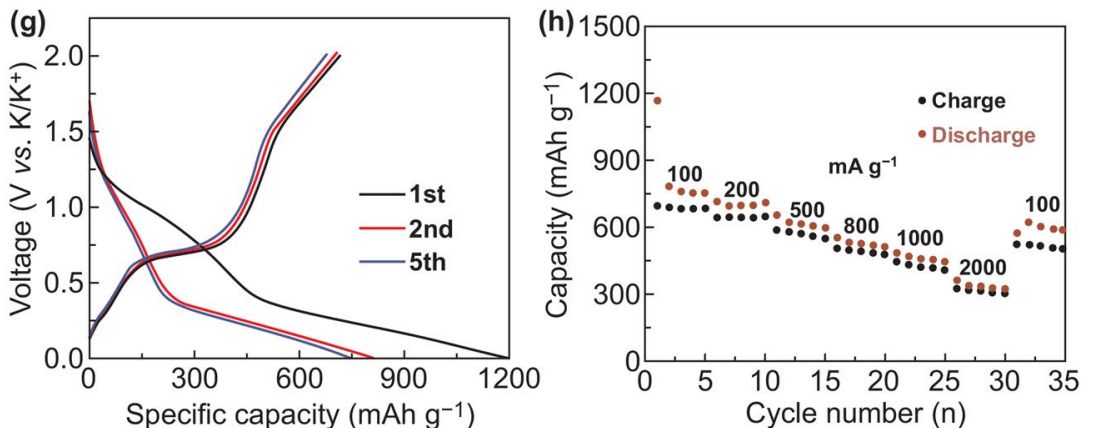

Fig.5 a Sb@CSN's schematic diagram. b Single Sb@CSN sphere exhibited in TEM image. c Voltage profiles as well as d Related cycle capacities of Sb@CSN at $200 \mathrm{~mA} \mathrm{~g}^{-1}$. Reproduced with permission from Ref. [90]. Copyright 2019, Royal Society of Chemistry. e Schematic illustration of red P@CN composite. f TEM image of red P@CN composite. $\mathbf{g}$ Voltage curves of red P@CN composite for the selected cycles. h Rate capabilities of red P@CN composite in the range of 100-2000 mA g ${ }^{-1}$. Reproduced with permission from Ref. [122]. Copyright 2018, John Wiley and Sons

C.E., rate performances, and cycle properties of recent reported 1D anode materials of PIBs are outlined in Table 2.

\subsection{One-Dimensional Carbon Materials}

CNTs can be considered as a representative example among 1D carbon materials. It is well established that CNTs with remarkable mechanical strength and excellent electrical properties have been applied in PIBs field [136-139]. So far, CNTs not only can be used directly or doped with other elements, but also can be composited with other materials to serve as electrode materials. As for composites, a CNTbackboned mesoporous carbon confining red $\mathrm{P}$ composite
(P@TBMC) was formed as anode material for SIBs/PIBs (Fig. 6a) [50]. P encapsulated completely within the pores, and homogenous distributions in the composite were confirmed (Fig. 6b). In these composites, the main function of red $\mathrm{P}$ was to provide high $\mathrm{K}$ storage capacity. The multiwalled CNTs not only supported the structure as backbone, but also boosted the electrons transfer because of the high content of $s p^{2}$ carbon. Therefore, the P@ TBMC-2.4 (2.4 means the resorcinol mass ( $\mathrm{g}$ ) in the recipe) anode exhibited a depotassiation capacity of $244 \mathrm{mAh} \mathrm{g}^{-1}$ at $0.5 \mathrm{~A} \mathrm{~g}^{-1}$ after 200 cycles, which displayed stable cyclability (Fig. 6c).

Generally, heteroatom-doped carbon materials have better $\mathrm{K}$ storage properties than non-doped ones, so 
Table 2 Comparison of state-of-the-art performances of 1D anode materials in PIBs

\begin{tabular}{|c|c|c|c|c|}
\hline Materials & Initial C.E. $(\%)$ & $\begin{array}{l}\text { Rate capacity }\left(\mathrm{mAh} \mathrm{g}^{-1}\right) \\
\text { at the current density } \\
\left(\mathrm{mA} \mathrm{g}^{-1}\right)\end{array}$ & $\begin{array}{l}\text { Cycle capacity }\left(\mathrm{mAh} \mathrm{g}^{-1}\right) \text { at the } \\
\text { current density }\left(\mathrm{mA} \mathrm{g}^{-1}\right)(\text { cycle } \\
\text { number })\end{array}$ & References \\
\hline $\mathrm{Ti}_{3} \mathrm{C}_{2}$ & - & 60 at 300 & 42 at $200(500)$ & {$[52]$} \\
\hline Cryptomelane-type $\mathrm{MnO}_{2} / \mathrm{CNT}$ hybrids & 40.07 & 127.2 at 1000 & 226.5 at $100(500)$ & {$[126]$} \\
\hline C-NCNFs & 37.8 & 84.7 at $5 \mathrm{C}$ & 103.4 at $2 \mathrm{C}(500)$ & {$[53]$} \\
\hline b-NCNTs & 23.3 & 186 at 1000 & 204 at $500(1000)$ & {$[54]$} \\
\hline M-NCNTs & 24.45 & 102 at 2000 & 102 at $2000(500)$ & {$[55]$} \\
\hline Highly N-doped CNFs & 49 & 101 at 20,000 & 146 at $2000(4000)$ & {$[81]$} \\
\hline Cup-stacked NCNT mats & 14.2 & 75 at 1000 & 236 at $20(100)$ & {$[127]$} \\
\hline Red P & 68.26 & 71 at 3000 & 300 at $1000(60)$ & {$[56]$} \\
\hline $\mathrm{Sb} / \mathrm{HCT}$ & 70 & 211.5 at 5000 & 300.1 at $2000(120)$ & {$[57]$} \\
\hline $\begin{array}{l}\text { 3D amorphous carbon encapsulated CoS/ } \\
\text { NCNTs on CoS-coated CNFs }\end{array}$ & 57.6 & 133.1 at 6400 & $\approx 130$ at $3200(600)$ & {$[128]$} \\
\hline $\begin{array}{l}\text { Carbon-encapsulated CoP nanoparticles } \\
\text { embedded in CNTs supported on CNFs }\end{array}$ & 53.2 & $\sim 292$ at 3200 & 247 at $800(1000)$ & [129] \\
\hline Sub-micro-carbon fiber@CNTs & - & 108 at $5 \mathrm{C}$ & more than 193 at $1 \mathrm{C} \mathrm{(300)}$ & {$[130]$} \\
\hline $\begin{array}{l}\text { Pyrrolic/pyridinic-N-doped necklace-like } \\
\text { hollow carbon }\end{array}$ & - & 204.8 at 2000 & 161.3 at $1000(1600)$ & {$[131]$} \\
\hline $\begin{array}{l}\text { Bi-nanorod networks confined in } \mathrm{N}, \mathrm{S} \text { co- } \\
\text { doped carbon matrix }\end{array}$ & 65 & 289 at 6000 & 285 at $5000(1000)$ & [132] \\
\hline rGO/CNT hybrid papers & - & 110 at 100 & 148 at $50(200)$ & {$[133]$} \\
\hline $\begin{array}{l}\text { Porous Mn-Fe-Se composite adhered/inserted } \\
\text { with interlaced CNTs }\end{array}$ & 33.43 & 83 at 800 & 141 at $50(70)$ & {$[134]$} \\
\hline $\begin{array}{l}\text { Hollow NCNFs anchored hierarchical FeP } \\
\text { nanosheets }\end{array}$ & 57 & 103 at 800 & 210 at $100(1000)$ & {$[135]$} \\
\hline
\end{tabular}

heteroatom-doped CNTs may perform better than ordinary CNTs. So a $\mathrm{CoSe}_{2}$ strung by CNTs with N-doping (NCNF@CS) was prepared by two-step hydrothermal means as a PIBs anode (Fig. 6d) [51]. Then, the CNTs made every octahedral $\mathrm{CoSe}_{2}$ particle arrange in sequence with zigzag void space among particles (Fig. 6e). Remarkably, the NCNF@CS-6 h (6 h means the reaction hours) anode reached the reversible capacity of $196 \mathrm{mAh} \mathrm{g}^{-1}$ at $2.0 \mathrm{~A} \mathrm{~g}^{-1}$ (Fig. 6f). Moreover, a capacity of $173 \mathrm{mAh} \mathrm{g}^{-1}$ at $2.0 \mathrm{~A} \mathrm{~g}^{-1}$ after over 600 cycles was exhibited (Fig. 6g). The electrochemical performances of NCNF@CS-6 h electrode were ascribed to the use of CNTs and octahedral $\mathrm{CoSe}_{2}$ particles arranging in sequence, where conductive $\mathrm{N}$-doped CNTs not only hindered the agglomeration and anchored the active materials as backbone but also effectively promoted the electronic transfer. Based on aforementioned work, CNTs can enhance the electrochemical behaviors by boosting electronic and ionic diffusion and keeping structural integrity. Therefore, novel composites about CNTs deserve to research for PIBs anode materials in the further experiments.

\subsection{One-Dimensional MCs and MOs}

To date, 1D MCs and MOs mainly include various K-Ti-O anode materials with common formula $\mathrm{K}_{2} \mathrm{Ti}_{\mathrm{n}} \mathrm{O}_{2 \mathrm{n}+1}$, which are advantageous for insertion/extraction of K-ion [140]. As for $\mathrm{K}_{2} \mathrm{Ti}_{6} \mathrm{O}_{13}$, its crystal structure with open 3D framework and tunnel can facilitate $\mathrm{K}$-ion transfer. So $\mathrm{K}_{2} \mathrm{Ti}_{6} \mathrm{O}_{13}$ nanorods were synthesized as PIBs anode and the obtained electrode achieved stable long cycling performance, but its poor rate performance was exhibited [58]. Accordingly, carbon coating may be a practical way to further improve the rate capacities. Therefore, oriented nanorod-like $\mathrm{K}_{2} \mathrm{Ti}_{6} \mathrm{O}_{13}$ bunches with a thin carbon layer $(\mathrm{KTO} / \mathrm{C})$ were fabricated as PIBs electrode materials (Fig. 7a) [76]. The size of nanorods of KTO/C-700 (700 means the heat treatment temperature 


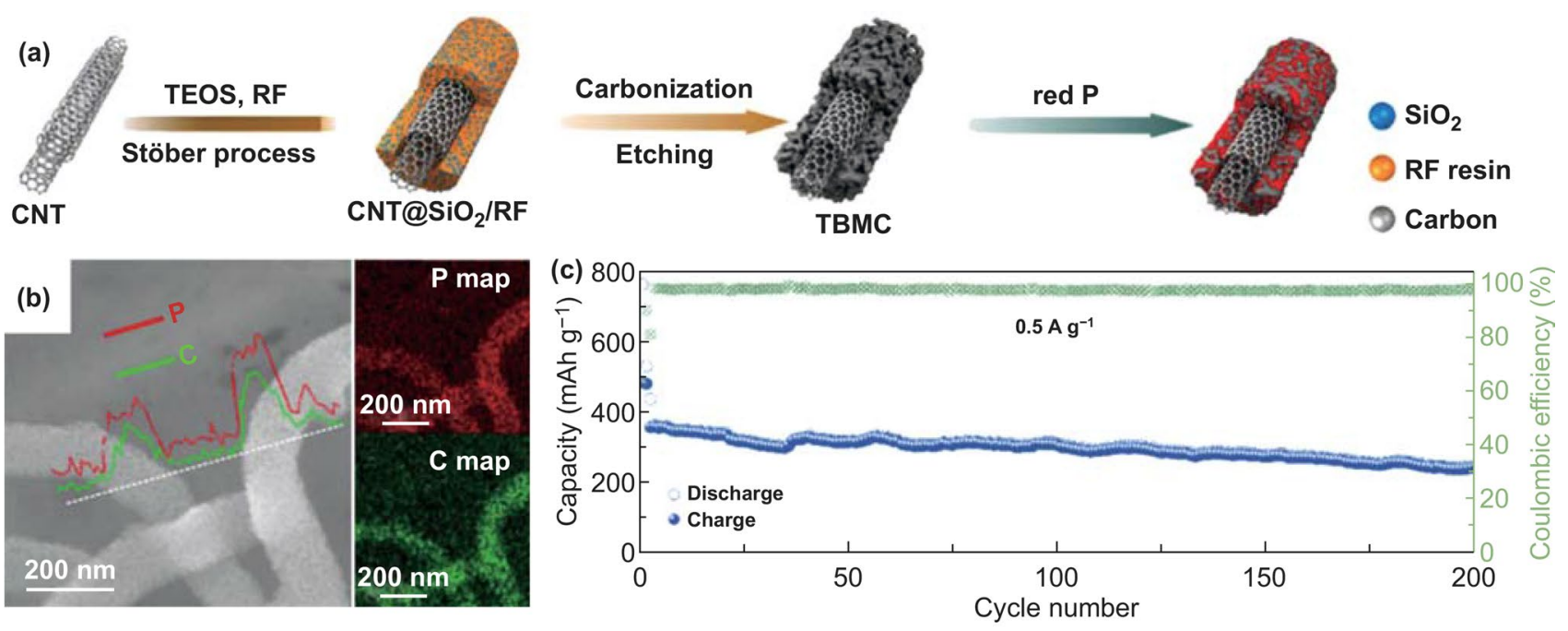

(d)

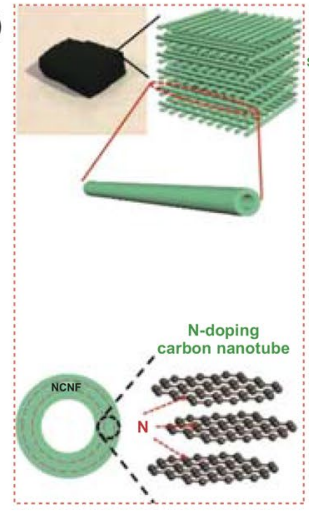

(f)

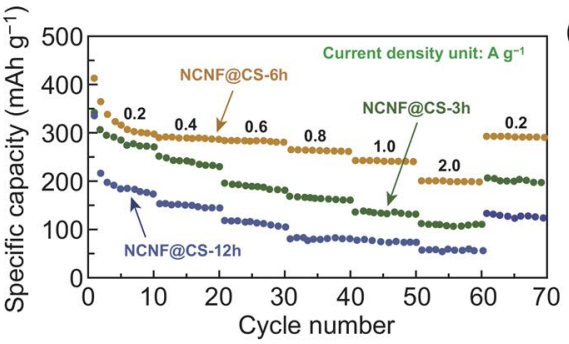

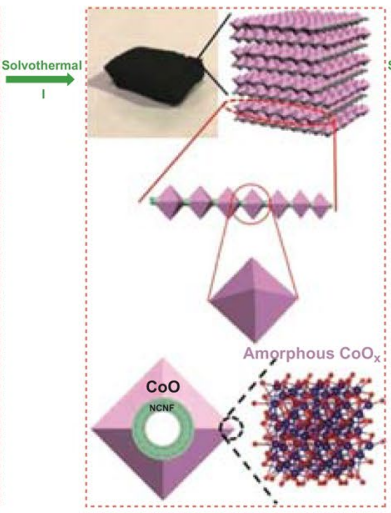
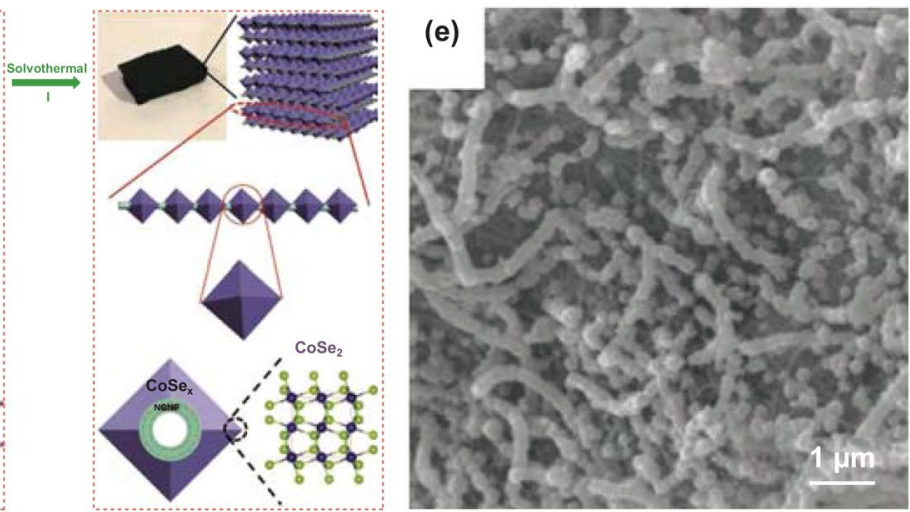

$\overparen{T}$

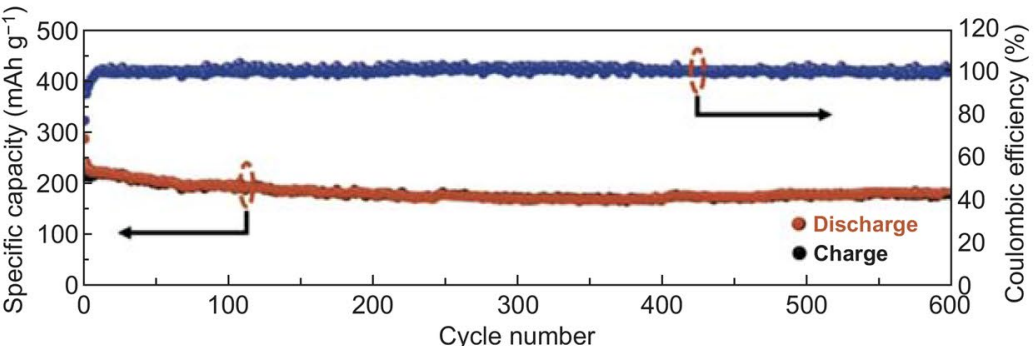

Fig. 6 a Schematic diagram for P@TBMC composite's fabrication process. b The corresponding EDS elemental mapping and line scanning of P@TBMC-2.4 displayed in SEM image. c Long-term cycle capacities at $0.5 \mathrm{~A} \mathrm{~g}^{-1}$ after initial two-cycle activation at $0.05 \mathrm{~A} \mathrm{~g}^{-1}$. Reproduced with permission from Ref. [50]. Copyright 2018, Elsevier. d Schematic diagram for NCNF@CS's preparation process. e SEM image of NCNF@ CS-6 h. f Rate capacities of the obtained three NCNF@CS samples. g Long-term cycling stability and C.E. of NCNF@ CS-6 h at 2.0 A g ${ }^{-1}$ over 600 cycles. Reproduced with permission from Ref. [51]. Copyright 2018, John Wiley and Sons

of $700{ }^{\circ} \mathrm{C}$ ) was well maintained compared with that of bare KTO (Fig. 7b). As for rate capacities, the KTO/C-700 electrode delivered $65.1 \mathrm{mAh} \mathrm{g}^{-1}$ at $500 \mathrm{~mA} \mathrm{~g}^{-1}$ (Fig. 7c). The electrochemical performances of the KTO/C-700 electrode were due to K-ion diffusion boosted by crystal orientations of KTO and electron conductivity improved by carbon layer. Besides, in 2016, $\mathrm{K}_{2} \mathrm{Ti}_{4} \mathrm{O}_{9}$ was fabricated as PIBs anode materials for the first time, but delivered low capacities and poor cycling performance [141]. It is necessary to control the morphology of $\mathrm{K}_{2} \mathrm{Ti}_{4} \mathrm{O}_{9}$ well so as to improve the electrochemical behavior. Therefore, $\mathrm{K}_{2} \mathrm{Ti}_{4} \mathrm{O}_{9}$ nanoribbons derived from MXene have been studied for PIBs anode materials due to unique structural features. Wu's group [92] reported that ultrathin nanoribbons of potassium titanate 

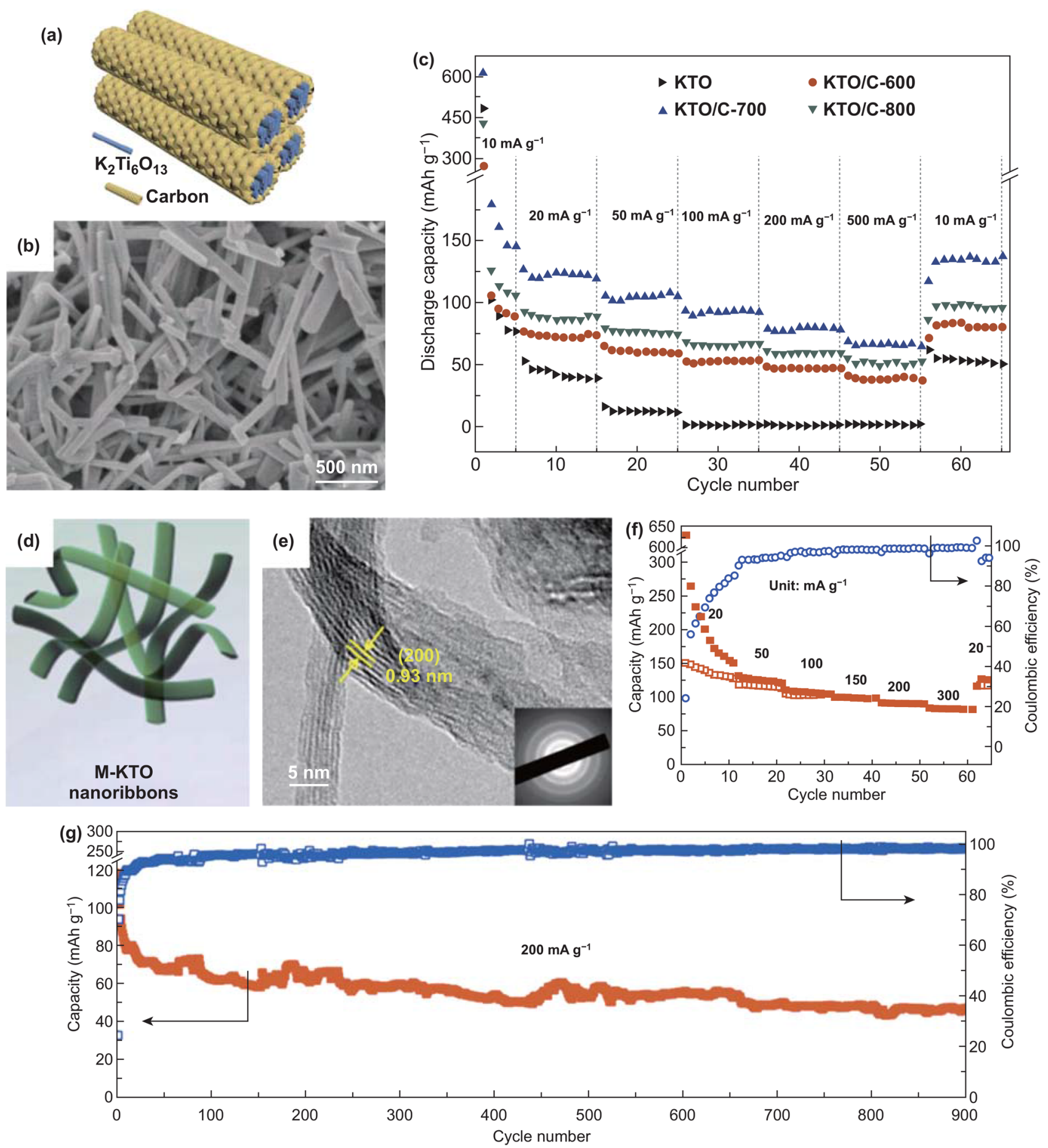

Fig. 7 a Schematic diagram of KTO/C. b SEM image of KTO/C-700. c Rate capacities of the obtained hybrids electrode. Reproduced with permission from Ref. [140]. Copyright 2020, Royal Society of Chemistry. d M-KTO nanoribbons' schematic illustration. e M-KTO's HRTEM image with the corresponding SAED patterns (inset). f M-KTO's rate performance. $\mathbf{g}$ Long cycle capacities as well as C.E. of the obtained sample at $200 \mathrm{~mA} \mathrm{~g}^{-1}$. Reproduced with permission from Ref. [92]. Copyright 2017, American Chemical Society 
(M-KTO, $\mathrm{K}_{2} \mathrm{Ti}_{4} \mathrm{O}_{9}$ ) were synthesized as anode materials for PIBs. The morphology of nanoribbons and the interlayer space with $0.93 \mathrm{~nm}$ were exhibited, which benefited K-ion insertion/extraction (Fig. 7d, e). As for electrochemical performances, the rate capacity of $81 \mathrm{mAh} \mathrm{g}^{-1}$ was attained at $300 \mathrm{~mA} \mathrm{~g}^{-1}$ as well as the retention of $51 \%$ (of the second charge capacity) was exhibited at $200 \mathrm{~mA} \mathrm{~g}^{-1}$ after over 900 cycles (Fig. 7f, g). The M-KTO electrode's electrochemical performances were ascribed to suitable interlayer spacing, narrow widths, ultrathin thickness, as well as open macroporous architectures. The convincing example verified that nanoribbons are beneficial to enhance electrochemical behavior due to well-designed structures. However, because only single material is used, the $\mathrm{K}$ storage capacity is not high enough, and it may need to be compounded with other materials in the subsequent research to further improve the electrochemical performances.

\subsection{One-Dimensional Alloying Materials}

Up to now, few studies about 1D alloying materials have involved in nanotubes, nanowires, nanofibers, and nanoribbons in the PIBs fields. Therefore, nanorod-like alloying materials with shorter ionic transfer path will be introduced by typical examples [57, 59, 91, 132, 142].

Nanorod-like Bi has been composited with carbon materials as anode materials for PIBs. For instance, Bi nanorods coated with mesoporous carbon were fabricated [142]. The unique structure with the core of Bi nanorods and outside carbon mesoporous shell had an effect on boosting the electronic and ionic diffusion as well as buffering the volumetric variation. Thus, the storage capacity reached $425 \mathrm{mAh} \mathrm{g}^{-1}$ at $0.2 \mathrm{~A} \mathrm{~g}^{-1}$. Compared with mesoporous carbon coatings, CNTs may encapsulate and confine Bi nanorods better due to their hollow tubular structures and good mechanical properties. Li et al. [91] synthesized Bi nanorods confined by hollow N-doped CNTs (Bi@N-CT) as anode materials of PIBs. The Bi nanorod structure was encapsulated in hollow structure with the carbon coating layer thickness of about $40 \mathrm{~nm}$ (Fig. 8a, b). In the electrochemical test, the capacity was $297 \mathrm{mAh} \mathrm{g}^{-1}$ at $20 \mathrm{C}$ (Fig. 8c). Additionally, the obtained electrode reached the capacity of $266 \mathrm{mAh} \mathrm{g}^{-1}$ at $10 \mathrm{C}$ after over 1000 cycles (Fig. 8d). These electrochemical performances were largely ascribed to the nanostructural design as well as the perfect coordination of Bi nanorods and
CNTs. In addition, the storage mechanism could be understood well by in situ XRD, which indicated the high reversibility of structure (Fig. 8e). Coincidentally, Bi nanorods were encapsulated in N-doped CNTs (Bi@C nanorods) for PIBs anode [59]. The N-doped CNTs were originated from the carbonization of polydopamine, different from the above example using polypyrrole. The morphology of Bi nanorods, hollow structural robustness, and carbon coating layer conductive network were beneficial for the obtained anode to deliver the capacity of $179.1 \mathrm{mAh} \mathrm{g}^{-1}$ at $0.5 \mathrm{~A} \mathrm{~g}^{-1}$ after over 300 cycles. Therefore, Bi nanorods compounded with hollow structure carbon materials are advantageous to restrict volume changes and keep long cycle stability.

\section{Two-Dimensional Nanomaterials for PIBs}

2D nanomaterials have attracted increasing attentions since the discovery of graphene in 2004, and they have been extensively studied for electrochemical energy storage because of unique structural features as well as physicochemical properties [143-151]. On the one hand, the large surface area of 2D nanomaterials is conducive to ionic adsorption, which is beneficial to improve capacitance. On the other hand, 2D nanomaterials with high conductivity and tunable interlayer spacing can boost electronic transfer and benefit ionic intercalation, respectively [152]. Based on these advantages, 2D materials have become favored materials for researchers. Therefore, the corresponding 2D materials will be introduced typically. And then, the initial C.E., rate performances, and cycle properties of recent reported 2D anode materials of PIBs are summarized in Table 3.

\subsection{Two-Dimensional Carbon Materials}

As a typical example of 2D carbon materials, graphene has been used for PIBs because of its high surface area, extraordinary mechanical strength, as well as high electrical conductivity [167-169]. In 2015, it was the first time that the $\mathrm{K}$-ion intercalation of rGO film was studied by Luo and co-workers [170]. Although the reversible capacity was $222 \mathrm{mAh} \mathrm{g}^{-1}$, rGO with poor rate capability was due to its inferior electronic conductivity. Therefore, graphene need to be modified and modifying its structure may be one of the effective strategies to improve its electrochemical performances. Firstly, single heteroatom 
(a)

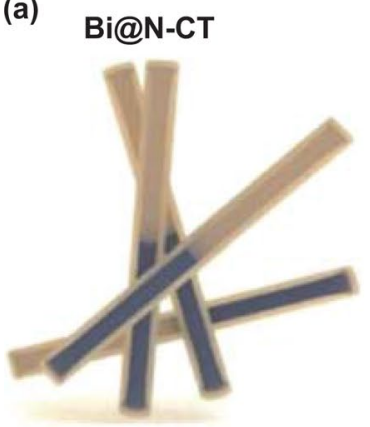

(b)

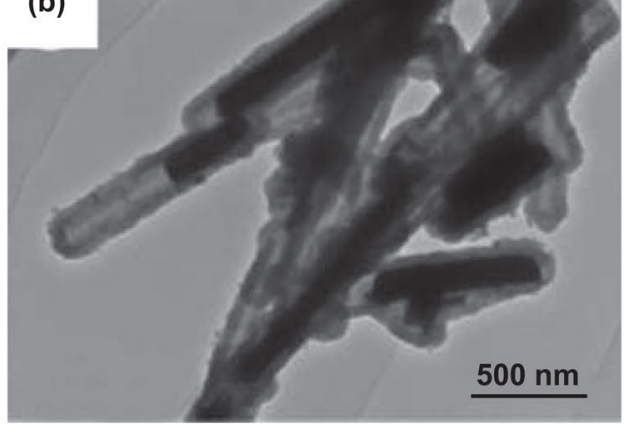

(c) $450+\frac{1}{-\quad 1 \quad i \quad j} 120$

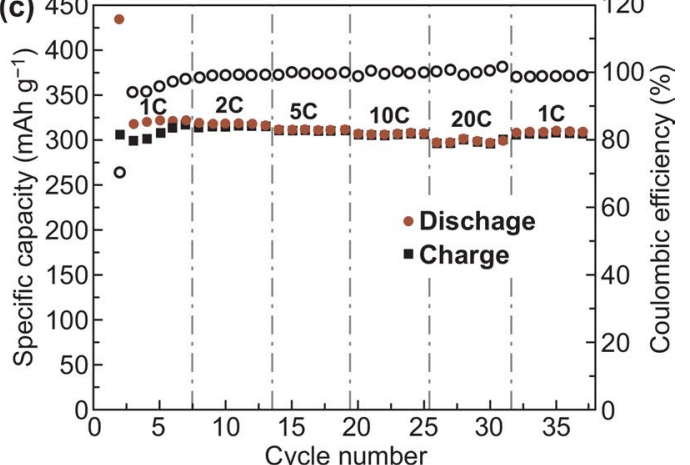

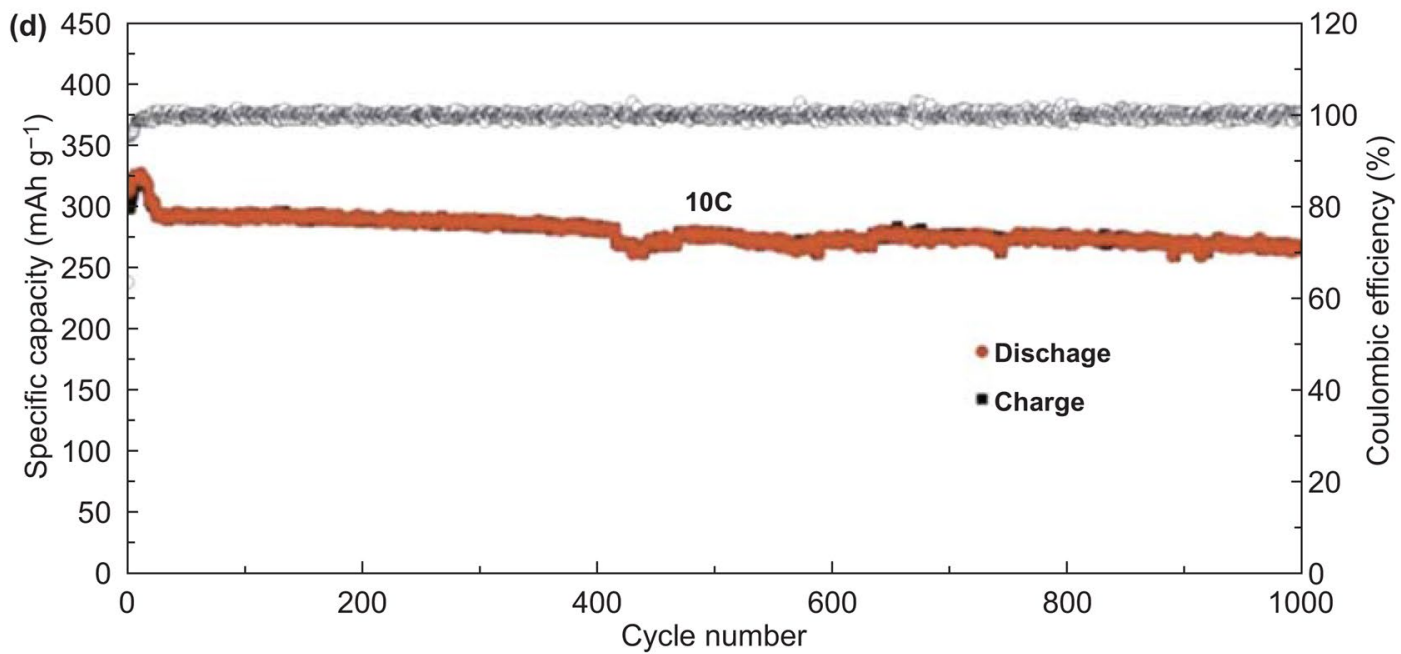

(e)
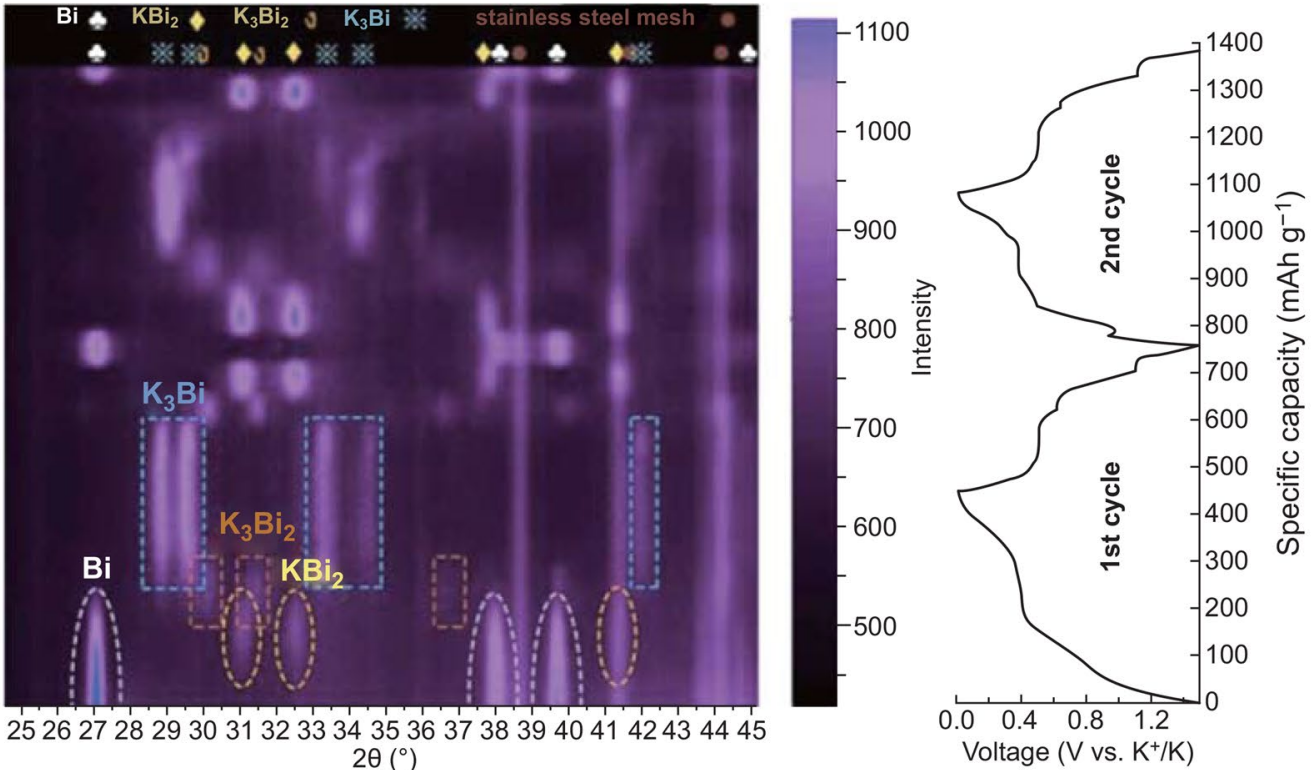

$\left.25262728293031323334353{ }^{\circ}\right)$

Voltage (V vs. $\left.\mathrm{K}^{+} / \mathrm{K}\right)$

Fig. 8 a Bi@N-CT’s schematic diagram. b Bi@N-CT's TEM image. c Rate performance of the obtained electrode at different C-rates (1 C is $385 \mathrm{mAh} \mathrm{g}^{-1}$ ). d Long-term cycling performance of $\mathrm{Bi} @ \mathrm{~N}-\mathrm{CT}$ at $10 \mathrm{C}$. e Contour plot of the obtained electrode's in situ XRD results in the course of discharge/charge process about the first two cycles with discharge/charge curves. Reproduced with permission from Ref. [91]. Copyright 2020, Royal Society of Chemistry 
Table 3 Comparison of the state-of-the-art performances of 2D anode materials in PIBs

\begin{tabular}{|c|c|c|c|c|}
\hline Materials & Initial C.E. (\%) & $\begin{array}{l}\text { Rate capacity }\left(\mathrm{mAh}^{-1}\right) \\
\text { at the current density } \\
\left(\mathrm{mA} \mathrm{g}^{-1}\right)\end{array}$ & $\begin{array}{l}\text { Cycle capacity }\left(\mathrm{mAh} \mathrm{g}^{-1}\right) \text { at the current } \\
\text { density }\left(\mathrm{mA} \mathrm{g}^{-1}\right)(\text { cycle number })\end{array}$ & References \\
\hline Nanocrystalline $\mathrm{SnS}_{2}$ coated onto $\mathrm{rGO}$ & - & 120 at 2000 & 280 at $25(25)$ & {$[153]$} \\
\hline $\mathrm{Ti}_{3} \mathrm{CNTz}$ & 28.4 & 32 at 500 & 75 at $20(100)$ & {$[60]$} \\
\hline $\mathrm{MoS}_{2} @ \mathrm{rGO}$ & - & 178 at 500 & 381 at $100(100)$ & {$[61]$} \\
\hline $\mathrm{MoS}_{2} @ \mathrm{SnO}_{2} @ \mathrm{C}$ & 73 & 86 at 800 & 250 at $100(20)$ & {$[62]$} \\
\hline $\mathrm{MoS}_{2} / \mathrm{C}$ & - & 164 at 2000 & 180 at $500(240)$ & {$[154]$} \\
\hline $\begin{array}{l}\text { Envelope-like N-doped carbon } \\
\text { nanosheets }\end{array}$ & $\approx 20$ & 168 at 2000 & 151 at $1000(1000)$ & {$[155]$} \\
\hline $\mathrm{VSe}_{2}$ & 69.1 & 172 at 2000 & $\begin{array}{l}\approx 87.3 \% \text { of the capacity retention at } 2000 \\
\quad(500)\end{array}$ & {$[63]$} \\
\hline FSCC & 62.7 & 139 at 1000 & 226 at $100(100)$ & {$[156]$} \\
\hline $\mathrm{SnS}_{2}$ /graphene & 40.5 & 290 at 2000 & 559 at $100(50)$ & {$[157]$} \\
\hline $\mathrm{CuO}$ nanoplates & 50.8 & 163 at 2000 & 206 at $1000(100)$ & {$[158]$} \\
\hline $\mathrm{SnS}_{2} / \mathrm{rGO}$ & 51.2 & 247 at 1000 & 205 at $1000(300)$ & {$[64]$} \\
\hline $\begin{array}{l}\text { Amorphous carbon/graphitic carbon } \\
\text { nanoplates }\end{array}$ & 15.7 & 120 at 5000 & 192 at $1000(5200)$ & [159] \\
\hline $\mathrm{SnS}_{2} @ \mathrm{C} @ \mathrm{rGO}$ & 53.0 & 287.8 at 500 & 170.9 at $500(500)$ & {$[160]$} \\
\hline $\mathrm{HeTiO}_{2} \mathrm{eC}$ micro-tubes & 49.1 & 97.3 at 2000 & 132.8 at $500(1200)$ & [161] \\
\hline $\mathrm{MnCO}_{3}$ nanorods@rGO & - & 98 at 2000 & 701 at $200(500)$ & {$[162]$} \\
\hline $\begin{array}{l}\mathrm{N} \text { and } \mathrm{P} \text { co-doped vertical graphene/ } \\
\text { carbon cloth }\end{array}$ & 53.47 & 156.1 at 2000 & 142.4 at $1000(1000)$ & [163] \\
\hline 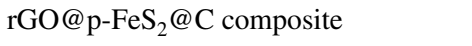 & - & 298 at 2000 & 322 at $1000(30)$ & [164] \\
\hline $\begin{array}{l}\mathrm{SnP}_{0.94} \text { nanoplates/graphene oxide } \\
\text { composite }\end{array}$ & 42 & 57 at 1000 & 106 at $200(100)$ & {$[165]$} \\
\hline Activated crumbled graphene & $\approx 39$ & 210 at 2000 & 245 at $500(2800)$ & [166] \\
\hline
\end{tabular}

doping has been used to regulate the structure of graphene. Few-layered graphene with $\mathrm{N}$-doping was reported as PIBs anode materials, which realized the charge capacity of over $350 \mathrm{mAh} \mathrm{g}^{-1}$ at $50 \mathrm{~mA} \mathrm{~g}^{-1}$ and the cycle capacity of more than $210 \mathrm{mAh} \mathrm{g}^{-1}$ at $100 \mathrm{~mA} \mathrm{~g}^{-1}$ after 100 cycles because the obtained electrode could provide abundant sites for ion storage and boost ionic transfer [171]. Based on an improved method, similar few-layer N-doped graphene (FLNG) was prepared as electrode materials in PIBs [65]. Its storage mechanism was made up of two parts including trapping $\mathrm{K}$-ion on the surface and into the defect sites (Fig. 9a, b). The FLNG could supply more $\mathrm{K}$-ion storage active sites and enhance electronic as well as ionic diffusion because of few-layer structure, $\mathrm{N}$-doping impact and high surface area, so the long cycle capacity of $150 \mathrm{mAh} \mathrm{g}^{-1}$ was realized at $500 \mathrm{~mA} \mathrm{~g}^{-1}$ after 500 cycles. Besides, in order to regulate the structure of graphene better, co-doping with two different heteroatoms has been utilized. Ma et al. [66] fabricated graphene with $\mathrm{P}$ and $\mathrm{O}$ co-doping (PODG) as PIBs electrode materials (Fig. 9c). The ultrathin film of PODG with only a few layers was displayed in the TEM image (Fig. 9d). As for PODG, graphene and elements with $\mathrm{P}$ and $\mathrm{O}$ not only boosted $\mathrm{K}$-ion diffusion by the expanding interlayer spacing, but also promoted K-ion adsorption because of large surface area as well as sufficient defects. Therefore, the PODG electrode delivered $165 \mathrm{mAh} \mathrm{g}^{-1}$ at $2000 \mathrm{~mA} \mathrm{~g}^{-1}$ (Fig. 9e). Moreover, PODG electrode delivered about 385, 235, and $160 \mathrm{mAh} \mathrm{g}^{-1}$ at 500, 1000, as well as $2000 \mathrm{~mA} \mathrm{~g}^{-1}$ after 600 cycles, respectively (Fig. 9f). Accordingly, expanding interlayer spacing and abundant active sites can be achieved by dual doping, so Luan and co-workers [172] further synthesized the multilayer graphene with $\mathrm{N}$ and P dual-doping (NPG) in PIBs electrode materials field. As for its electrochemical behavior, the rate capacity of $194 \mathrm{mAh} \mathrm{g}^{-1}$ was achieved at $1000 \mathrm{~mA} \mathrm{~g}^{-1}$. In addition, the cycle capacity of $242 \mathrm{mAh} \mathrm{g}^{-1}$ was obtained at $500 \mathrm{~mA} \mathrm{~g}^{-1}$ after 500 cycles. These electrochemical 
(a)

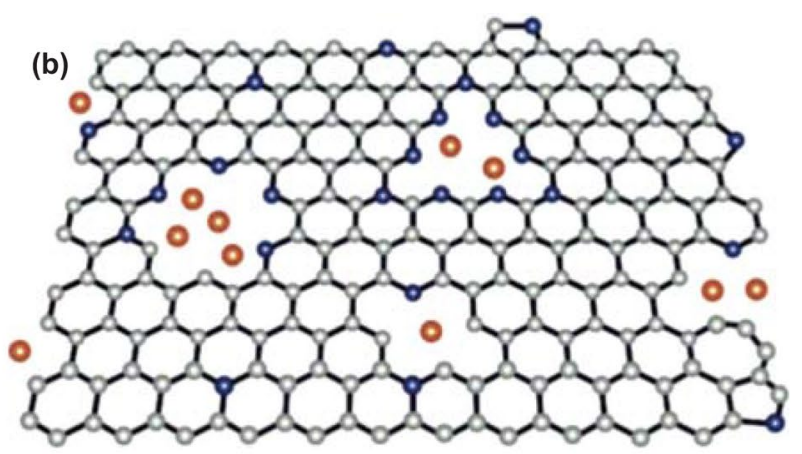

(c)
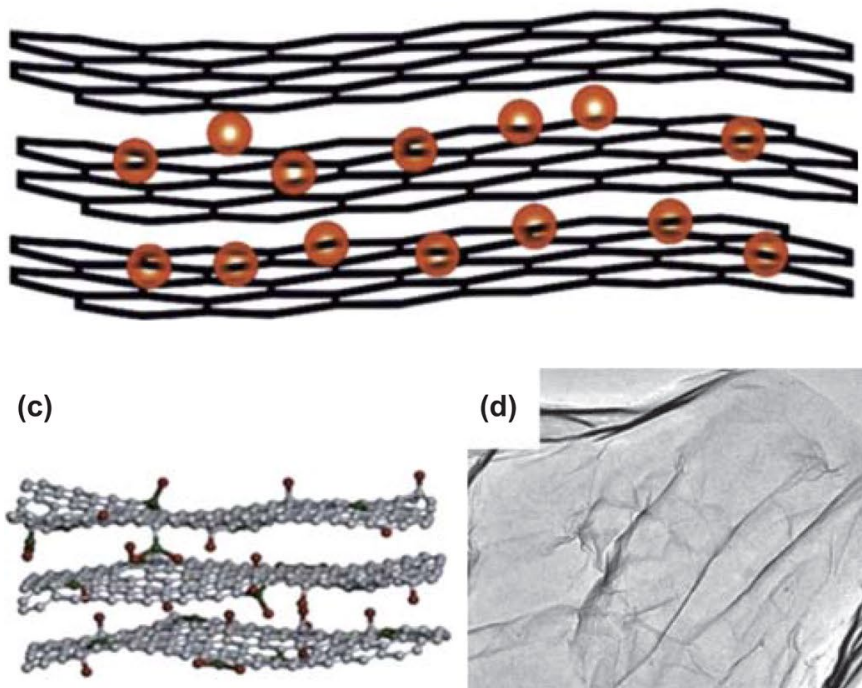

(d)
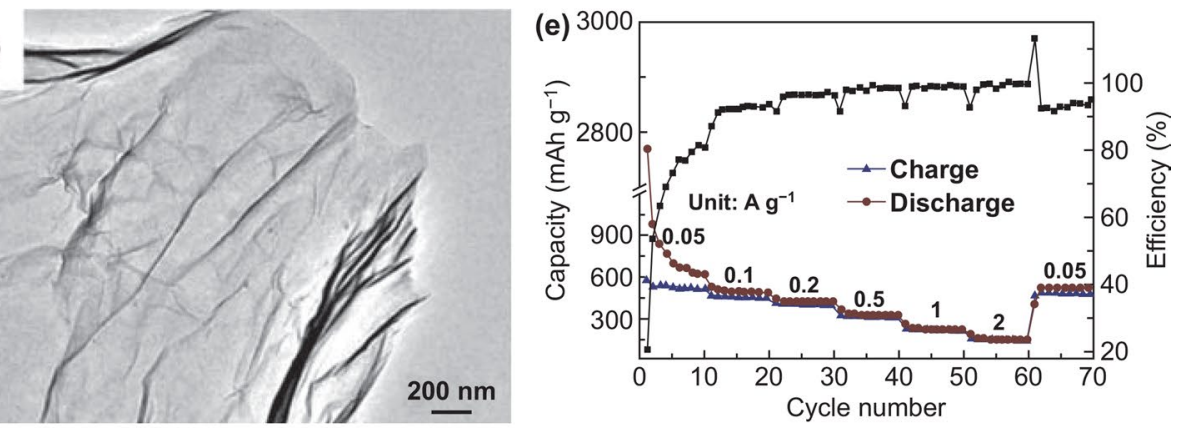

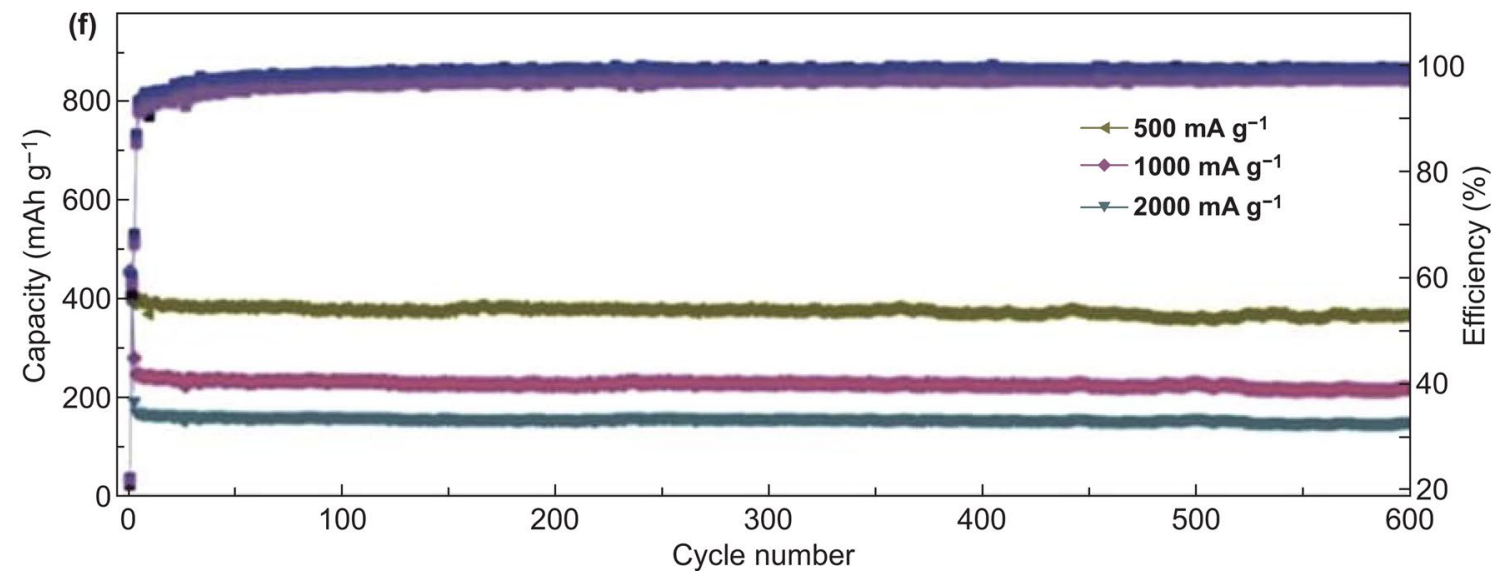

Fig. 9 Schematic diagram of $\mathrm{K}^{+}$trapped $\mathbf{a}$ in the surface and $\mathbf{b}$ in the defect sites. Reproduced with permission from Ref. [65]. Copyright 2018, Elsevier. c Schematic diagram and d TEM image of PODG. e The rate capability of the PODG electrode. $\mathbf{f}$ Cycle capacities of the obtained anode under three different current densities. Reproduced with permission from Ref. [66]. Copyright 2017, Royal Society of Chemistry

performances were mainly due to the NPG with sufficient active sites for ion storage, expanding interlayer spacing, and enhanced electrochemical conductivity. Given the aforementioned examples, graphene can improve electrochemical performances of PIBs anode by heteroatom doping (e.g., N, P, and O). However, the obstructions of graphene in practical applications are attributed to low initial coulomb efficiency, potential plateau lack, and the large voltage hysteresis [173]. Therefore, some strategies should be undertaken in the further experiments.

\subsection{Two-Dimensional MCs and MOs}

Among 2D MCs and MOs, 2D transition metal chalcogenides (2D TMCs), including $\mathrm{MoS}_{2}, \mathrm{MoSe}_{2}, \mathrm{VS}_{2}, \mathrm{VSe}_{2}$, $\mathrm{V}_{5} \mathrm{~S}_{8}$, etc., have been studied in PIBs anode materials for the reason that they have sufficient active sites, short ionic transfer pathways, and low intercalation barriers [174]. Taking $\mathrm{MoSe}_{2}$ as an example, it possesses sandwich-like lamellar structure, but low intrinsic conductivity, compounding with carbon materials, could be considered to enhance its 

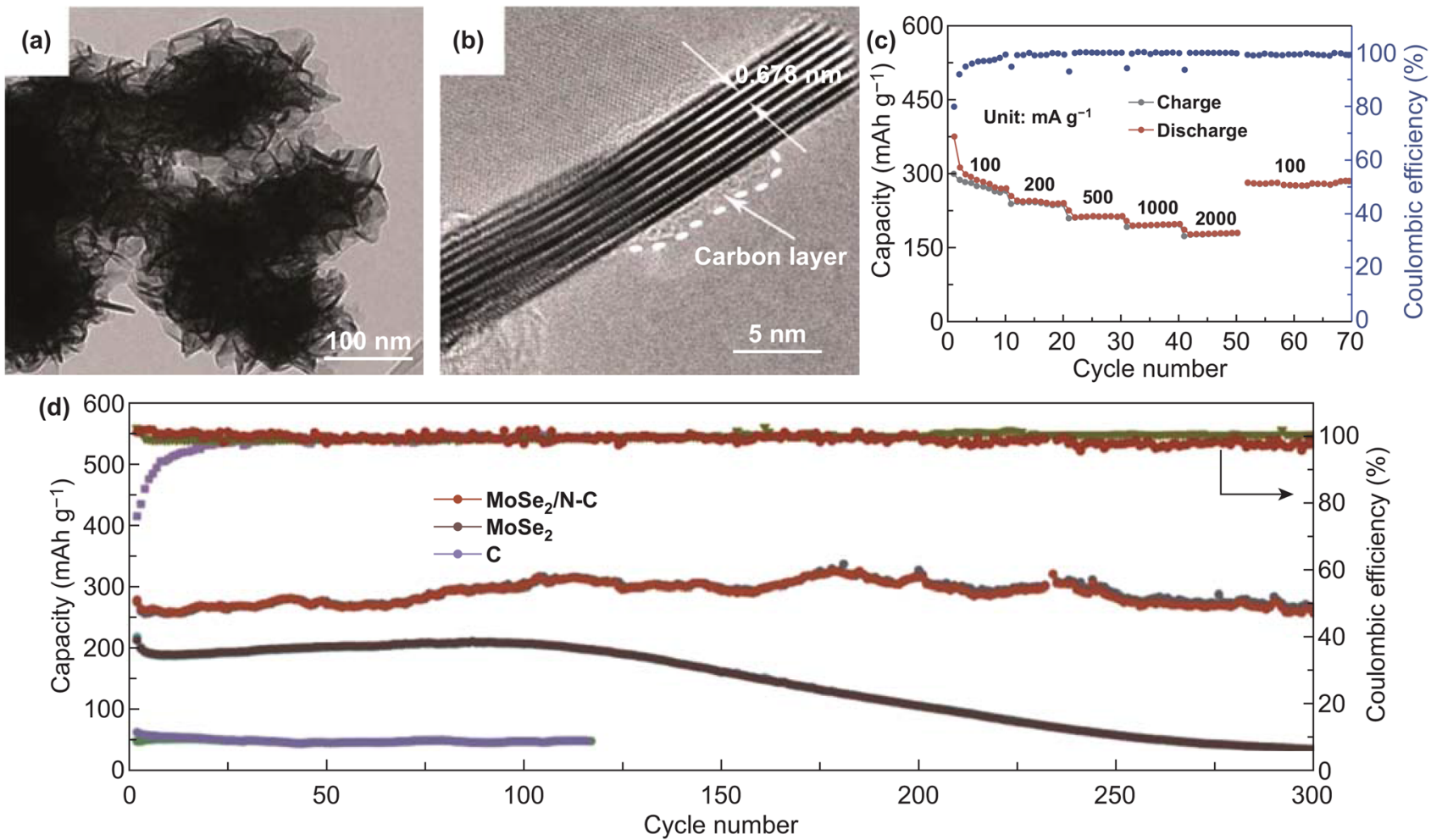

(e)

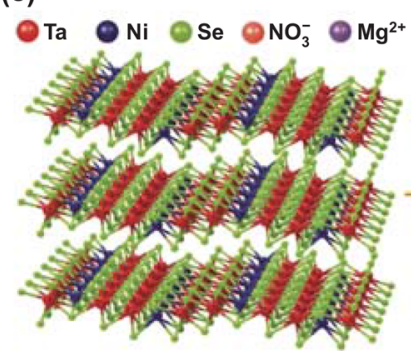

(f)

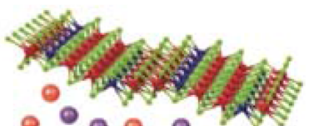

- $\odot \circ \ominus$

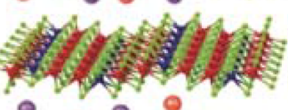

$\circ \circ$

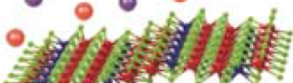

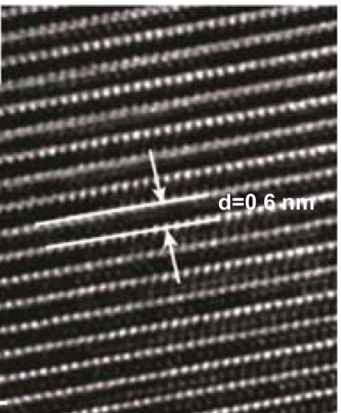

(g)

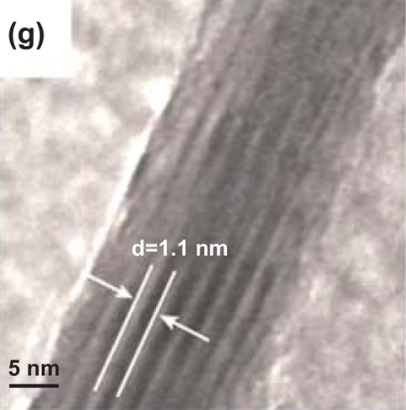

(h)

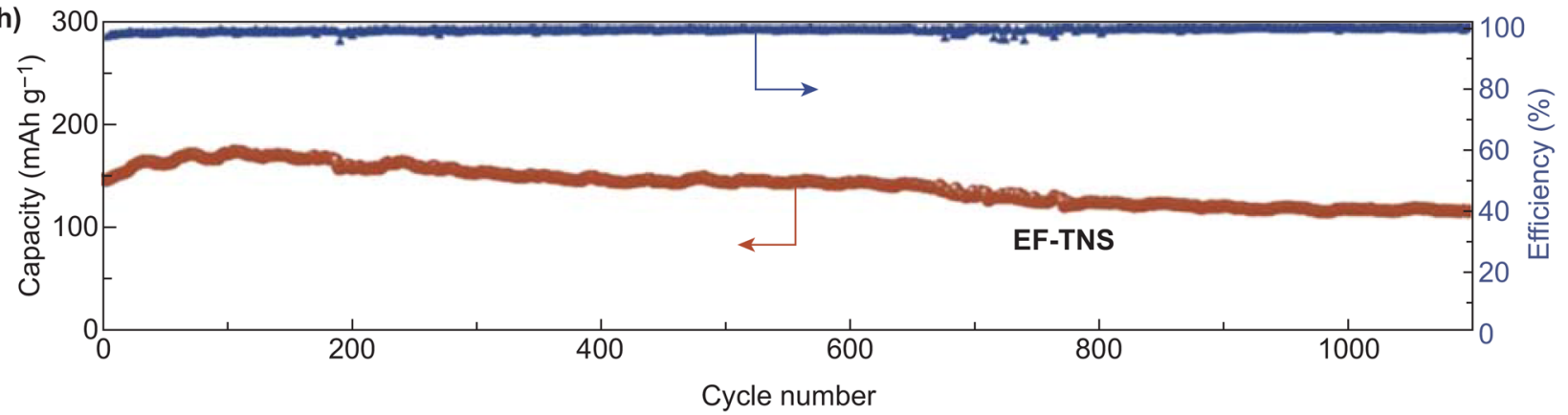

Fig. 10 a TEM image of $\mathrm{MoSe}_{2} / \mathrm{N}-\mathrm{C}$. b HRTEM image of $\mathrm{MoSe}_{2} / \mathrm{N}-\mathrm{C}$. $\mathbf{c}$ Rate capability of $\mathrm{MoSe}_{2} / \mathrm{N}-\mathrm{C}$ from 100 to $2000 \mathrm{~mA} \mathrm{~g}^{-1}$. d Long Cycle capacities of $\mathrm{MoSe}_{2} / \mathrm{N}-\mathrm{C}, \mathrm{MoSe}_{2}$, as well as C at $100 \mathrm{~mA} \mathrm{~g}{ }^{-1}$. Reproduced with permission from Ref. [67]. Copyright 2018, John Wiley and Sons. e Schematic diagram of expanding process of EF-TNS. f HRTEM image of pristine $\mathrm{Ta}_{2} \mathrm{NiSe}_{5}$. $\mathrm{g}$ HRTEM image of intercalated $\mathrm{Ta}_{2} \mathrm{NiSe}_{5} . \mathbf{h}$ Stable cycle capacities of EF-TNS anode at $500 \mathrm{~mA} \mathrm{~g}^{-1}$. Reproduced with permission from Ref. [68]. Copyright 2019, John Wiley and Sons 
electrochemical performances. So $\mathrm{MoSe}_{2} / \mathrm{N}$-doped carbon $\left(\mathrm{MoSe}_{2} / \mathrm{N}-\mathrm{C}\right)$ composite was synthesized as anode materials in PIBs [67]. Spherical structure was composed of a great number of nanosheets, and the interplanar spacing with $0.678 \mathrm{~nm}$ was beneficial to $\mathrm{K}^{+}$insertion/extraction (Fig. 10a, b). In addition, the coated carbon layer encapsulating the $\mathrm{MoSe}_{2}$ nanosheets effectively improved conductivity and obstructed the aggregation of the nanosheets. As for electrochemical performances, the $\mathrm{MoSe}_{2} / \mathrm{N}-\mathrm{C}$ electrode remained $178 \mathrm{mAh} \mathrm{g}^{-1}$ at $2000 \mathrm{~mA} \mathrm{~g}^{-1}$ as well as maintained $258.2 \mathrm{mAh} \mathrm{g}^{-1}$ after 300 cycles at $100 \mathrm{~mA} \mathrm{~g}^{-1}$ (Fig. 10c, d). Besides, quite a few binary 2D TMCs have also been reported to improve the electrochemical performances of PIBs anode, but a few studies about ternary 2D TMCs have been published. Gradually, ternary 2D TMCs have aroused increasing interesting in PIBs anode due to their unique structure and properties $[68,175,176]$. Then, expanded few-layered ternary $\mathrm{Ta}_{2} \mathrm{NiSe}_{5}$ (EF-TNS) flakes were reported [68]. The $\mathrm{Ta}_{2} \mathrm{NiSe}_{5}$ with expanded interlayer was realized by $\mathrm{Mg}_{2}{ }^{+} / \mathrm{NO}_{3}{ }^{-}$ion assisted intercalation (Fig. 10e). First of all, ternary $\mathrm{Ta}_{2} \mathrm{NiSe}_{5}$ was beneficial to increase the capacity. Secondly, the obtained EF-TNS had a few-layered structure, which was in favor of buffering the volume variation. Thirdly, the interlayer distance of EF-TNS was expanded from 0.6 to $1.1 \mathrm{~nm}$ after intercalation, which facilitated $\mathrm{K}$-ion diffusion and benefited for $\mathrm{K}^{+}$ions intercalating along zigzag pathways (Fig. 10f, g). These three advantages made it have good $\mathrm{K}$ storage performances and become promising anode materials. As a consequence, the EF-TNS electrode delivered the capacity of $116 \mathrm{mAh} \mathrm{g}^{-1}$ at $500 \mathrm{~mA} \mathrm{~g}^{-1}$ after 1100 cycles (Fig. 10h).

In order to further search for appropriate anode materials, 2D metal-based oxides have been studied in PIBs [177]. $\mathrm{Sb}_{2} \mathrm{O}_{3}$ flakes anchored onto $\mathrm{rGO}$ were synthesized by $\mathrm{Li}$ and co-workers [178], which delivered the long cycle capacity of $201 \mathrm{mAh} \mathrm{g}^{-1}$ at $500 \mathrm{~mA} \mathrm{~g}^{-1}$ after 3300 cycles. As for the reason of the remarkable electrochemical behavior, it was found that the $\mathrm{Sb}_{2} \mathrm{O}_{3}$ flakes and $\mathrm{rGO}$ could not only make electrode and electrolyte close, but also enhance conductivity and buffer the volume expansion. In addition, further strategies should be taken so as to relieve the stress variation of $\mathrm{Sb}_{2} \mathrm{O}_{3}$ better, such as designing rational structures and synthesizing bimetallic compounds; especially, bimetallic compounds with the better electrochemical behavior are ascribed to the synergistic effects, more active sites, and interfacial effects, compared with the single-metal counterparts [179-182]. Accordingly, Wang et al. [183] fabricated $\mathrm{Sb}_{2} \mathrm{MoO}_{6}$ nanoplates composited with $\mathrm{rGO}$ as anode materials of PIBs. In these composites, with the help of Mo element, the conductivity could be improved and the volume changes of Sb could be relieved in the course of charge and discharge process. Therefore, the electrochemical performances would be enhanced and the capacity of $247 \mathrm{mAh} \mathrm{g}^{-1}$ was delivered at $500 \mathrm{~mA} \mathrm{~g}^{-1}$ after 100 cycles.

\subsection{Two-Dimensional Alloying Materials}

Phosphorene can be regarded as a typical 2D alloying materials in PIBs. In 2014, monolayer and few-layer phosphorene were exfoliated from black phosphorus by scotch-tape-based micro-cleavage method [184, 185]. However, monolayer phosphorene could not be utilized directly as electrode materials, which was ascribed to be easily oxidized when it exposed to air [186, 187]. Therefore, He et al. [188] indirectly verified that the monolayer phosphorene was beneficial to improve performances of GeSe electrode by firstprinciples calculation. Moreover, phosphorene with sulfur doping could be considered as the PIBs anode materials by using ab initio density functional theory [189]. Furthermore, few-layer phosphorene has started to be directly utilized for PIBs because of high carrier mobility and superior mechanical flexibility [190]. And then, Nikhil Koratkar's group [69] fabricated few-layer phosphorene composited with $\mathrm{rGO}$ (FLP/rGO) as anode materials (Fig. 11a). The TEM image of FLP/rGO indicated FLP encapsulated with $\mathrm{rGO}$ and the existing evidence of both FLP and rGO was provided by the SAED pattern (Fig. 11b). In these composites, FLP and rGO were beneficial for enhancing electrical conductivity as well as buffering volumetric variation in the course of alloying reaction. The FLP/rGO (1:3) electrode delivered different capacities at different current density, especially $\sim 400$ and $\sim 230 \mathrm{mAh} \mathrm{g}^{-1}$ at $\sim 0.6 \mathrm{C}$ as well as $\sim 1.2 \mathrm{C}$, respectively. As for cycle performance, FLP/rGO (1:3) delivered the capacity of $\sim 230 \mathrm{mAh} \mathrm{g}^{-1}$ at $\sim 0.5 \mathrm{C}$ after 300 cycles (Fig. 11c, d). Furthermore, in terms of alloying mechanism, 

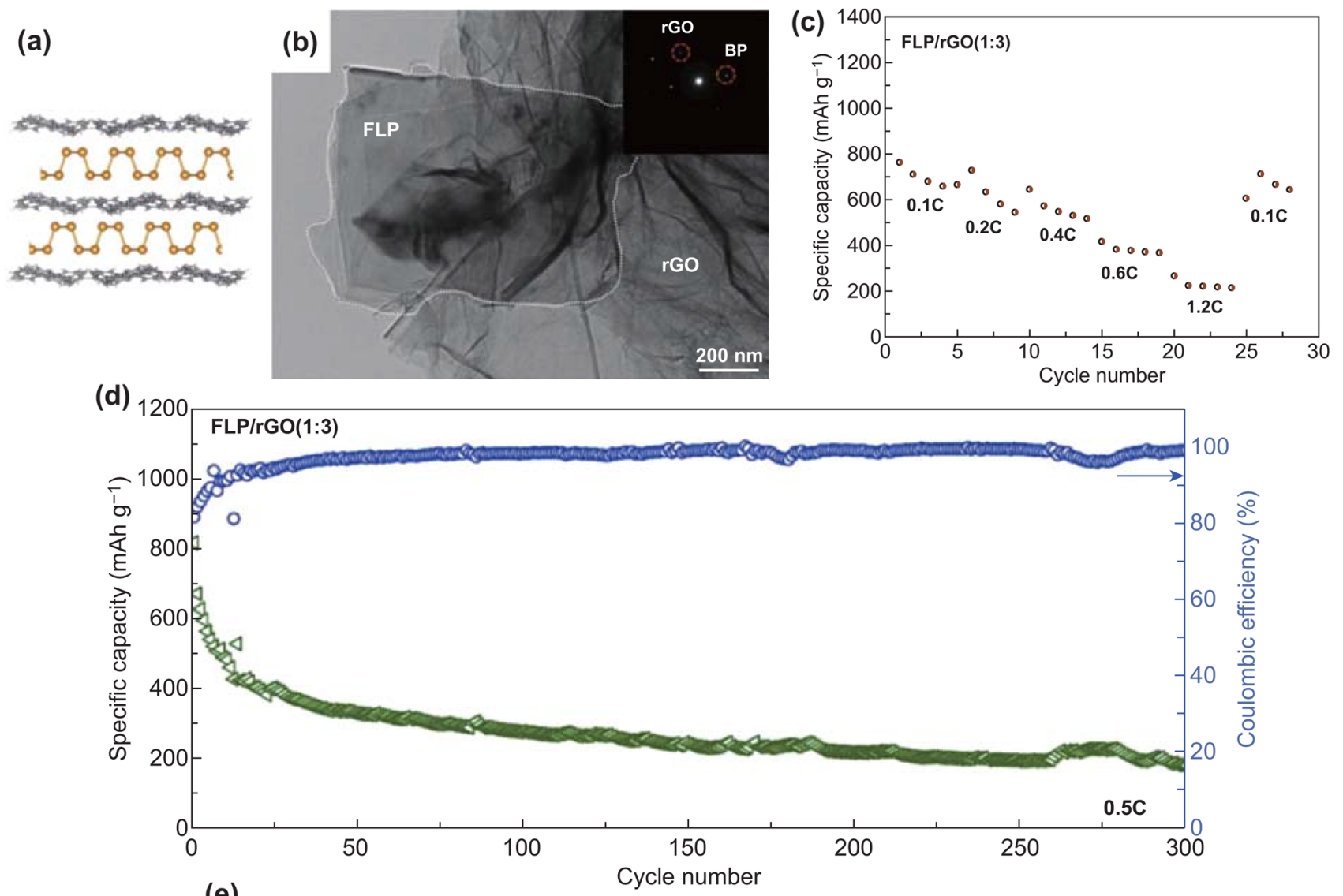

(e)
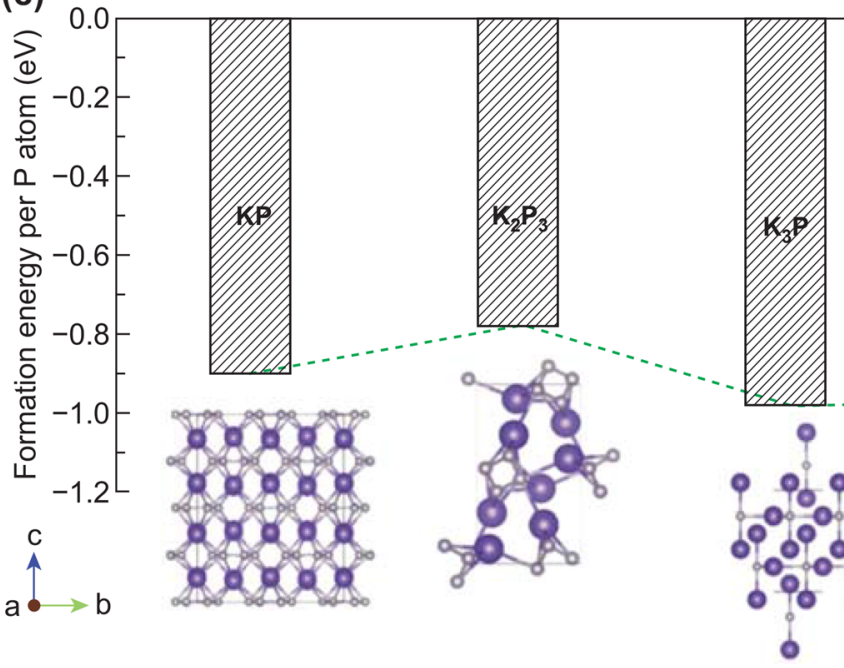

$\mathrm{P}$ atom $\mathrm{K}$ atom $\quad$ P-P bond $\quad$ K-P bond

Fig. 11 a Schematic diagram and b TEM image (inset shows SAED pattern) of FLP/rGO. $\mathbf{c}$ Rate capability of FLP/rGO (1:3) at various C-rates between $\sim 0.1$ and 1.2 C. d Cycling performance of FLP/rGO (1:3) at $\sim 0.5$ C. e various alloys' formation energies calculated by DFT. Reproduced with permission from Ref. [69]. Copyright 2019, American Chemical Society

the author confirmed that $\mathrm{K}_{4} \mathrm{P}_{3}$ bringing about high capacity was the type of alloy and used DFT calculation to give a further understanding about the formation of $\mathrm{K}_{4} \mathrm{P}_{3}$ (Fig. 11e).
Further experiments can focus on phosphorene compounded with other materials or doped with heteroatom to enhance the electrochemical performances. 


\section{Three-Dimensional Nanomaterials for PIBs}

3D nanomaterials are essential to the application of batteries, due to unique features such as high specific areas, interlinked porous channels, high conductivity and outstanding structural mechanical stability [191, 192]. 3D nanomaterials could overcome the insufficiency of 1D and 2D nanomaterials caused by evident aggregation [193]. In addition, some 3D nanomaterials can be directly used as free-standing electrodes, simplifying the preparation process of battery. To date, 3D nanomaterials in PIBs electrode materials field mainly include 3D carbon nanomaterials,

Table 4 Comparison of the state-of-the-art performances of 3D anode materials in PIBs

\begin{tabular}{|c|c|c|c|c|}
\hline Materials & Initial C.E. (\%) & $\begin{array}{l}\text { Rate capacity }\left(\mathrm{mAh} \mathrm{g}^{-1}\right) \\
\text { at the current density } \\
\left(\mathrm{mA} \mathrm{g}^{-1}\right)\end{array}$ & $\begin{array}{l}\text { Cycle capacity }\left(\mathrm{mAh} \mathrm{g}^{-1}\right) \text { at the current } \\
\text { density }\left(\mathrm{mA} \mathrm{g}^{-1}\right)(\text { cycle number) }\end{array}$ & References \\
\hline $\mathrm{N}$ - and O-rich $\mathrm{CNF}$ & 35 & 70 at $10 \mathrm{C}$ & 160 at $1 \mathrm{C}(300)$ & [198] \\
\hline $\begin{array}{l}\text { Cobalt(II) terephthalate-based layered } \\
\text { MOF }\end{array}$ & 60.65 & 131 at 1000 & 188 at $1000(600)$ & [199] \\
\hline Tire-derived carbons & 37.1 & 60 at $2 \mathrm{C}$ & 155 at $\mathrm{C} / 2(200)$ & [200] \\
\hline Hard wood-based hard carbon & 56 & 135 at 100 & - & [201] \\
\hline $\mathrm{AC}$ & - & 30 at 1000 & 100.3 at $200(100)$ & [74] \\
\hline Porous CNF paper & 24.1 & 140 at 5000 & 211 at $200(1200)$ & {$[202]$} \\
\hline $\begin{array}{l}\text { S/O co-doped porous hard carbon micro- } \\
\text { spheres }\end{array}$ & 61.7 & 158 at 1000 & 108.4 at 1000 (2000 cycles $)$ & [203] \\
\hline $\mathrm{Co}_{3}\left[\mathrm{Co}(\mathrm{CN})_{6}\right]_{2}$ & 45.5 & 112 at 2000 & 297.5 at $100(200)$ & [75] \\
\hline Skimmed cotton-derived hard carbon & 73 & 165.2 at 4000 & 240 at $200(150)$ & [204] \\
\hline HPCS & 45.3 & 150 at 500 & 276.4 at $500(100)$ & [76] \\
\hline $\mathrm{SnO}_{2}$-graphene-CNFs & 44.13 & 114.81 at 1000 & 202.06 at $1000(100)$ & [205] \\
\hline $\mathrm{MoS}_{2} / \mathrm{N}$-Doped C & - & 131 at 2000 & 151 at $5000(1000)$ & [206] \\
\hline Hierarchically N-doped porous carbon & 43.1 & 185 at 10,000 & 144.4 at $5000(1000)$ & [89] \\
\hline $\mathrm{HNTO} / \mathrm{CS}$ & - & 50 at 1000 & 88.9 at $1000(1555)$ & [93] \\
\hline High pyridine NPC & - & 186.2 at 2000 & 231.6 at $5000(2000)$ & [207] \\
\hline $\begin{array}{l}\text { Zero-strain potassium fluoromanganate } \\
\text { hollow nanocubes }\end{array}$ & 65 & 78 at 1000 & 110 at $4000(10,000)$ & [208] \\
\hline $\mathrm{N}$-doped hierarchically porous carbon & 30.28 & 193.1 at 500 & 121.3 at $5000(1000)$ & [209] \\
\hline $\mathrm{KTi}_{2}\left(\mathrm{PO}_{4}\right)_{3} @ \mathrm{C}$ nanocomposites & 35.3 & 131.1 at 1000 & 69.7 at $1000(1000)$ & [210] \\
\hline NOHPHC & 25 & 118 at 3000 & 230.6 at $500(100)$ & [77] \\
\hline $\mathrm{Sn}_{4} \mathrm{P}_{3}$ in N-doped carbon fibers & 64.17 & 169.6 at 2000 & 160.7 at 5000 after 1000 & [211] \\
\hline Bi@3DGFs & 51.1 & 113 at 10,000 & 164 at $1000(400)$ & [212] \\
\hline $\mathrm{N}$-doped biomorphic carbon & 55.1 & 102.6 at 2000 & 119.9 at $1000(1000)$ & [213] \\
\hline $\begin{array}{l}\text { Nanosheets-assembled CuSe Crystal } \\
\text { Pillar }\end{array}$ & 92.4 & 280 at 5000 & 337 at $100(40)$ & {$[214]$} \\
\hline rGO aerogel & 44 & 92 at $6.7 \mathrm{C}$ & 125 at $1.6 \mathrm{C}(500)$ & [78] \\
\hline $\mathrm{KVPO}_{4} \mathrm{~F}$ & - & 65 at 2000 & 133 at $100(100)$ & [215] \\
\hline MXene@Sb & 57.29 & 270.81 at 500 & $\begin{array}{l}\text { capacity retention of } 79.1435 \% \text { at } 500 \\
(500 \text { cycles })\end{array}$ & [216] \\
\hline RedP@N-PHCNFs & - & 342 at 5000 & 282 at 5000 (800 cycles) & [217] \\
\hline NOHPHC & - & 110 at 1000 & 80 at $2000(3000)$ & [218] \\
\hline Yolk shell FeP@C nanoboxes & 47 & 37 at 2000 & 205 at $1000(300)$ & [219] \\
\hline $\begin{array}{l}\text { Multicore shell Bi@N-doped carbon } \\
\text { nanospheres }\end{array}$ & 43 & 152 at 100,000 & 203 at $10,000(1000)$ & {$[220]$} \\
\hline Graphitic nanocarbons & - & 56.6 at 5000 & 189 at $200(200)$ & [79] \\
\hline $\mathrm{HHC}$ & 46.88 & 42 at 3200 & 67.6 at $500(100)$ & {$[80]$} \\
\hline $\begin{array}{l}\mathrm{N} \text {-doped soft carbon frameworks built of } \\
\text { well-interconnected nanocapsules }\end{array}$ & 30.9 & 151 at 5000 & 165 at $1000(500)$ & {$[221]$} \\
\hline
\end{tabular}


3D MCs and MOs, and 3D alloying materials [194-197]. At the following section, the relationship between these materials and their electrochemical performances will be discussed systematically. Meanwhile, the initial C.E., rate performances, and cycle properties of recent reported 3D anode materials of PIBs are summarized in Table 4.

\subsection{Three-Dimensional Carbon Materials}

3D carbon materials mainly include 3D interconnected structures, which can promote electronic and ionic transport as well as improve mechanical stability [222-224]. Among 3D interconnected networks, 3D carbon nanofiber frameworks are typical materials and were used in PIBs anode materials field in 2018. Li et al. [225] reported bacterial-derived and compressible carbon nanofiber foam (CNFF) with hierarchical pores as electrode materials in PIBs (Fig. 12a). The diameters of fibers were between 10 and $30 \mathrm{~nm}$ shown in the SEM image (Fig. 12b). According to the authors' report, two kinds of pores were found in this CNFF. The first was numerous nanopores originating from nanofibers' surface; the other was hierarchical pores between fiber and fiber. Those
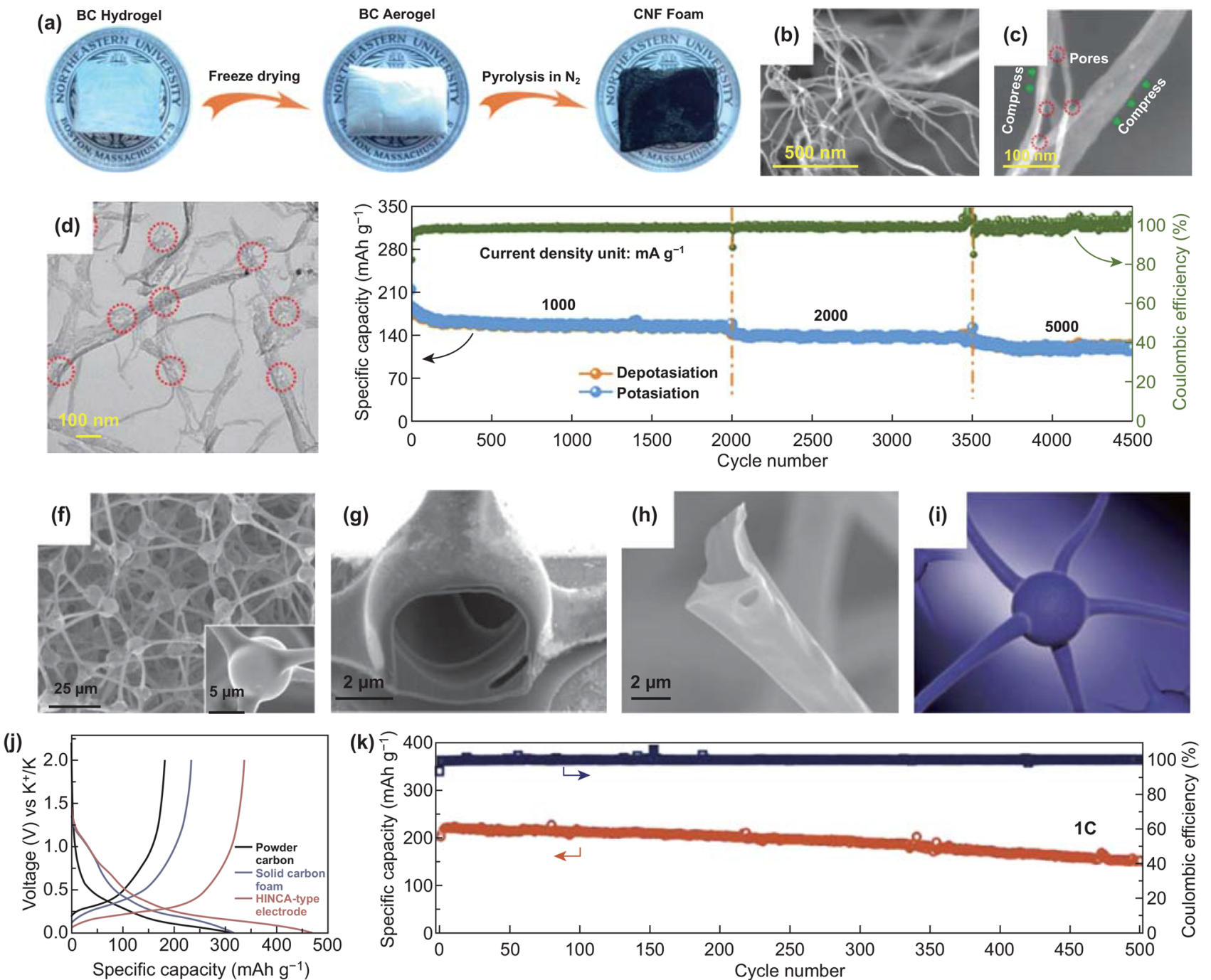

Fig. 12 a Schematic diagram of preparation of CNFF. SEM images of b CNFF and $\mathbf{c}$ CNFs. d TEM image of CNFF. e Long-term cycling performance of CNFF electrode at three current densities. The battery rested for 10 days before using different current density. Reproduced with permission from Ref. [225]. Copyright 2018, American Chemical Society. f SEM image of HINCA and its tetrapod center (inset). SEM images of $\mathbf{g}$ the tetrapod-joint cross section and $\mathbf{h}$ a tetrapod-unit broken arm. $\mathbf{i}$ Neuron structural Cartoon. $\mathbf{j}$ Charge/discharge curves of the $1^{\text {st }}$ cycle at $0.1 \mathrm{C}\left(28 \mathrm{~mA} \mathrm{~g}^{-1}\right)$. k). Long cycle performance of the HINCA-type product at $1 \mathrm{C}$. Reproduced with permission from Ref. [226]. Copyright 2018, American Chemical Society 
pores could benefit K-ions absorption in the course of charge and discharge process (Fig. 12c, d). In the electrochemical test, the CNFF electrode achieved a reversible capacity of $158 \mathrm{mAh} \mathrm{g}^{-1}$ at $1000 \mathrm{~mA} \mathrm{~g}^{-1}$ after 2000 cycles. Furthermore, after a period of time, the same battery could also run 1500 and 1000 cycles at 2000 and $5000 \mathrm{~mA} \mathrm{~g}^{-1}$, respectively (Fig. 12e), showing superior cycle stability. The splendid electrochemical behavior of the CNFF anode was ascribed to the hierarchical pores of the structure, the 3D carbon foam, and the quasi-amorphous carbon, which not only enhanced ionic adsorption and diffusion but also relieved the volume variation. Additionally, 3D porous structures have also been used in PIBs. Bin et al. [226] fabricated interconnected carbon architecture with hollow structure and neuron-like morphology (HINCA) as anode materials. As for HINCA, interconnected tetrapod backbones with tubular structure and hollow structural spherical joint were exhibited and better comprehend by cartoon (Fig. 12f-i). The aforementioned structural characteristics could facilitate electronic conductivity and possess flexible mechanical robustness. Then, the HINCA-type electrode delivered the capacity of $340 \mathrm{mAh} \mathrm{g}^{-1}$ as well as showed only slight capacity decay of $\sim 0.05 \%$ per cycle over 500 cycles at $1 \mathrm{C}$ (Fig. 12j, k). The HINCA-type electrode's electrochemical performances were due to carbon structure with hollow feature, which kept the stability of structure during potassiation/depotassiation process and promoted the ions and electrons transport. With similar structures, hollow neuronal carbon skeleton (HNCS) was fabricated, which exhibited interlinked hollow architecture with high content of pyridinic $\mathrm{N}$ [227]. The interlinked hollow framework and pyridinic $\mathrm{N}$ could enhance ionic transfer and adsorption as well as tolerate the stress variation to improve corresponding performances. As for electrochemical performances, the electrode delivered the rate capacity of $110 \mathrm{mAh} \mathrm{g}^{-1}$ at $1000 \mathrm{~mA} \mathrm{~g}^{-1}$ and $134 \mathrm{mAh} \mathrm{g}^{-1}$ at $0.5 \mathrm{~A} \mathrm{~g}^{-1}$ after 500 cycles. Overall, 3D carbon materials are beneficial to boost ionic and electronic transport and keep high mechanical robustness, resulting in improved electrochemical performances.

\subsection{Three-Dimensional MCs and MOs}

3D MCs and MOs have aroused increasing attentions in PIBs electrode materials. For example, in 2017, it was the first time that Ren et al. [70] used $\mathrm{MoS}_{2}$ particles as electrode materials in PIBs. The author indicated that the micro-sized $\mathrm{MoS}_{2}$ with layer structure was beneficial to stably form K-ion intercalation compound $\left(\mathrm{K}_{0.4} \mathrm{MoS}_{2}\right)$ during potassiation to $0.5 \mathrm{~V}$. It is demonstrated that $\mathrm{MoS}_{2}$ may be considered as another choice of PIBs anode materials. Besides, increasing 3D metal-based oxides have been tried for PIBs anode. In 2018, Li and co-workers [228] firstly introduced orthorhombic niobium pentoxide $\left(\mathrm{T}-\mathrm{Nb}_{2} \mathrm{O}_{5}\right)$ into PIBs anode field. The urchin-like interlinked hierarchical structure of $\mathrm{T}-\mathrm{Nb}_{2} \mathrm{O}_{5}$ assembled by nanowires was exhibited (Fig. 13a), which could boost K-ion diffusion. Therefore, the capacity of $104 \mathrm{mAh} \mathrm{g}^{-1}$ was delivered at $0.4 \mathrm{~A} \mathrm{~g}^{-1}$ in terms of rate performance (Fig. 13b, c). In addition, interconnected $\mathrm{K}_{2} \mathrm{Ti}_{6} \mathrm{O}_{13}$ nanowires framework was fabricated as electrode materials in PIBs [71]. The $\mathrm{K}_{2} \mathrm{Ti}_{6} \mathrm{O}_{13}$ nanowires with a diameter of around $5.5 \mathrm{~nm}$ (name as TBTN) were displayed (Fig. 13d). In this framework, ionic diffusion and mechanical robustness could be enhanced due to $3 \mathrm{D}$ interlinked architectures. Thus, the TBTN electrode delivered the rate capacities of $11 \mathrm{mAh} \mathrm{g}^{-1}$ at $10 \mathrm{C}$ (Fig. 13e). Besides, the cycle capacity of around $120 \mathrm{mAh} \mathrm{g}^{-1}$ was exhibited at 0.2 $\mathrm{C}$ after 20th cycle (Fig. 13f). From the above analysis, it can be concluded that good structural design helps to improve the performances of 3D MCs and MOs, but these properties are not satisfactory enough. Judging from the characteristics of these materials, the reason may put down to their poor conductivity. Therefore, it is necessary for 3D MCs and MOs to combine other modification methods to obtain satisfactory electrochemical performances.

\subsection{Three-Dimensional Alloying Materials}

3D alloying materials are beneficial to contact largely with electrolyte and buffer the volume expansion, especially 3D porous structures. Pristine Bi block was used as PIBs anode and would gradually transform into 3D porous networks after 100 cycles during charge and discharge process (Fig. 14a, b) [229]. The formed porous networks not only enhanced ionic transfer but also restricted the stress variation in the course of potassium/depotassium process. Therefore, the capacity retention realized $86.9 \%$ after 300 cycles at 2 C (Fig. 14c). This method provides new ideas for constructing porous alloying materials. So nanoporous Sb (NP-Sb) was synthesized as PIBs anode materials (Fig. 14d) [72]. The pores of NP-Sb-20 (20 means the percentage of $\mathrm{Sb}$ atom) were uniformly distributed in the continuous porous 

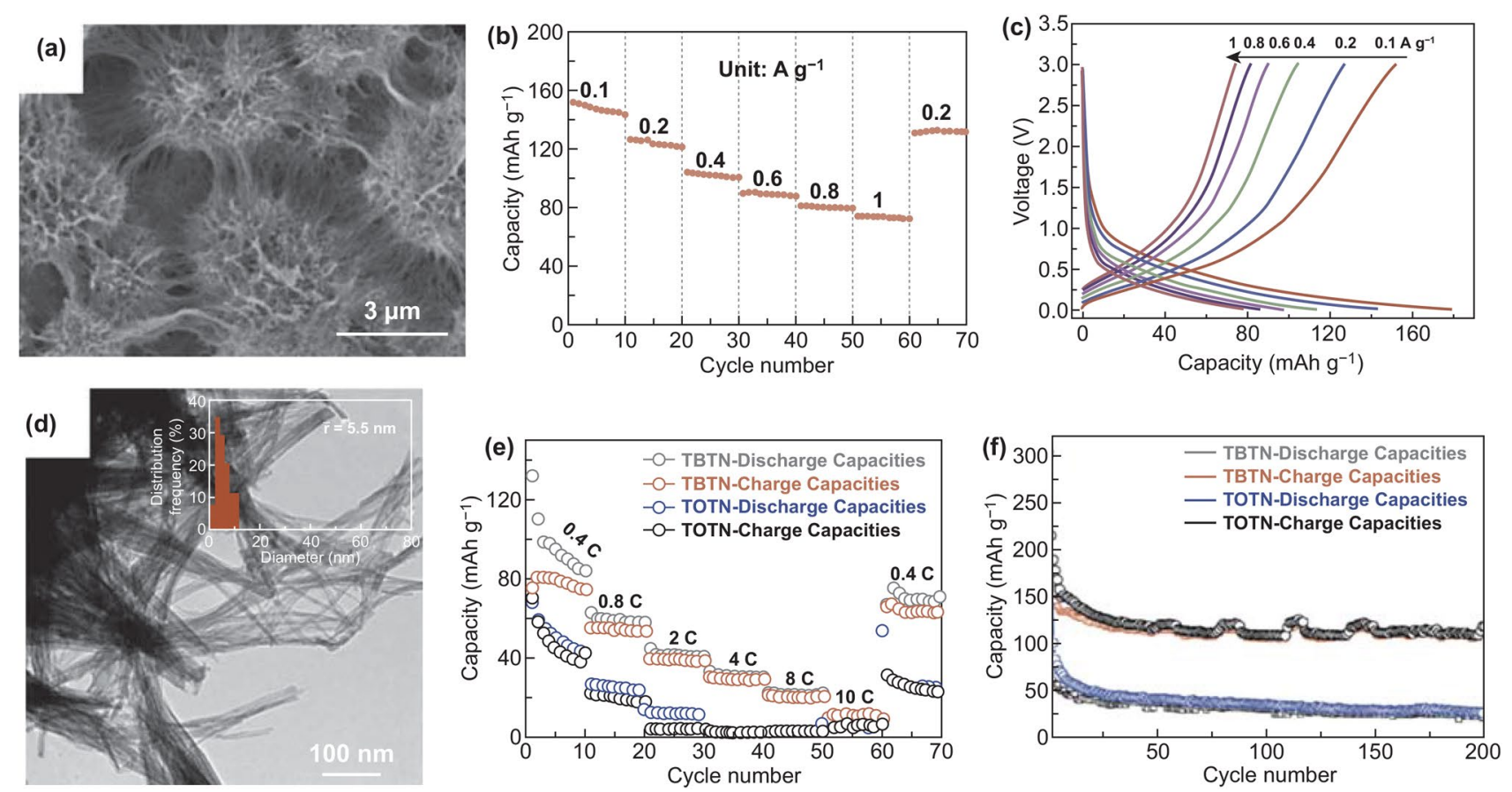

Fig. 13 a T- $\mathrm{Nb}_{2} \mathrm{O}_{5}$ 's $\mathrm{SEM}$ image. b T- $\mathrm{Nb}_{2} \mathrm{O}_{5}$ anode's rate performance in the range of $0.1-1 \mathrm{~A} \mathrm{~g}^{-1}$. c Corresponding charge capacities under various current densities. Reproduced with permission from Ref. [228]. Copyright 2018, Royal Society of Chemistry. d TEM image of TBTN with average diameter of around $5.5 \mathrm{~nm}$. e Rate performance and $\mathbf{f}$ cycle performance of TBTN. Reproduced with permission from Ref. [71]. Copyright 2018, John Wiley and Sons

structure (Fig. 14e). Benefiting from the 3D porous architecture, the NP-Sb-20 could effectively tolerate stress variation and promote ions transportation. As for rate performance, the bulk Sb only delivered $30 \mathrm{mAh} \mathrm{g}^{-1}$ at $500 \mathrm{~mA} \mathrm{~g}^{-1}$, while the NP-Sb-20 delivered $265 \mathrm{mAh} \mathrm{g}^{-1}$ (Fig. 14f). Obviously, the performances improvement was due to the nanoporous structure of Sb. Besides, in 2019, nanoporous Ge was fabricated for the first time, which delivered the capacity of around $120 \mathrm{mAh} \mathrm{g}^{-1}$ at $20 \mathrm{~mA} \mathrm{~g}^{-1}$ over 400 cycles [73]. Based on nanoporous $\mathrm{Ge}$ with the numerous pores as well as nanoscale ligaments, the stable cycling performance was ascribed to shorter diffusion distance of K-ion as well as the adequate space for volumetric variation. Overall, 3D porous structures are of benefit to alloying materials and further efforts should be made to improve the electrochemical behavior.

Additionally, given the discussion about multi-dimensional structures, related nanomaterials possess attractive advantages and unfavorable disadvantages, so optimized strategies should be taken to improve their electrochemical performances. Accordingly, the corresponding advantages, disadvantages, and optimized strategies are outlined in Table 5.

\section{Summary and Outlook}

As aforementioned, PIBs have been investigated due to better advantages compared with LIBs and SIBs, such as abundant resources, lower price, and smaller stokes radius of solvated ions. However, there are still some obstacles to PIBs for commercial applications, such as large volumetric variation induced by large size of K-ion during charge and discharge process, weak ionic diffusivity in solid phase, inferior kinetics of $\mathrm{K}^{+}$reaction, the existence of side and irreversible reactions, the imperfect energy store mechanism compared with LIBs, the production of dendrite and related safety problems. Accordingly, nanostructural design has been considered as one of the effective strategies to enhance corresponding performances. 

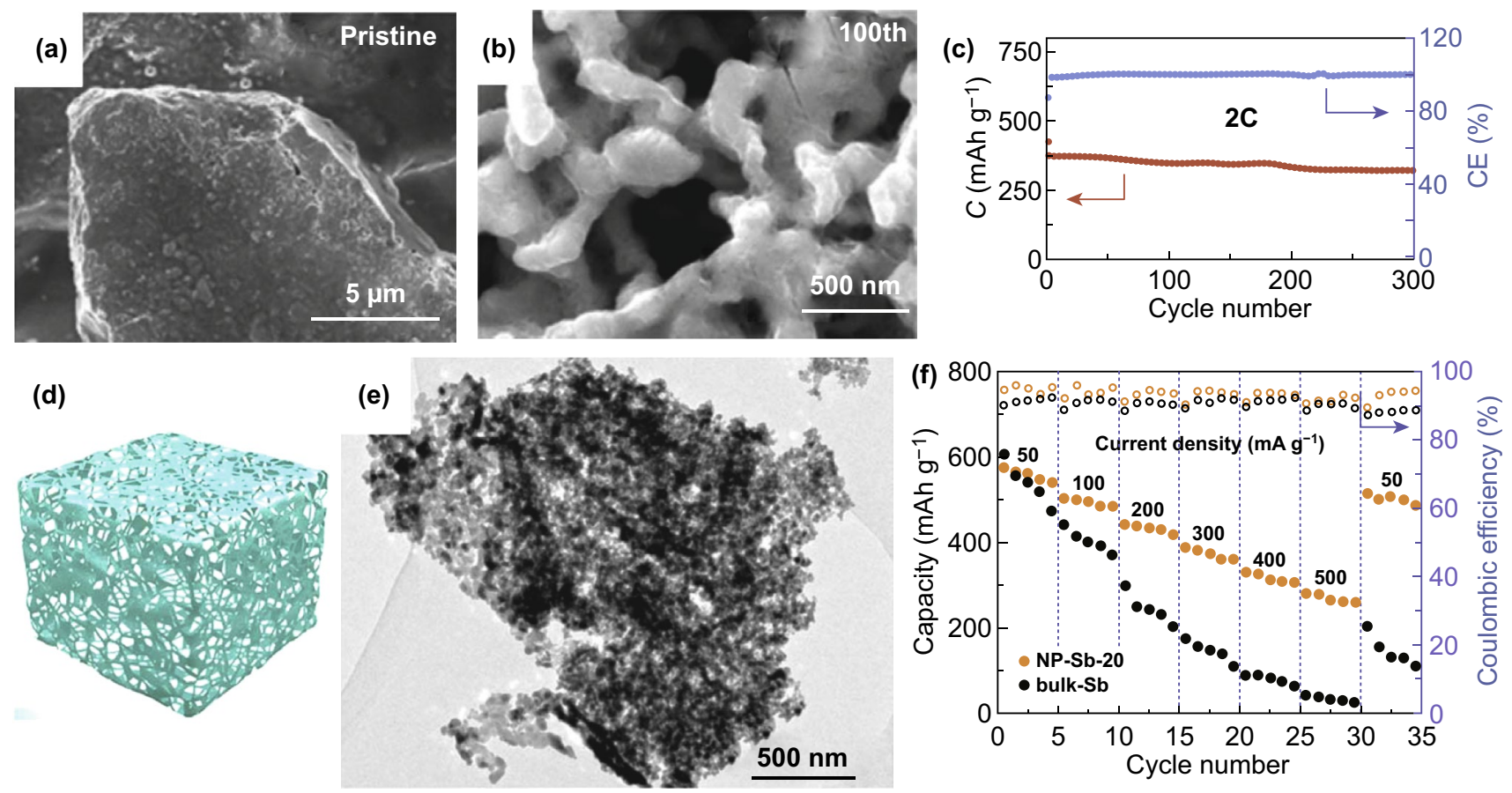

Fig. 14 SEM image of a pristine Bi and b Bi after 100th cycle. $\mathbf{c}$ Cycle performance of Bi electrode $\left(1 \mathrm{C}=384.7 \mathrm{mAh}^{-1}\right)$. Reproduced with permission from Ref. [229]. Copyright 2018, John Wiley and Sons. d Schematic illustration of NP-Sb. e TEM image of NP-Sb-20. d Rate performance of two samples in the range of $50-500 \mathrm{~mA} \mathrm{~g}^{-1}$. Reproduced with permission from Ref. [72]. Copyright 2018, American Chemical Society

In summary, 0D-3D nanomaterials about PIBs anode materials have been summarized and involved in the relationship with the corresponding electrochemical performances, mainly concerning carbon materials, MCs and MOs, and alloying materials. OD nanomaterials have been utilized in PIBs anode materials due to nano-size and large surface area, which can boost ionic transportation and alleviate the stress changes. In addition, 1D nanomaterials with high length-to-diameter aspect ratios possess high mechanical robustness as well as shorter electronic and ionic transport path. Moreover, 2D nanomaterials have also possessed large surface area to enhance ionic adsorption and diffusion in PIBs anode materials field. Finally, the interconnected structure about 3D nanomaterials can make largely electrode and electrolyte contact, which can facilitate ionic transfer.

Given aforementioned information, 0D-3D nanomaterials possess different structural and morphological features, corresponding to different electrochemical performances. Therefore, in order to better understand the different effect of multi-dimensional nanomaterials, it is necessary to make a comparison about their electrochemical performances. Furthermore, the corresponding comparision would be discussed by taking 0D-3D carbon materials as examples. And then, typical carbon nanomaterials will be introduced, including carbon nanocage, CNTs, graphene, and graphite. Among them, 0D carbon nanocage possesses large surface area and unique cage-like structure, which makes it have well electrochemical performances (e.g., $195 \mathrm{mAh} \mathrm{g}^{-1}$ at $0.2 \mathrm{C}$ after 100 cycles for CNC) [42]. Additionally, as representative $1 \mathrm{D}$ carbon nanomaterial, compared with $0 \mathrm{D}$ nanocage, CNTs with high aspect ratio are conducive to enhance the mechanical strength of electrode materials. So the structure of related electrode can be maintained stable and durable during charging and discharging, improving the long cycling life (e.g., $244 \mathrm{mAh} \mathrm{g}^{-1}$ at $0.5 \mathrm{~A} \mathrm{~g}^{-1}$ after 200 cycles for P@TBMC-2.4) [50]. As for graphene, with large landing platform, they are beneficial for adsorbing K-ion and are different from 0D as well as 1D carbon materials, which can evidently improve the capacity by adsorption mechanism (e.g., $385 \mathrm{mAh} \mathrm{g}^{-1}$ at $500 \mathrm{~mA} \mathrm{~g}^{-1}$ after 600 
cycles for PODG) [66]. Moreover, graphite can be used to inhibit the aggregation as a comparison of 0D-2D nanomaterials, which can keep structure stable and retain the stable capacity (e.g., $174 \mathrm{mAh} \mathrm{g}^{-1}$ at $200 \mathrm{~mA} \mathrm{~g}^{-1}$ after 500 cycles for expanded graphite) [109]. According to the comparison and discussion of 0D-3D carbon materials, the difference of electrochemical performances of multi-dimensional nanomaterials can be well understood. Additionally, the synthetic methods are important to prepare nanostructures with excellent electrochemical performances. Therefore, the main preparation methods about their advantages and disadvantages are summarized in Table 6. From the results of comparison, Ball milling may be considered as the practical strategies to obtain nanomaterials in the industries, which is attributed to its facile operability, low cost, and large scale.

Although significant progress has been achieved due to nanostructure design with different dimensions, more efforts should be made for PIBs anode materials to improve electrochemical performances as followed:

1. Novel architecture should be proposed. For example, carbon dots have been directly explored for LIBs and SIBs, while carbon dots only as raw materials were used to fabricate PIBs anode materials. Thus, further experiments may focus on novel structure design.

2. Novel synthetic strategies about different dimensional structures like 3D printing method can be used in PIBs field. Therefore, it is necessary to create methods with simple process and low cost.

3. Different dimensional structures can be assembled to fabricate various materials with unique morphology to sufficiently achieve the properties of every component.

4. Using new materials to design different dimensional structures is beneficial for increasing the variety of anodes as well as trying to improve the electrochemical performances.

5. The relationship between different dimensional structural electrodes and various electrolytes should be studied. To date, a few studies have involved in the impact of electrolytes on corresponding performances.

6. Some energy store mechanisms of PIBs still keep unclear, so more efforts should be undertaken.

All in all, it is one of the key preconditions for commercial PIBs anode materials to utilize simple preparation methods and simplified processes in different dimensional materials fabrication. Meanwhile, high-performance, low-cost, and good-stability materials will be considered as the desire 
Table 6 Summary of advantages and disadvantage of various synthesis methods for multi-dimensional structures

\begin{tabular}{|c|c|c|c|}
\hline Synthesis methods & Advantages & Disadvantages & References \\
\hline Ball milling method & $\begin{array}{l}\text { Facile; highly effective; economic; } \\
\text { scalable }\end{array}$ & $\begin{array}{l}\text { Products with uneven and large } \\
\text { size; generation of noise }\end{array}$ & {$[33,40,45,48,250]$} \\
\hline $\begin{array}{l}\text { Hydrothermal/solvothermal } \\
\text { method }\end{array}$ & $\begin{array}{l}\text { Facile morphological control; } \\
\text { controllable size; high purity }\end{array}$ & $\begin{array}{l}\text { High cost; simple morphology; } \\
\text { difficult controlled processes; } \\
\text { existing safety problems }\end{array}$ & {$[38,46,61,62,99,106,157,199]$} \\
\hline Solution method & $\begin{array}{l}\text { Well-controlled size; uniform } \\
\text { dispersion }\end{array}$ & Related toxic reagent & {$[47,63,95,165,214,251,252]$} \\
\hline $\begin{array}{l}\text { Vaporization-condensation } \\
\text { method }\end{array}$ & $\begin{array}{l}\text { Uniform and small size; control- } \\
\text { lable nanostructure }\end{array}$ & $\begin{array}{l}\text { Difficult controlled distribution; } \\
\text { low production efficiency }\end{array}$ & {$[50,122,217,253]$} \\
\hline $\begin{array}{l}\text { Calcination/carbothermic reduc- } \\
\text { tion }\end{array}$ & $\begin{array}{l}\text { Well operability; generation of } \\
\text { new phases }\end{array}$ & $\begin{array}{l}\text { Large energy consumption; gen- } \\
\text { eration of toxic gases }\end{array}$ & $\begin{array}{c}{[44,53-55,57,80,81,89,96-98,} \\
100-102,104,105,128,129, \\
131,132,135,198,202]\end{array}$ \\
\hline Electrodeposition method & Uniform size; controllable & $\begin{array}{l}\text { Related toxic reagent; large energy } \\
\text { consumption }\end{array}$ & [49] \\
\hline Solid-liquid reaction method & Simple; facile operability & $\begin{array}{l}\text { Related dangerous solution and } \\
\text { toxic reagent }\end{array}$ & {$[52,60,103,254-256]$} \\
\hline $\begin{array}{l}\text { Chemical vapor deposition } \\
\text { method }\end{array}$ & $\begin{array}{l}\text { Precise controlled products; high } \\
\text { purity }\end{array}$ & $\begin{array}{l}\text { Required relatively high deposi- } \\
\text { tion temperatures; involving } \\
\text { some dangerous precursors; } \\
\text { large energy consumption }\end{array}$ & {$[127,257]$} \\
\hline
\end{tabular}

choice in the practical application. Therefore, this review is devoted to provide new insights for further research.

Acknowledgements This work was financially supported by the Start-up Funding of Jinan University (Grant No. 88016105 and Grant No. 55800001), the discipline construction outstanding young backbone project (Grant No. 12819023), and the Fundamental Research Funds for the Central Universities (Grant No. 11620317).

Open Access This article is licensed under a Creative Commons Attribution 4.0 International License, which permits use, sharing, adaptation, distribution and reproduction in any medium or format, as long as you give appropriate credit to the original author(s) and the source, provide a link to the Creative Commons licence, and indicate if changes were made. The images or other third party material in this article are included in the article's Creative Commons licence, unless indicated otherwise in a credit line to the material. If material is not included in the article's Creative Commons licence and your intended use is not permitted by statutory regulation or exceeds the permitted use, you will need to obtain permission directly from the copyright holder. To view a copy of this licence, visit http://creativecommons.org/licenses/by/4.0/.

\section{References}

1. A. Eftekhari, Potassium secondary cell based on Prussian blue cathode. J. Power Sour. 126(1), 221-228 (2004). https ://doi.org/10.1016/j.jpowsour.2003.08.007
2. R. Rajagopalan, Y. Tang, X. Ji, C. Jia, H. Wang, Advancements and challenges in potassium ion batteries: a comprehensive review. Adv. Funct. Mater. 30(12), 1909486 (2020). https://doi.org/10.1002/adfm.201909486

3. B. Dunn, H. Kamath, J.-M. Tarascon, Electrical energy storage for the grid: a battery of choices. Science 334(6058), 928-935 (2011). https://doi.org/10.1126/science.1212741

4. Z. Yang, J. Zhang, M.C.W. Kintner-Meyer, X. Lu, D. Choi et al., Electrochemical energy storage for green grid. Chem. Rev. 111(5), 3577-3613 (2011). https://doi.org/10.1021/ cr100290v

5. N. Nitta, F. Wu, J.T. Lee, G. Yushin, Li-ion battery materials: present and future. Mater. Today 18(5), 252-264 (2015). https://doi.org/10.1016/j.mattod.2014.10.040

6. P.W. Gruber, P.A. Medina, G.A. Keoleian, S.E. Kesler, M.P. Everson et al., Global lithium availability. J. Ind. Ecol. 15(5), 760-775 (2011). https://doi.org/10.111 $1 /$ j.1530-9290.2011.00359.x

7. H. Vikström, S. Davidsson, M. Höök, Lithium availability and future production outlooks. Appl. Energy 110, 252-266 (2013). https://doi.org/10.1016/j.apenergy.2013.04.005

8. B. Swain, Recovery and recycling of lithium: a review. Sep. Purif. Technol. 172, 388-403 (2017). https://doi. org/10.1016/j.seppur.2016.08.031

9. N. Wang, C. Chu, X. Xu, Y. Du, J. Yang et al., Comprehensive new insights and perspectives into Ti-based anodes for next-generation alkaline metal $\left(\mathrm{Na}^{+}, \mathrm{K}^{+}\right)$ion batteries. Adv. Energy Mater. 8(27), 1801888 (2018). https://doi. org/10.1002/aenm.201801888 
10. J.-Y. Hwang, S.-T. Myung, Y.-K. Sun, Recent progress in rechargeable potassium batteries. Adv. Funct. Mater. 28(43), 1802938 (2018). https://doi.org/10.1002/adfm.201802938

11. M.M. Huie, D.C. Bock, E.S. Takeuchi, A.C. Marschilok, K.J. Takeuchi, Cathode materials for magnesium and magnesiumion based batteries. Coord. Chem. Rev. 287, 15-27 (2015). https://doi.org/10.1016/j.ccr.2014.11.005

12. D. Selvakumaran, A. Pan, S. Liang, G. Cao, A review on recent developments and challenges of cathode materials for rechargeable aqueous $\mathrm{Zn}$-ion batteries. J. Mater. Chem. A 7(31), 18209-18236 (2019). https://doi.org/10.1039/c9ta0 $5053 \mathrm{a}$

13. Y. Zhang, S. Liu, Y. Ji, J. Ma, H. Yu, Emerging nonaqueous aluminum-ion batteries: challenges, status, and perspectives. Adv. Mater. 30(38), 1706310 (2018). https://doi.org/10.1002/ adma.201706310

14. M. Walter, M.V. Kovalenko, K.V. Kravchyk, Challenges and benefits of post-lithium-ion batteries. New J. Chem. 44(5), 1677-1683 (2020). https://doi.org/10.1039/c9nj05682c

15. W. Liu, L. Dong, B. Jiang, Y. Huang, X. Wang et al., Layered vanadium oxides with proton and zinc ion insertion for zinc ion batteries. Electrochim. Acta 320, 134565 (2019). https:// doi.org/10.1016/j.electacta.2019.134565

16. M. Xu, S. Lei, J. Qi, Q. Dou, L. Liu et al., Opening magnesium storage capability of two-dimensional MXene by intercalation of cationic surfactant. ACS Nano 12(4), 3733-3740 (2018). https://doi.org/10.1021/acsnano.8b00959

17. F. Wu, H. Yang, Y. Bai, C. Wu, Paving the path toward reliable cathode materials for aluminum-ion batteries. Adv. Mater. 31(16), 1806510 (2019). https://doi.org/10.1002/adma.20180 6510

18. Z. Li, B. Niu, J. Liu, J. Li, F. Kang, Rechargeable aluminumion battery based on $\mathrm{MoS}_{2}$ microsphere cathode. ACS Appl. Mater. Interfaces 10(11), 9451-9459 (2018). https://doi. org/10.1021/acsami.8b00100

19. F. Liu, Y. Liu, X. Zhao, K. Liu, H. Yin et al., Prelithiated $\mathrm{V}_{2} \mathrm{C}$ MXene: a high-performance electrode for hybrid magnesium/lithium-ion batteries by ion cointercalation. Small 16(8), 1906076 (2020). https://doi.org/10.1002/smll.20190 6076

20. B. Jiang, C. Xu, C. Wu, L. Dong, J. Li et al., Manganese sesquioxide as cathode material for multivalent zinc ion battery with high capacity and long cycle life. Electrochim. Acta 229, 422-428 (2017). https://doi.org/10.1016/j.elect acta.2017.01.163

21. S. Liu, J.J. Hu, N.F. Yan, G.L. Pan, G.R. Li et al., Aluminum storage behavior of anatase $\mathrm{TiO}_{2}$ nanotube arrays in aqueous solution for aluminum ion batteries. Energy Environ. Sci. 5(12), 9743-9746 (2012). https://doi.org/10.1039/c2ee2 $2987 \mathrm{k}$

22. S. Lee, J. Cho, Critical requirements for rapid charging of rechargeable Al- and Li-ion batteries. Angew. Chem. Int. Ed. 54(33), 9452-9455 (2015). https://doi.org/10.1002/ anie. 201504466

23. Y. Tian, Y. An, H. Wei, C. Wei, Y. Tao et al., Micron-sized nanoporous vanadium pentoxide arrays for high-performance gel zinc-ion batteries and potassium batteries. Chem. Mater. 32(9), 4054-4064 (2020). https://doi.org/10.1021/acs.chemm ater.0c00787

24. Q. Zhang, J. Luan, Y. Tang, X. Ji, H. Wang, Interfacial design of dendrite-free zinc anodes for aqueous zinc-ion batteries. Angew. Chem. Int. Ed. 59(32), 13180-13191 (2020). https:// doi.org/10.1002/anie.202000162

25. M. Zoidl, C. God, P. Handel, R. Fischer, C. Lenardt et al., Communication-imidazole based magnesium salt as conductive salt for rechargeable magnesium-ion batteries. J. Electrochem. Soc. 163(10), A2461-A2463 (2016). https://doi. org/10.1149/2.0101613jes

26. L. Bin, R. Masse, C. Liu, Y. Hu, W. Li et al., Kinetic surface control for improved magnesium-electrolyte interfaces for magnesium ion batteries. Energy Storage Mater. 22, 96-104 (2019). https://doi.org/10.1016/j.ensm.2019.06.035

27. R.A. Adams, A. Varma, V.G. Pol, Carbon anodes for nonaqueous alkali metal-ion batteries and their thermal safety aspects. Adv. Energy Mater. 9(35), 1900550 (2019). https:// doi.org/10.1002/aenm.201900550

28. Z. Jian, W. Luo, X. Ji, Carbon electrodes for K-ion batteries. J. Am. Chem. Soc. 137(36), 11566-11569 (2015). https://doi. org/10.1021/jacs.5b06809

29. S. Komaba, T. Hasegawa, M. Dahbi, K. Kubota, Potassium intercalation into graphite to realize high-voltage/highpower potassium-ion batteries and potassium-ion capacitors. Electrochem. Commun. 60, 172-175 (2015). https:// doi.org/10.1016/j.elecom.2015.09.002

30. C. Vaalma, G.A. Giffin, D. Buchholz, S. Passerini, Nonaqueous $\mathrm{K}$-ion battery based on layered $\mathrm{K}_{0.3} \mathrm{MnO}_{2}$ and hard carbon/carbon black. J. Electrochem. Soc. 163(7), A1295A1299 (2016). https://doi.org/10.1149/2.0921607jes

31. Z. Jian, Z. Xing, C. Bommier, Z. Li, X. Ji, Hard carbon microspheres: potassium-ion anode versus sodium-ion anode. Adv. Energy Mater. 6(3), 1501874 (2016). https://doi.org/10.1002/ aenm.201501874

32. J. Zhao, X. Zou, Y. Zhu, Y. Xu, C. Wang, Electrochemical intercalation of potassium into graphite. Adv. Funct. Mater. 26(44), 8103-8110 (2016). https://doi.org/10.1002/ adfm. 201602248

33. I. Sultana, M.M. Rahman, T. Ramireddy, Y. Chen, A.M. Glushenkov, High capacity potassium-ion battery anodes based on black phosphorus. J. Mater. Chem. A 5(45), 2350623512 (2017). https://doi.org/10.1039/C7TA02483E

34. X. Wu, D.P. Leonard, X. Ji, Emerging non-aqueous potassium-ion batteries: challenges and opportunities. Chem. Mater. 29(12), 5031-5042 (2017). https://doi.org/10.1021/ acs.chemmater.7b01764

35. M. Okoshi, Y. Yamada, S. Komaba, A. Yamada, H. Nakai, Theoretical analysis of interactions between potassium ions and organic electrolyte solvents: a comparison with lithium, sodium, and magnesium ions. J. Electrochem. Soc. 164(2), A54-A60 (2016). https://doi.org/10.1149/2.0211702jes

36. C. Zhang, H. Zhao, Y. Lei, Recent research progress of anode materials for potassium-ion batteries. Energy Environ. Mater. 3(2), 105-120 (2020). https://doi.org/10.1002/eem2.12059 
37. H. Li, Z. Cheng, A. Natan, A.M. Hafez, D. Cao et al., Dualfunction, tunable, nitrogen-doped carbon for high-performance Li metal-sulfur full cell. Small 15(5), 1804609 (2019). https://doi.org/10.1002/smll.201804609

38. Y. Lu, J. Chen, Robust self-supported anode by integrating $\mathrm{Sb} 2 \mathrm{~S} 3$ nanoparticles with $\mathrm{S}, \mathrm{N}$-codoped graphene to enhance K-storage performance. Sci. China Chem. 60(12), 1533-1539 (2017). https://doi.org/10.1007/s11426-017-9166-0

39. I. Sultana, M.M. Rahman, S. Mateti, V.G. Ahmadabadi, A.M. Glushenkov et al., K-ion and Na-ion storage performances of $\mathrm{Co}_{3} \mathrm{O}_{4}-\mathrm{Fe}_{2} \mathrm{O}_{3}$ nanoparticle-decorated super $\mathrm{P}$ carbon black prepared by a ball milling process. Nanoscale $9(10), 3646-$ 3654 (2017). https://doi.org/10.1039/C6NR09613A

40. W. Zhang, J. Mao, S. Li, Z. Chen, Z. Guo, Phosphorus-based alloy materials for advanced potassium-ion battery anode. J. Am. Chem. Soc. 139(9), 3316-3319 (2017). https://doi. org/10.1021/jacs.6b12185

41. H. Gao, T. Zhou, Y. Zheng, Q. Zhang, Y. Liu et al., CoS quantum dot nanoclusters for high-energy potassium-ion batteries. Adv. Funct. Mater. 27(43), 1702634 (2017). https:// doi.org/10.1002/adfm.201702634

42. B. Cao, Q. Zhang, H. Liu, B. Xu, S. Zhang et al., Graphitic Carbon Nanocage as a Stable and High Power Anode for Potassium-Ion Batteries. Adv. Energy Mater. 8(25), 1801149 (2018). https://doi.org/10.1002/aenm.201801149

43. W. Wang, B. Jiang, C. Qian, F. Lv, J. Feng et al., Pistachioshuck-like $\mathrm{MoSe}_{2} / \mathrm{C}$ core/shell nanostructures for highperformance potassium-ion storage. Adv. Mater. 30(30), 1801812 (2018). https://doi.org/10.1002/adma.201801812

44. Q. Liu, L. Fan, R. Ma, S. Chen, X. Yu et al., Super long-life potassium-ion batteries based on an antimony@ carbon composite anode. Chem. Commun. 54(83), 11773-11776 (2018). https://doi.org/10.1039/C8CC05257C

45. X. Wu, W. Zhao, H. Wang, X. Qi, Z. Xing et al., Enhanced capacity of chemically bonded phosphorus/carbon composite as an anode material for potassium-ion batteries. J. Power Sour. 378, 460-467 (2018). https://doi.org/10.1016/j.jpows our.2017.12.077

46. C. Liu, S. Luo, H. Huang, Y. Zhai, Z. Wang, Direct growth of $\mathrm{MoO}_{2}$ /reduced graphene oxide hollow sphere composites as advanced anode materials for potassium-ion batteries. Chemsuschem 12(4), 873-880 (2019). https://doi.org/10.1002/ cssc. 201802494

47. C. Nithya, P. Vishnuprakash, S. Gopukumar, $\mathrm{A} \mathrm{Mn}_{3} \mathrm{O}_{4}$ nanospheres@rGO architecture with capacitive effects on high potassium storage capability. Nanoscale Adv. 1(11), 43474358 (2019). https://doi.org/10.1039/C9NA00425D

48. R. Verma, P.N. Didwal, H.-S. Ki, G. Cao, C.-J. Park, $\mathrm{SnP}_{3} /$ carbon nanocomposite as an anode material for potassium-ion batteries. ACS Appl. Mater. Interfaces 11(30), 26976-26984 (2019). https://doi.org/10.1021/acsami.9b08088

49. H. Qiu, L. Zhao, M. Asif, X. Huang, T. Tang et al., $\mathrm{SnO}_{2}$ nanoparticles anchored on carbon foam as a freestanding anode for high performance potassium-ion batteries. Energy Environ. Sci. 13(2), 571-578 (2020). https://doi.org/10.1039/ C9EE03682B
50. D. Liu, X. Huang, D. Qu, D. Zheng, G. Wang et al., Confined phosphorus in carbon nanotube-backboned mesoporous carbon as superior anode material for sodium/potassiumion batteries. Nano Energy 52, 1-10 (2018). https://doi. org/10.1016/j.nanoen.2018.07.023

51. Q. Yu, B. Jiang, J. Hu, C.-Y. Lao, Y. Gao et al., Metallic octahedral $\mathrm{CoSe}_{2}$ threaded by N-doped carbon nanotubes: a flexible framework for high-performance potassium-ion batteries. Adv. Sci. 5(10), 1800782 (2018). https://doi.org/10.1002/ advs. 201800782

52. P. Lian, Y. Dong, Z.-S. Wu, S. Zheng, X. Wang et al., Alkalized $\mathrm{Ti}_{3} \mathrm{C}_{2}$ MXene nanoribbons with expanded interlayer spacing for high-capacity sodium and potassium ion batteries. Nano Energy 40, 1-8 (2017). https://doi.org/10.1016/j. nanoen.2017.08.002

53. R. Hao, H. Lan, C. Kuang, H. Wang, L. Guo, Superior potassium storage in chitin-derived natural nitrogen-doped carbon nanofibers. Carbon 128, 224-230 (2018). https://doi. org/10.1016/j.carbon.2017.11.064

54. Y. Liu, C. Yang, Q. Pan, Y. Li, G. Wang et al., Nitrogendoped bamboo-like carbon nanotubes as anode material for high performance potassium ion batteries. J. Mater. Chem. A 6(31), 15162-15169 (2018). https://doi.org/10.1039/C8TA0 $4694 \mathrm{H}$

55. P. Xiong, X. Zhao, Y. Xu, Nitrogen-doped carbon nanotubes derived from metal-organic frameworks for potassium-ion battery anodes. Chemsuschem 11(1), 202-208 (2018). https ://doi.org/10.1002/cssc.201701759

56. W.-C. Chang, J.-H. Wu, K.-T. Chen, H.-Y. Tuan, Red phosphorus potassium-ion battery anodes. Adv. Sci. 6(9), 1801354 (2019). https://doi.org/10.1002/advs.201801354

57. W. Luo, F. Li, W. Zhang, K. Han, J.-J. Gaumet et al., Encapsulating segment-like antimony nanorod in hollow carbon tube as long-lifespan, high-rate anodes for rechargeable K-ion batteries. Nano Res. 12(5), 1025-1031 (2019). https://doi. org/10.1007/s12274-019-2335-6

58. K. Cao, H. Liu, W. Li, C. Xu, Q. Han et al., $\mathrm{K}_{2} \mathrm{Ti}_{6} \mathrm{O}_{13}$ nanorods for potassium-ion battery anodes. J. Electroanal. Chem. 841, 51-55 (2019). https://doi.org/10.1016/j.jelec hem.2019.04.020

59. X. Xiang, D. Liu, X. Zhu, K. Fang, K. Zhou et al., Evaporation-induced formation of hollow bismuth@N-doped carbon nanorods for enhanced electrochemical potassium storage. Appl. Surf. Sci. 514, 145947 (2020). https://doi. org/10.1016/j.apsusc.2020.145947

60. M. Naguib, R.A. Adams, Y. Zhao, D. Zemlyanov, A. Varma et al., Electrochemical performance of MXenes as K-ion battery anodes. Chem. Commun. 53(51), 6883-6886 (2017). https://doi.org/10.1039/C7CC02026K

61. K. Xie, K. Yuan, X. Li, W. Lu, C. Shen et al., Superior potassium ion storage via vertical $\mathrm{MoS}_{2}$ "nano-rose" with expanded interlayers on graphene. Small 13(42), 1701471 (2017). https://doi.org/10.1002/smll.201701471

62. Z. Chen, D. Yin, M. Zhang, Sandwich-like $\mathrm{MoS}_{2} @ \mathrm{SnO}_{2} @ \mathrm{C}$ with high capacity and stability for sodium/potassium 
ion batteries. Small 14(17), 1703818 (2018). https://doi. org/10.1002/smll.201703818

63. C. Yang, J. Feng, F. Lv, J. Zhou, C. Lin et al., Metallic graphene-like $\mathrm{VSe}_{2}$ ultrathin nanosheets: superior potassium-ion storage and their working mechanism. Adv. Mater. 30(27), 1800036 (2018). https://doi.org/10.1002/adma.201800036

64. L. Fang, J. Xu, S. Sun, B. Lin, Q. Guo et al., Few-layered tin sulfide nanosheets supported on reduced graphene oxide as a high-performance anode for potassium-ion batteries. Small 15(10), 1804806 (2019). https://doi.org/10.1002/smll.20180 4806

65. Z. Ju, P. Li, G. Ma, Z. Xing, Q. Zhuang et al., Few layer nitrogen-doped graphene with highly reversible potassium storage. Energy Storage Mater. 11, 38-46 (2018). https://doi. org/10.1016/j.ensm.2017.09.009

66. G. Ma, K. Huang, J.-S. Ma, Z. Ju, Z. Xing et al., Phosphorus and oxygen dual-doped graphene as superior anode material for room-temperature potassium-ion batteries. J. Mater. Chem. A 5(17), 7854-7861 (2017). https://doi.org/10.1039/ C7TA01108C

67. J. Ge, L. Fan, J. Wang, Q. Zhang, Z. Liu et al., $\mathrm{MoSe}_{2} / \mathrm{N}$-doped carbon as anodes for potassium-ion batteries. Adv. Energy Mater. 8(29), 1801477 (2018). https://doi. org/10.1002/aenm.201801477

68. H. Tian, X. Yu, H. Shao, L. Dong, Y. Chen et al., Unlocking few-layered ternary chalcogenides for high-performance potassium-ion storage. Adv. Energy Mater. 9(29), 1901560 (2019). https://doi.org/10.1002/aenm.201901560

69. R. Jain, P. Hundekar, T. Deng, X. Fan, Y. Singh et al., Reversible alloying of phosphorene with potassium and its stabilization using reduced graphene oxide buffer layers. ACS Nano 13(12), 14094-14106 (2019). https://doi.org/10.1021/acsna no.9b06680

70. X. Ren, Q. Zhao, W.D. McCulloch, Y. Wu, $\mathrm{MoS}_{2}$ as a longlife host material for potassium ion intercalation. Nano Res. 10(4), 1313-1321 (2017). https://doi.org/10.1007/s1227 4-016-1419-9

71. S.-M. Xu, Y.-C. Ding, X. Liu, Q. Zhang, K.-X. Wang et al., Boosting potassium storage capacity based on stress-induced size-dependent solid-solution behavior. Adv. Energy Mater. 8(32), 1802175 (2018). https://doi.org/10.1002/aenm.20180 2175

72. Y. An, Y. Tian, L. Ci, S. Xiong, J. Feng et al., Micron-sized nanoporous antimony with tunable porosity for high-performance potassium-ion batteries. ACS Nano 12(12), 1293212940 (2018). https://doi.org/10.1021/acsnano.8b08740

73. Q. Yang, Z. Wang, W. Xi, G. He, Tailoring nanoporous structures of $\mathrm{Ge}$ anodes for stable potassium-ion batteries. Electrochem. Commun. 101, 68-72 (2019). https://doi.org/10.1016/j. elecom.2019.02.016

74. Z. Tai, Q. Zhang, Y. Liu, H. Liu, S. Dou, Activated carbon from the graphite with increased rate capability for the potassium ion battery. Carbon 123, 54-61 (2017). https://doi. org/10.1016/j.carbon.2017.07.041

75. L. Deng, Z. Yang, L. Tan, L. Zeng, Y. Zhu et al., Investigation of the prussian blue analog $\mathrm{Co}_{3}\left[\mathrm{Co}(\mathrm{CN})_{6}\right]_{2}$ as an anode material for nonaqueous potassium-ion batteries. Adv. Mater. 30(31), 1802510 (2018). https://doi.org/10.1002/adma.20180 2510

76. K. Huang, Z. Xing, L. Wang, X. Wu, W. Zhao et al., Direct synthesis of 3D hierarchically porous carbon/Sn composites via in situ generated $\mathrm{NaCl}$ crystals as templates for potassium-ion batteries anode. J. Mater. Chem. A 6(2), 434-442 (2018). https://doi.org/10.1039/C7TA08171E

77. J. Yang, Z. Ju, Y. Jiang, Z. Xing, B. Xi et al., Enhanced capacity and rate capability of nitrogen/oxygen dual-doped hard carbon in capacitive potassium-ion storage. Adv. Mater. 30(4), 1700104 (2018). https://doi.org/10.1002/adma.20170 0104

78. L. Liu, Z. Lin, J.-Y. Chane-Ching, H. Shao, P.-L. Taberna et al., 3D rGO aerogel with superior electrochemical performance for K-Ion battery. Energy Storage Mater. 19, 306-313 (2019). https://doi.org/10.1016/j.ensm.2019.03.013

79. W. Zhang, J. Ming, W. Zhao, X. Dong, M.N. Hedhili et al., Graphitic nanocarbon with engineered defects for high-performance potassium-ion battery anodes. Adv. Funct. Mater. 29(35), 1903641 (2019). https://doi.org/10.1002/adfm.20190 3641

80. Y. Zhang, L. Yang, Y. Tian, L. Li, J. Li et al., Honeycomb hard carbon derived from carbon quantum dots as anode material for K-ion batteries. Mater. Chem. Phys. 229, 303-309 (2019). https://doi.org/10.1016/j.matchemphy s.2019.03.021

81. Y. Xu, C. Zhang, M. Zhou, Q. Fu, C. Zhao et al., Highly nitrogen doped carbon nanofibers with superior rate capability and cyclability for potassium ion batteries. Nat. Commun. 9(1), 1720 (2018). https://doi.org/10.1038/s41467-018-04190-z

82. C. Shen, T. Cheng, C. Liu, L. Huang, M. Cao et al., Bismuthene from sonoelectrochemistry as a superior anode for potassium-ion batteries. J. Mater. Chem. A 8(1), 453-460 (2020). https://doi.org/10.1039/C9TA11000C

83. V. Gabaudan, R. Berthelot, L. Stievano, L. Monconduit, Inside the alloy mechanism of $\mathrm{Sb}$ and $\mathrm{Bi}$ electrodes for $\mathrm{K}$-ion batteries. J. Phys. Chem. C 122(32), 18266-18273 (2018). https://doi.org/10.1021/acs.jpcc.8b04575

84. I. Sultana, M.M. Rahman, Y. Chen, A.M. Glushenkov, Potassium-ion battery anode materials operating through the alloying-dealloying reaction mechanism. Adv. Funct. Mater. 28(5), 1703857 (2018). https://doi.org/10.1002/ adfm.201703857

85. B. Wang, Z. Deng, Y. Xia, J. Hu, H. Li et al., Anode materials: realizing reversible conversion-alloying of $\mathrm{Sb}(\mathrm{V})$ in polyantimonic acid for fast and durable lithium- and potassium-ion storage. Adv. Energy Mater. 10(1), 2070002 (2020). https://doi.org/10.1002/aenm.202070002

86. H. Huang, J. Wang, X. Yang, R. Hu, J. Liu et al., Unveiling the advances of nanostructure design for alloy-type potassium-ion battery anodes via in situ TEM. Angew. Chem. Int. Ed. 59(34), 14504-14510 (2020). https://doi. org/10.1002/anie.202004193

87. X. Ge, S. Liu, M. Qiao, Y. Du, Y. Li et al., Enabling superior electrochemical properties for highly efficient 
potassium storage by impregnating ultrafine $\mathrm{Sb}$ nanocrystals within nanochannel-containing carbon nanofibers. Angew. Chem. Int. Ed. 58(41), 14578-14583 (2019). https ://doi.org/10.1002/anie.201908918

88. J. Lang, J. Li, X. Ou, F. Zhang, K. Shin et al., A flexible potassium-ion hybrid capacitor with superior rate performance and long cycling life. ACS Appl. Mater. Interfaces 12(2), 2424-2431 (2020). https://doi.org/10.1021/acsam i.9b17635

89. D. Li, X. Ren, Q. Ai, Q. Sun, L. Zhu et al., Facile fabrication of nitrogen-doped porous carbon as superior anode material for potassium-ion batteries. Adv. Energy Mater. 8(34), 1802386 (2018). https://doi.org/10.1002/aenm.20180 2386

90. J. Zheng, Y. Yang, X. Fan, G. Ji, X. Ji et al., Extremely stable antimony-carbon composite anodes for potassium-ion batteries. Energy Environ. Sci. 12(2), 615-623 (2019). https://doi. org/10.1039/C8EE02836B

91. H. Li, C. Zhao, Y. Yin, Y. Zou, Y. Xia et al., N-doped carbon coated bismuth nanorods with a hollow structure as an anode for superior-performance potassium-ion batteries. Nanoscale 12(7), 4309-4313 (2020). https://doi.org/10.1039/C9NR0 9867D

92. Y. Dong, Z.-S. Wu, S. Zheng, X. Wang, J. Qin et al., $\mathrm{Ti}_{3} \mathrm{C}_{2}$ MXene-derived sodium/potassium titanate nanoribbons for high-performance sodium/potassium ion batteries with enhanced capacities. ACS Nano 11(5), 4792-4800 (2017). https://doi.org/10.1021/acsnano.7b01165

93. P. Li, W. Wang, S. Gong, F. Lv, H. Huang et al., Hydrogenated $\mathrm{Na}_{2} \mathrm{Ti}_{3} \mathrm{O}_{7}$ epitaxially grown on flexible n-doped carbon sponge for potassium-ion batteries. ACS Appl. Mater. Interfaces 10(44), 37974-37980 (2018). https://doi.org/10.1021/ acsami.8b11354

94. J. Jiang, Y. Zhang, P. Nie, G. Xu, M. Shi et al., Progress of nanostructured electrode materials for supercapacitors. Adv. Sustain. Syst. 2(1), 1700110 (2018). https://doi.org/10.1002/ adsu.201700110

95. Y. Ai, Y. You, F. Wei, X. Jiang, Z. Han et al., Hollow bioderived polymer nanospheres with ordered mesopores for sodium-ion battery. Nano-Micro Lett. 12(1), 31 (2020). https://doi.org/10.1007/s40820-020-0370-1

96. H. Wang, X. Wu, X. Qi, W. Zhao, Z. Ju, Sb nanoparticles encapsulated in $3 \mathrm{D}$ porous carbon as anode material for lithium-ion and potassium-ion batteries. Mater. Res. Bull. 103, 32-37 (2018). https://doi.org/10.1016/j.materresbu 11.2018 .03 .018

97. C. Yan, X. Gu, L. Zhang, Y. Wang, L. Yan et al., Highly dispersed $\mathrm{Zn}$ nanoparticles confined in a nanoporous carbon network: promising anode materials for sodium and potassium ion batteries. J. Mater. Chem. A 6(36), 1737117377 (2018). https://doi.org/10.1039/C8TA05297B

98. W. Zhang, W. Miao, X. Liu, L. Li, Z. Yu et al., High-rate and ultralong-stable potassium-ion batteries based on antimony-nanoparticles encapsulated in nitrogen and phosphorus co-doped mesoporous carbon nanofibers as an anode material. J. Alloys Compd. 769, 141-148 (2018). https:// doi.org/10.1016/j.jallcom.2018.07.369

99. Z. Liu, K. Han, P. Li, W. Wang, D. He et al., Tuning metallic $\mathrm{Co}_{0.85}$ Se quantum dots/carbon hollow polyhedrons with tertiary hierarchical structure for high-performance potassium ion batteries. Nano-Micro Lett. 11(1), 96 (2019). https ://doi.org/10.1007/s40820-019-0326-5

100. A. Mahmood, S. Li, Z. Ali, H. Tabassum, B. Zhu et al., Ultrafast sodium/potassium-ion intercalation into hierarchically porous thin carbon shells. Adv. Mater. 31(2), 1805430 (2019). https://doi.org/10.1002/adma.201805430

101. Q. Tan, P. Li, K. Han, Z. Liu, Y. Li et al., Chemically bubbled hollow FexO nanospheres anchored on 3D N-doped few-layer graphene architecture as a performance-enhanced anode material for potassium-ion batteries. J. Mater. Chem. A 7(2), 744-754 (2019). https://doi.org/10.1039/C8TA0 $9797 \mathrm{~F}$

102. M. Tao, G. Du, Y. Zhang, W. Gao, D. Liu et al., TiOxNy nanoparticles/C composites derived from MXene as anode material for potassium-ion batteries. Chem. Eng. J. 369, 828-833 (2019). https://doi.org/10.1016/j.cej.2019.03.144

103. Z. Wang, K. Dong, D. Wang, S. Luo, Y. Liu et al., Ultrafine $\mathrm{SnO}_{2}$ nanoparticles encapsulated in 3D porous carbon as a high-performance anode material for potassium-ion batteries. J. Power Sour. 441, 227191 (2019). https://doi.org/10.1016/j. jpowsour.2019.227191

104. H. Wu, Q. Yu, C.-Y. Lao, M. Qin, W. Wang et al., Scalable synthesis of VN quantum dots encapsulated in ultralarge pillared N-doped mesoporous carbon microsheets for superior potassium storage. Energy Storage Mater. 18, 43-50 (2019). https://doi.org/10.1016/j.ensm.2018.09.025

105. Y. Han, W. Li, K. Zhou, X. Wu, H. Wu et al., Bimetallic sulfide $\mathrm{Co}_{9} \mathrm{~S}_{8} / \mathrm{N}-\mathrm{C} @ \mathrm{MoS}_{2}$ dodecahedral heterogeneous nanocages for boosted $\mathrm{Li} / \mathrm{K}$ storage. ChemNanoMat 6(1), 132-138 (2020). https://doi.org/10.1002/cnma.201900601

106. G. Ma, X. Xu, Z. Feng, C. Hu, Y. Zhu et al., Carbon-coated mesoporous $\mathrm{Co}_{9} \mathrm{~S}_{8}$ nanoparticles on reduced graphene oxide as a long-life and high-rate anode material for potassiumion batteries. Nano Res. 13(3), 802-809 (2020). https://doi. org/10.1007/s12274-020-2699-7

107. Q. Gan, J. Xie, Y. Zhu, F. Zhang, P. Zhang et al., Sub-20 nm carbon nanoparticles with expanded interlayer spacing for high-performance potassium storage. ACS Appl. Mater. Interfaces 11(1), 930-939 (2019). https://doi.org/10.1021/ acsami.8b18553

108. Z. Xing, Y. Qi, Z. Jian, X. Ji, Polynanocrystalline graphite: a new carbon anode with superior cycling performance for K-ion batteries. ACS Appl. Mater. Interfaces 9(5), 43434351 (2017). https://doi.org/10.1021/acsami.6b06767

109. Y. An, H. Fei, G. Zeng, L. Ci, B. Xi et al., Commercial expanded graphite as a low-cost, long-cycling life anode for potassium-ion batteries with conventional carbonate electrolyte. J. Power Sour. 378, 66-72 (2018). https://doi. org/10.1016/j.jpowsour.2017.12.033

110. S. Liu, J. Mao, Q. Zhang, Z. Wang, W.K. Pang et al., An intrinsically non-flammable electrolyte for 
high-performance potassium batteries. Angew. Chem. Int. Ed. 59(9), 3638-3644 (2020). https://doi.org/10.1002/ anie. 201913174

111. Z. Li, N. Sun, R.A. Soomro, Z. Guan, L. Ma et al., Structurally engineered hollow graphitized carbon nanocages as high-performance anodes for potassium ion batteries. ACS Nano (2020). https://doi.org/10.1021/acsnano.0c01150

112. H. Hou, C.E. Banks, M. Jing, Y. Zhang, X. Ji, Carbon quantum dots and their derivative $3 \mathrm{~d}$ porous carbon frameworks for sodium-ion batteries with ultralong cycle life. Adv. Mater. 27(472D Materials), 7861-7866 (2015). https ://doi.org/10.1002/adma.201503816

113. M. Jing, J. Wang, H. Hou, Y. Yang, Y. Zhang et al., Carbon quantum dot coated $\mathrm{Mn}_{3} \mathrm{O}_{4}$ with enhanced performances for lithium-ion batteries. J. Mater. Chem. A 3(32), 1682416830 (2015). https://doi.org/10.1039/C5TA03610K

114. L. Ruiyi, J. Yuanyuan, Z. Xiaoyan, L. Zaijun, G. Zhiguo et al., Significantly enhanced electrochemical performance of lithium titanate anode for lithium ion battery by the hybrid of nitrogen and sulfur co-doped graphene quantum dots. Electrochim. Acta 178, 303-311 (2015). https://doi. org/10.1016/j.electacta.2015.08.018

115. Y. Yang, X. Ji, M. Jing, H. Hou, Y. Zhu et al., Carbon dots supported upon $\mathrm{N}$-doped $\mathrm{TiO}_{2}$ nanorods applied into sodium and lithium ion batteries. J. Mater. Chem. A 3(10), 5648-5655 (2015). https://doi.org/10.1039/C4TA05611F

116. Y. Zhang, C.W. Foster, C.E. Banks, L. Shao, H. Hou et al., Graphene-rich wrapped petal-like rutile $\mathrm{TiO}_{2}$ tuned by carbon dots for high-performance sodium storage. Adv. Mater. 28(42), 9391-9399 (2016). https://doi.org/10.1002/ adma.201601621

117. D. Kong, Y. Wang, S. Huang, Y.V. Lim, J. Zhang et al., Surface modification of $\mathrm{Na}_{2} \mathrm{Ti}_{3} \mathrm{O}_{7}$ nanofibre arrays using $\mathrm{N}$-doped graphene quantum dots as advanced anodes for sodium-ion batteries with ultra-stable and high-rate capability. J. Mater. Chem. A 7(20), 12751-12762 (2019). https ://doi.org/10.1039/C9TA01641D

118. H. Nan, Y. Zhang, H. Wei, H. Chen, C. Xue et al., Lowcost and environmentally friendly synthesis of an $\mathrm{Al}^{3+}$ and $\mathrm{Mn}^{4+}$ co-doped $\mathrm{Li}_{4} \mathrm{Ti}_{5} \mathrm{O}_{12}$ composite with carbon quantum dots as an anode for lithium-ion batteries. RSC Adv. 9(38), 22101-22105 (2019). https://doi.org/10.1039/C9RA0 $3897 \mathrm{C}$

119. X. Yin, C. Zhi, W. Sun, L.-P. Lv, Y. Wang, Multilayer NiO@ $\mathrm{Co}_{3} \mathrm{O}_{4} @$ graphene quantum dots hollow spheres for high-performance lithium-ion batteries and supercapacitors. J. Mater. Chem. A 7(13), 7800-7814 (2019). https://doi.org/10.1039/ C8TA11982A

120. Y. Zhang, K. Zhang, K. Jia, G. Liu, S. Ren et al., Preparation of coal-based graphene quantum dots $/ \alpha-\mathrm{Fe}_{2} \mathrm{O}_{3}$ nanocomposites and their lithium-ion storage properties. Fuel 241, 646-652 (2019). https://doi.org/10.1016/j.fuel.2018.12.030

121. Y. Fang, R. Hu, B. Liu, Y. Zhang, K. Zhu et al., MXenederived $\mathrm{TiO}_{2}$ /reduced graphene oxide composite with an enhanced capacitive capacity for $\mathrm{Li}$-ion and $\mathrm{K}$-ion batteries.
J. Mater. Chem. A 7(10), 5363-5372 (2019). https://doi. org/10.1039/C8TA12069B

122. P. Xiong, P. Bai, S. Tu, M. Cheng, J. Zhang et al., Red phosphorus nanoparticle@3D interconnected carbon nanosheet framework composite for potassium-ion battery anodes. Small 14(33), 1802140 (2018). https://doi.org/10.1002/ smll.201802140

123. S. Iijima, Helical microtubules of graphitic carbon. Nature 354(6348), 56-58 (1991). https://doi.org/10.1038/354056a0

124. H. Li, D. Li, H. Zhou, One-Dimensional Nanostructured Metal Oxides for Lithium Ion Batteries, vol. 13 (Wiley, Hoboken, 2012), pp. 295-320

125. T. Jin, Q. Han, Y. Wang, L. Jiao, 1D nanomaterials: design, synthesis, and applications in sodium-ion batteries. Small 14(2), 1703086 (2018). https://doi.org/10.1002/smll.20170 3086

126. S. Chong, Y. Wu, C. Liu, Y. Chen, S. Guo et al., Cryptomelane-type $\mathrm{MnO}_{2}$ /carbon nanotube hybrids as bifunctional electrode material for high capacity potassium-ion full batteries. Nano Energy 54, 106-115 (2018). https://doi. org/10.1016/j.nanoen.2018.09.072

127. X. Zhao, Y. Tang, C. Ni, J. Wang, A. Star et al., Free-standing nitrogen-doped cup-stacked carbon nanotube mats for potassium-ion battery anodes. ACS Appl. Energy Mater. 1(4), 1703-1707 (2018). https://doi.org/10.1021/acsaem.8b00182

128. W. Miao, Y. Zhang, H. Li, Z. Zhang, L. Li et al., ZIF-8/ZIF67-derived 3D amorphous carbon-encapsulated CoS/NCNTs supported on CoS-coated carbon nanofibers as an advanced potassium-ion battery anode. J. Mater. Chem. A 7(10), 55045512 (2019). https://doi.org/10.1039/C8TA12457D

129. W. Miao, X. Zhao, R. Wang, Y. Liu, L. Li et al., Carbon shell encapsulated cobalt phosphide nanoparticles embedded in carbon nanotubes supported on carbon nanofibers: a promising anode for potassium ion battery. J. Colloid Interface Sci. 556, 432-440 (2019). https://doi.org/10.1016/j. jcis.2019.08.090

130. C. Shen, K. Yuan, T. Tian, M. Bai, J.-G. Wang et al., Flexible sub-micro carbon fiber@CNTs as anodes for potassium-ion batteries. ACS Appl. Mater. Interfaces 11(5), 5015-5021 (2019). https://doi.org/10.1021/acsami.8b18834

131. W. Yang, J. Zhou, S. Wang, W. Zhang, Z. Wang et al., Freestanding film made by necklace-like $\mathrm{N}$-doped hollow carbon with hierarchical pores for high-performance potassium-ion storage. Energy Environ. Sci. 12(5), 1605-1612 (2019). https ://doi.org/10.1039/C9EE00536F

132. T. Jiao, S. Wu, J. Cheng, D. Chen, D. Shen et al., Bismuth nanorod networks confined in a robust carbon matrix as longcycling and high-rate potassium-ion battery anodes. J. Mater. Chem. A 8, 8440-8446 (2020). https://doi.org/10.1039/ D0TA02414G

133. S. Peng, L. Wang, Z. Zhu, K. Han, Electrochemical performance of reduced graphene oxide/carbon nanotube hybrid papers as binder-free anodes for potassium-ion batteries. J. Phys. Chem. Solids 138, 109296 (2020). https://doi. org/10.1016/j.jpcs.2019.109296 
134. J. Wang, B. Wang, X. Liu, J. Bai, H. Wang et al., Prussian blue analogs (PBA) derived porous bimetal ( $\mathrm{Mn}, \mathrm{Fe}$ ) selenide with carbon nanotubes as anode materials for sodium and potassium ion batteries. Chem. Eng. J. 382, 123050 (2020). https://doi.org/10.1016/j.cej.2019.123050

135. X. Wang, J. Ma, J. Wang, X. Li, N-doped hollow carbon nanofibers anchored hierarchical FeP nanosheets as highperformance anode for potassium-ion batteries. J. Alloys Compd. 821, 153268 (2020). https://doi.org/10.1016/j.jallc om.2019.153268

136. B.I. Yakobson, R.E. Smalley, Fullerene nanotubes: $\mathrm{C} 1,000,000$ and beyond: some unusual new molecules-long, hollow fibers with tantalizing electronic and mechanical properties-have joined diamonds and graphite in the carbon family. Am. Sci. Sci. Res. Honor Soc. 85(4), 324-337 (1997)

137. B.Q. Wei, R. Vajtai, P.M. Ajayan, Reliability and current carrying capacity of carbon nanotubes. Appl. Phys. Lett. 79(8), 1172-1174 (2001). https://doi.org/10.1063/1.1396632

138. H. Dai, Carbon nanotubes: opportunities and challenges. Surf. Sci. 500(1), 218-241 (2002). https://doi.org/10.1016/ S0039-6028(01)01558-8

139. Q. Zhao, M.B. Nardelli, J. Bernholc, Ultimate strength of carbon nanotubes: a theoretical study. Phys. Rev. B 65(14), 144105 (2002). https://doi.org/10.1103/PhysRevB.65.14410 5

140. C. Liu, H. Wang, S. Zhang, M. Han, Y. Cao et al., $\mathrm{K}_{2} \mathrm{Ti}_{6} \mathrm{O}_{13} /$ carbon core-shell nanorods as a superior anode material for high-rate potassium-ion batteries. Nanoscale 12(21), 1142711434 (2020). https://doi.org/10.1039/D0NR00898B

141. B. Kishore, V.G.N. Munichandraiah, $\mathrm{K}_{2} \mathrm{Ti}_{4} \mathrm{O}_{9}$ : a promising anode material for potassium ion batteries. J. Electrochem. Soc. 163(13), A2551-A2554 (2016). https://doi. org/10.1149/2.0421613jes

142. S. Qi, X. Xie, X. Peng, D.H.L. Ng, M. Wu et al., Mesoporous carbon-coated bismuth nanorods as anode for potassium-ion batteries. Phys. Status Solidi RRL 13(10), 1900209 (2019). https://doi.org/10.1002/pssr.201900209

143. K.S. Novoselov, A.K. Geim, S.V. Morozov, D. Jiang, Y. Zhang et al., Electric field effect in atomically thin carbon films. Science 306(5696), 666-669 (2004). https://doi. org/10.1126/science.1102896

144. H. Li, Y. Hou, F. Wang, M.R. Lohe, X. Zhuang et al., Flexible all-solid-state supercapacitors with high volumetric capacitances boosted by solution processable mxene and electrochemically exfoliated graphene. Adv. Energy Mater. 7(4), 1601847 (2017). https://doi.org/10.1002/aenm.20160 1847

145. X. Liu, M.C. Hersam, Interface characterization and control of $2 \mathrm{~d}$ materials and heterostructures. Adv. Mater. 30(39), 1801586 (2018). https://doi.org/10.1002/adma.201801586

146. S. Das, D. Pandey, J. Thomas, T. Roy, The role of graphene and other $2 \mathrm{~d}$ materials in solar photovoltaics. Adv. Mater. 31(1), 1802722 (2019). https://doi.org/10.1002/adma.20180 2722

147. Y. Sun, L. Jiao, D. Han, F. Wang, P. Zhang et al., Hierarchical architecture of polyaniline nanoneedle arrays on electrochemically exfoliated graphene for supercapacitors and sodium batteries cathode. Mater. Des. 188, 108440 (2020). https://doi.org/10.1016/j.matdes.2019.108440

148. P. Xiong, B. Sun, N. Sakai, R. Ma, T. Sasaki et al., 2D superlattices for efficient energy storage and conversion. Adv. Mater. 32(18), 1902654 (2020). https://doi. org/10.1002/adma.201902654

149. X. Zhao, H. Li, F. Han, M. Dai, Y. Sun et al., Electrochemical exfoliation of graphene as an anode material for ultralong cycle lithium ion batteries. J. Phys. Chem. Solids 139, 109301 (2020). https://doi.org/10.1016/j.jpcs.2019.109301

150. Y. Wu, Y. Sun, J. Zheng, J. Rong, H. Li et al., MXenes: advanced materials in potassium ion batteries. Chem. Eng. J. 404, 126565 (2021). https://doi.org/10.1016/j. cej. 2020.126565

151. H. Li, S. Gan, H. Wang, D. Han, L. Niu, Intercorrelated superhybrid of $\mathrm{AgBr}$ supported on graphitic- $\mathrm{C}_{3} \mathrm{~N}_{4}$-decorated nitrogen-doped graphene: high engineering photocatalytic activities for water purification and $\mathrm{CO}_{2}$ reduction. Adv. Mater. 27(43), 6906-6913 (2015). https://doi. org/10.1002/adma.201502755

152. H. Cui, Y. Guo, W. Ma, Z. Zhou, 2 D materials for electrochemical energy storage: design, preparation, and application. Chemsuschem 13(6), 1155-1171 (2020). https://doi. org/10.1002/cssc.201903095

153. V. Lakshmi, Y. Chen, A.A. Mikhaylov, A.G. Medvedev, I. Sultana et al., Nanocrystalline $\mathrm{SnS}_{2}$ coated onto reduced graphene oxide: demonstrating the feasibility of a non-graphitic anode with sulfide chemistry for potassium-ion batteries. Chem. Commun. 53(59), 8272-8275 (2017). https ://doi.org/10.1039/C7CC03998K

154. B. Jia, Y. Zhao, M. Qin, W. Wang, Z. Liu et al., Multirole organic-induced scalable synthesis of a mesoporous $\mathrm{MoS}_{2}$-monolayer/carbon composite for high-performance lithium and potassium storage. J. Mater. Chem. A 6(24), 11147-11153 (2018). https://doi.org/10.1039/C8TA03166E

155. L. Liu, Y. Chen, Y. Xie, P. Tao, Q. Li et al., Understanding of the ultrastable K-ion storage of carbonaceous anode. Adv. Funct. Mater. 28(29), 1801989 (2018). https://doi. org/10.1002/adfm.201801989

156. Q. Yu, J. Hu, Y. Gao, J. Gao, G. Suo et al., Iron sulfide/ carbon hybrid cluster as an anode for potassium-ion storage. J. Alloys Compd. 766, 1086-1091 (2018). https://doi. org/10.1016/j.jallcom.2018.07.065

157. D.-S. Bin, S.-Y. Duan, X.-J. Lin, L. Liu, Y. Liu et al., Structural engineering of $\mathrm{SnS}_{2} /$ Graphene nanocomposite for high-performance K-ion battery anode. Nano Energy 60, 912-918 (2019). https://doi.org/10.1016/j.nanoe n.2019.04.032

158. K. Cao, H. Liu, W. Li, Q. Han, Z. Zhang et al., CuO nanoplates for high-performance potassium-ion batteries. Small 15(36), 1901775 (2019). https://doi.org/10.1002/smll.20190 1775

159. D. Li, X. Cheng, R. Xu, Y. Wu, X. Zhou et al., Manipulation of 2D carbon nanoplates with a core-shell structure for high-performance potassium-ion batteries. J. Mater. Chem. A 
7(34), 19929-19938 (2019). https://doi.org/10.1039/C9TA0 $4663 \mathrm{~A}$

160. D. Li, Q. Sun, Y. Zhang, L. Chen, Z. Wang et al., Surfaceconfined $\mathrm{SnS}_{2} @ \mathrm{C} @ \mathrm{rGO}$ as high-performance anode materials for sodium- and potassium-ion batteries. Chemsuschem 12(12), 2689-2700 (2019). https://doi.org/10.1002/ cssc. 201900719

161. Y. Li, C. Yang, F. Zheng, Q. Pan, Y. Liu et al., Design of $\mathrm{TiO}_{2} \mathrm{eC}$ hierarchical tubular heterostructures for high performance potassium ion batteries. Nano Energy 59, 582-590 (2019). https://doi.org/10.1016/j.nanoen.2019.03.002

162. C. Nithya, J.H. Lee, N.H. Kim, Hydrothermal fabrication of $\mathrm{MnCO}_{3} @ \mathrm{rGO}$ : a promising anode material for potassium-ion batteries. Appl. Surf. Sci. 484, 1161-1167 (2019). https://doi. org/10.1016/j.apsusc.2019.04.181

163. W. Qiu, H. Xiao, Y. Li, X. Lu, Y. Tong, Nitrogen and phosphorus codoped vertical graphene/carbon cloth as a binderfree anode for flexible advanced potassium ion full batteries. Small 15(23), 1901285 (2019). https://doi.org/10.1002/ smll.201901285

164. Q. Yao, J. Zhang, X. Shi, B. Deng, K. Hou et al., Rational synthesis of two-dimensional G@porous $\mathrm{FeS}_{2} @ \mathrm{C}$ composite as high-rate anode materials for sodium/potassium ion batteries. Electrochim. Acta 307, 118-128 (2019). https://doi. org/10.1016/j.electacta.2019.03.184

165. X. Zhao, W. Wang, Z. Hou, G. Wei, Y. Yu et al., $\mathrm{SnP}_{0.94}$ nanoplates/graphene oxide composite for novel potassiumion battery anode. Chem. Eng. J. 370, 677-683 (2019). https ://doi.org/10.1016/j.cej.2019.03.250

166. B. Lee, M. Kim, S. Kim, J. Nanda, S.J. Kwon et al., High capacity adsorption-dominated potassium and sodium ion storage in activated crumpled graphene. Adv. Energy Mater. 10(17), 1903280 (2020). https://doi.org/10.1002/aenm.20190 3280

167. A.A. Balandin, S. Ghosh, W. Bao, I. Calizo, D. Teweldebrhan et al., Superior thermal conductivity of single-layer graphene. Nano Lett. 8(3), 902-907 (2008). https://doi.org/10.1021/ n10731872

168. C. Lee, X. Wei, J.W. Kysar, J. Hone, Measurement of the elastic properties and intrinsic strength of monolayer graphene. Science 321(5887), 385-388 (2008). https://doi.org/10.1126/ science. 1157996

169. M.D. Stoller, S. Park, Y. Zhu, J. An, R.S. Ruoff, Graphenebased ultracapacitors. Nano Lett. 8(10), 3498-3502 (2008). https://doi.org/10.1021/n1802558y

170. W. Luo, J. Wan, B. Ozdemir, W. Bao, Y. Chen et al., Potassium ion batteries with graphitic materials. Nano Lett. 15(11), 7671-7677 (2015). https://doi.org/10.1021/acs.nanol ett.5b03667

171. K. Share, A.P. Cohn, R. Carter, B. Rogers, C.L. Pint, Role of nitrogen-doped graphene for improved high-capacity potassium ion battery anodes. ACS Nano 10(10), 9738-9744 (2016). https://doi.org/10.1021/acsnano.6b05998

172. Y. Luan, R. Hu, Y. Fang, K. Zhu, K. Cheng et al., Nitrogen and phosphorus dual-doped multilayer graphene as universal anode for full carbon-based lithium and potassium ion capacitors. Nano-Micro Lett. 11(1), 30 (2019). https://doi. org/10.1007/s40820-019-0260-6

173. X. Wu, Y. Chen, Z. Xing, C.W.K. Lam, S.-S. Pang et al., Advanced carbon-based anodes for potassium-ion batteries. Adv. Energy Mater. 9(21), 1900343 (2019). https://doi. org/10.1002/aenm.201900343

174. J. Xu, J. Zhang, W. Zhang, C.-S. Lee, Interlayer nanoarchitectonics of two-dimensional transition-metal dichalcogenides nanosheets for energy storage and conversion applications. Adv. Energy Mater. 7(23), 1700571 (2017). https://doi. org/10.1002/aenm.201700571

175. Z. Ali, M. Asif, X. Huang, T. Tang, Y. Hou, Hierarchically porous $\mathrm{Fe}_{2} \mathrm{CoSe}_{4}$ binary-metal selenide for extraordinary rate performance and durable anode of sodium-ion batteries. Adv. Mater. 30(36), 1802745 (2018). https://doi.org/10.1002/ adma.201802745

176. L. Shen, Y. Wang, H. Lv, S. Chen, P.A. van Aken et al., Ultrathin $\mathrm{Ti}_{2} \mathrm{Nb}_{2} \mathrm{O}_{9}$ nanosheets with pseudocapacitive properties as superior anode for sodium-ion batteries. Adv. Mater. 30(51), 1804378 (2018). https://doi.org/10.1002/adma.20180 4378

177. Q. Zhang, C. Didier, W.K. Pang, Y. Liu, Z. Wang et al., Structural insight into layer gliding and lattice distortion in layered manganese oxide electrodes for potassium-ion batteries. Adv. Energy Mater. 9(30), 1900568 (2019). https://doi. org/10.1002/aenm.201900568

178. J. Li, N. Zhuang, J. Xie, X. Li, W. Zhuo et al., K-ion storage enhancement in $\mathrm{Sb}_{2} \mathrm{O}_{3}$ /reduced graphene oxide using etherbased electrolyte. Adv. Energy Mater. 10(5), 1903455 (2020). https://doi.org/10.1002/aenm.201903455

179. L. Wei, H.E. Karahan, S. Zhai, H. Liu, X. Chen et al., Amorphous bimetallic oxide-graphene hybrids as bifunctional oxygen electrocatalysts for rechargeable $\mathrm{Zn}$-air batteries. Adv. Mater. 29(38), 1701410 (2017). https://doi.org/10.1002/ adma.201701410

180. Y. Huang, Z. Wang, Y. Jiang, S. Li, M. Wang et al., Conductivity and pseudocapacitance optimization of bimetallic antimony-indium sulfide anodes for sodium-ion batteries with favorable kinetics. Adv. Sci. 5(10), 1800613 (2018). https:// doi.org/10.1002/advs.201800613

181. Z. Liang, C. Qu, W. Zhou, R. Zhao, H. Zhang et al., Synergistic effect of Co-Ni hybrid phosphide nanocages for ultrahigh capacity fast energy storage. Adv. Sci. 6(8), 1802005 (2019). https://doi.org/10.1002/advs.201802005

182. J. Wang, L. Fan, Z. Liu, S. Chen, Q. Zhang et al., In situ alloying strategy for exceptional potassium ion batteries. ACS Nano 13(3), 3703-3713 (2019). https://doi. org/10.1021/acsnano.9b00634

183. J. Wang, B. Wang, Z. Liu, L. Fan, Q. Zhang et al., Nature of bimetallic oxide $\mathrm{Sb}_{2} \mathrm{MoO}_{6} / \mathrm{rGO}$ anode for high-performance potassium-ion batteries. Adv. Sci. 6(17), 1900904 (2019). https://doi.org/10.1002/advs.201900904

184. L. Li, Y. Yu, G.J. Ye, Q. Ge, X. Ou et al., Black phosphorus field-effect transistors. Nat. Nanotechnol. 9(5), 372-377 (2014). https://doi.org/10.1038/nnano.2014.35 
185. H. Liu, A.T. Neal, Z. Zhu, Z. Luo, X. Xu et al., Phosphorene: an unexplored $2 \mathrm{~d}$ semiconductor with a high hole mobility. ACS Nano 8(4), 4033-4041 (2014). https://doi. org/10.1021/nn501226z

186. S.P. Koenig, R.A. Doganov, H. Schmidt, A.H.C. Neto, B. Özyilmaz, Electric field effect in ultrathin black phosphorus. Appl. Phys. Lett. 104(10), 103106 (2014). https://doi. org/10.1063/1.4868132

187. Y. Cai, Q. Ke, G. Zhang, Y.-W. Zhang, Energetics, charge transfer, and magnetism of small molecules physisorbed on phosphorene. J. Phys. Chem. C 119(6), 3102-3110 (2015). https://doi.org/10.1021/jp510863p

188. C. He, J.H. Zhang, W.X. Zhang, T.T. Li, GeSe/BP van der Waals heterostructures as promising anode materials for potassium-ion batteries. J. Phys. Chem. C 123(9), 51575163 (2019). https://doi.org/10.1021/acs.jpcc.8b08909

189. J. Hao, Z. Wang, Y. Wang, Sulfur-doped phosphorene as a promising anode for $\mathrm{Na}$ and $\mathrm{K}$-ion batteries. Phys. Status Solidi B 256(8), 1800418 (2019). https://doi.org/10.1002/ pssb. 201800418

190. Y. Tao, T. Huang, C. Ding, F. Yu, D. Tan et al., Few-layer phosphorene: an emerging electrode material for electrochemical energy storage. Appl. Mater. Today 15, 18-33 (2019). https://doi.org/10.1016/j.apmt.2018.12.008

191. S. Chabi, C. Peng, D. Hu, Y. Zhu, Ideal three-dimensional electrode structures for electrochemical energy storage. Adv. Mater. 26(15), 2440-2445 (2014). https://doi. org/10.1002/adma.201305095

192. J. Xu, X. Wang, X. Wang, D. Chen, X. Chen et al., Threedimensional structural engineering for energy-storage devices: from microscope to macroscope. ChemElectroChem 1(6), 975-1002 (2014). https://doi.org/10.1002/ celc. 201400001

193. Z. Liu, X. Yuan, S. Zhang, J. Wang, Q. Huang et al., Threedimensional ordered porous electrode materials for electrochemical energy storage. NPG Asia Mater. 11(1), 12 (2019). https://doi.org/10.1038/s41427-019-0112-3

194. L.-F. Chen, Y. Feng, H.-W. Liang, Z.-Y. Wu, S.-H. Yu, Macroscopic-scale three-dimensional carbon nanofiber architectures for electrochemical energy storage devices. Adv. Energy Mater. 7(23), 1700826 (2017). https://doi. org/10.1002/aenm.201700826

195. K.T. Alali, J. Liu, Q. Liu, R. Li, K. Aljebawi et al., Grown carbon nanotubes on electrospun carbon nanofibers as a $3 \mathrm{~d}$ carbon nanomaterial for high energy storage performance. ChemistrySelect 4(19), 5437-5458 (2019). https://doi. org/10.1002/slct.201803828

196. S. Zhou, L. Zhou, Y. Zhang, J. Sun, J. Wen et al., Upgrading earth-abundant biomass into three-dimensional carbon materials for energy and environmental applications. J. Mater. Chem. A 7(9), 4217-4229 (2019). https://doi. org/10.1039/C8TA12159A

197. S. Zhu, N. Zhao, J. Li, X. Deng, J. Sha et al., Hard-template synthesis of three-dimensional interconnected carbon networks: rational design, hybridization and energy-related applications. Nano Today 29, 100796 (2019). https://doi. org/10.1016/j.nantod.2019.100796

198. R.A. Adams, J.-M. Syu, Y. Zhao, C.-T. Lo, A. Varma et al., Binder-free $\mathrm{N}$ - and O-rich carbon nanofiber anodes for long cycle life K-ion batteries. ACS Appl. Mater. Interfaces 9(21), 17872-17881 (2017). https://doi.org/10.1021/acsam i. $7 \mathrm{~b} 02476$

199. C. Li, X. Hu, B. Hu, Cobalt(II) dicarboxylate-based metalorganic framework for long-cycling and high-rate potassium-ion battery anode. Electrochim. Acta 253, 439-444 (2017). https://doi.org/10.1016/j.electacta.2017.09.090

200. Y. Li, R.A. Adams, A. Arora, V.G. Pol, A.M. Levine et al., Sustainable potassium-ion battery anodes derived from waste-tire rubber. J. Electrochem. Soc. 164(6), A1234A1238 (2017). https://doi.org/10.1149/2.1391706jes

201. S.J.R. Prabakar, S.C. Han, C. Park, I.A. Bhairuba, M.J. Reece et al., Spontaneous formation of interwoven porous channels in hard-wood-based hard-carbon for high-performance anodes in potassium-ion batteries. J. Electrochem. Soc. 164(9), A2012-A2016 (2017). https://doi. org/10.1149/2.1251709jes

202. X. Zhao, P. Xiong, J. Meng, Y. Liang, J. Wang et al., High rate and long cycle life porous carbon nanofiber paper anodes for potassium-ion batteries. J. Mater. Chem. A. 5(36), 19237-19244 (2017). https://doi.org/10.1039/ C7TA04264G

203. M. Chen, W. Wang, X. Liang, S. Gong, J. Liu et al., Sulfur/ oxygen codoped porous hard carbon microspheres for highperformance potassium-ion batteries. Adv. Energy Mater. 8(19), 1800171 (2018). https://doi.org/10.1002/aenm.20180 0171

204. X. He, J. Liao, Z. Tang, L. Xiao, X. Ding et al., Highly disordered hard carbon derived from skimmed cotton as a highperformance anode material for potassium-ion batteries. J. Power Sour. 396, 533-541 (2018). https://doi.org/10.1016/j. jpowsour.2018.06.073

205. Z. Huang, Z. Chen, S. Ding, C. Chen, M. Zhang, Enhanced conductivity and properties of $\mathrm{SnO}_{2}$-graphene-carbon nanofibers for potassium-ion batteries by graphene modification. Mater. Lett. 219, 19-22 (2018). https://doi. org/10.1016/j.matlet.2018.02.053

206. B. Jia, Q. Yu, Y. Zhao, M. Qin, W. Wang et al., Bamboo-like hollow tubes with $\mathrm{MoS}_{2} / \mathrm{N}$-doped-c interfaces boost potassium-ion storage. Adv. Funct. Mater. 28(40), 1803409 (2018). https://doi.org/10.1002/adfm.201803409

207. Y. Li, C. Yang, F. Zheng, X. Ou, Q. Pan et al., High pyridine $\mathrm{N}$-doped porous carbon derived from metal-organic frameworks for boosting potassium-ion storage. J. Mater. Chem. A 6(37), 17959-17966 (2018). https://doi.org/10.1039/C8TA0 $6652 \mathrm{C}$

208. Z. Liu, P. Li, G. Suo, S. Gong, W. Wang et al., Zero-strain $\mathrm{K}_{0.6} \mathrm{Mn}_{1} \mathrm{~F}_{2.7}$ hollow nanocubes for ultrastable potassium ion storage. Energy Environ. Sci. 11(10), 3033-3042 (2018). https://doi.org/10.1039/C8EE01611A

209. X. Qi, K. Huang, X. Wu, W. Zhao, H. Wang et al., Novel fabrication of $\mathrm{N}$-doped hierarchically porous carbon with 
exceptional potassium storage properties. Carbon 131, 79-85 (2018). https://doi.org/10.1016/j.carbon.2018.01.094

210. Z. Wei, D. Wang, M. Li, Y. Gao, C. Wang et al., Fabrication of hierarchical potassium titanium phosphate spheroids: a host material for sodium-ion and potassium-ion storage. Adv. Energy Mater. 8(27), 1801102 (2018). https://doi. org/10.1002/aenm.201801102

211. W. Zhang, W.K. Pang, V. Sencadas, Z. Guo, Understanding high-energy-density $\mathrm{Sn}_{4} \mathrm{P}_{3}$ anodes for potassium-ion batteries. Joule 2(8), 1534-1547 (2018). https://doi.org/10.1016/j. joule.2018.04.022

212. X. Cheng, D. Li, Y. Wu, R. Xu, Y. Yu, Bismuth nanospheres embedded in three-dimensional (3D) porous graphene frameworks as high performance anodes for sodium- and potassium-ion batteries. J. Mater. Chem. A 7(9), 4913-4921 (2019). https://doi.org/10.1039/C8TA11947C

213. C. Gao, Q. Wang, S. Luo, Z. Wang, Y. Zhang et al., High performance potassium-ion battery anode based on biomorphic N-doped carbon derived from walnut septum. J. Power Sour. 415, 165-171 (2019). https://doi.org/10.1016/j.jpows our.2019.01.073

214. H. Lin, M. Li, X. Yang, D. Yu, Y. Zeng et al., Nanosheetsassembled CuSe crystal pillar as a stable and highpower anode for sodium-ion and potassium-ion batteries. Adv. Energy Mater. 9(20), 1900323 (2019). https://doi. org/10.1002/aenm.201900323

215. H. Tan, X. Du, J.-Q. Huang, B. Zhang, KVPO ${ }_{4} F$ as a novel insertion-type anode for potassium ion batteries. Chem. Commun. 55(75), 11311-11314 (2019). https://doi.org/10.1039/ C9CC05368A

216. Y. Tian, Y. An, S. Xiong, J. Feng, Y. Qian, A general method for constructing robust, flexible and freestanding MXene@ metal anodes for high-performance potassium-ion batteries. J. Mater. Chem. A 7(16), 9716-9725 (2019). https://doi. org/10.1039/C9TA02233C

217. Y. Wu, S. Hu, R. Xu, J. Wang, Z. Peng et al., Boosting potassium-ion battery performance by encapsulating red phosphorus in free-standing nitrogen-doped porous hollow carbon nanofibers. Nano Lett. 19(2), 1351-1358 (2019). https://doi. org/10.1021/acs.nanolett.8b04957

218. G. Xia, C. Wang, P. Jiang, J. Lu, J. Diao et al., Nitrogen/ oxygen co-doped mesoporous carbon octahedrons for highperformance potassium-ion batteries. J. Mater. Chem. A 7(19), 12317-12324 (2019). https://doi.org/10.1039/ C8TA12504J

219. F. Yang, H. Gao, J. Hao, S. Zhang, P. Li et al., Yolk-shell structured FeP@C nanoboxes as advanced anode materials for rechargeable lithium-/potassium-ion batteries. Adv. Funct. Mater. 29(16), 1808291 (2019). https://doi. org/10.1002/adfm.201808291

220. H. Yang, R. Xu, Y. Yao, S. Ye, X. Zhou et al., Multicoreshell Bi@N-doped carbon nanospheres for high power density and long cycle life sodium- and potassium-ion anodes. Adv. Funct. Mater. 29(13), 1809195 (2019). https://doi. org/10.1002/adfm.201809195
221. C. Liu, N. Xiao, H. Li, Q. Dong, Y. Wang et al., Nitrogendoped soft carbon frameworks built of well-interconnected nanocapsules enabling a superior potassium-ion batteries anode. Chem. Eng. J. 382, 121759 (2020). https://doi. org/10.1016/j.cej.2019.05.120

222. Z.-J. Fan, J. Yan, T. Wei, G.-Q. Ning, L.-J. Zhi et al., Nanographene-constructed carbon nanofibers grown on graphene sheets by chemical vapor deposition: high-performance anode materials for lithium ion batteries. ACS Nano 5(4), 2787-2794 (2011). https://doi.org/10.1021/ nn200195k

223. H. Jiang, P.S. Lee, C. Li, 3D carbon based nanostructures for advanced supercapacitors. Energy Environ. Sci. 6(1), 41-53 (2013). https://doi.org/10.1039/C2EE23284G

224. X. Han, C. Yu, S. Zhou, C. Zhao, H. Huang et al., Ultrasensitive iron-triggered nanosized $\mathrm{Fe}-\mathrm{CoOOH}$ integrated with graphene for highly efficient oxygen evolution. Adv. Energy Mater. 7(14), 1602148 (2017). https://doi.org/10.1002/ aenm. 201602148

225. H. Li, Z. Cheng, Q. Zhang, A. Natan, Y. Yang et al., Bacterial-derived, compressible, and hierarchical porous carbon for high-performance potassium-ion batteries. Nano Lett. 18(11), 7407-7413 (2018). https://doi.org/10.1021/acs. nanolett.8b03845

226. D.-S. Bin, X.-J. Lin, Y.-G. Sun, Y.-S. Xu, K. Zhang et al., Engineering hollow carbon architecture for high-performance K-ion battery anode. J. Am. Chem. Soc. 140(23), 7127-7134 (2018). https://doi.org/10.1021/jacs.8b02178

227. Y. Sun, Y. Zhang, Z. Xing, D. Wei, Z. Ju et al., A hollow neuronal carbon skeleton with ultrahigh pyridinic $\mathrm{N}$ content as a self-supporting potassium-ion battery anode. Sustain. Energy Fuels 4(3), 1216-1224 (2020). https://doi. org/10.1039/C9SE00889F

228. N. Li, F. Zhang, Y. Tang, Hierarchical T- $\mathrm{Nb}_{2} \mathrm{O}_{5}$ nanostructure with hybrid mechanisms of intercalation and pseudocapacitance for potassium storage and high-performance potassium dual-ion batteries. J. Mater. Chem. A 6(37), 17889-17895 (2018). https://doi.org/10.1039/C8TA0 $7987 \mathrm{~K}$

229. K. Lei, C. Wang, L. Liu, Y. Luo, C. Mu et al., A porous network of bismuth used as the anode material for highenergy-density potassium-ion batteries. Angew. Chem. Int. Ed. 57(17), 4687-4691 (2018). https://doi.org/10.1002/ anie.201801389

230. Y. Fang, X.-Y. Yu, X.W. Lou, Nanostructured electrode materials for advanced sodium-ion batteries. Matter 1(1), 90-114 (2019). https://doi.org/10.1016/j.matt.2019.05.007

231. X. Wei, X. Wang, X. Tan, Q. An, L. Mai, Nanostructured conversion-type negative electrode materials for low-cost and high-performance sodium-ion batteries. Adv. Funct. Mater. 28(46), 1804458 (2018). https://doi.org/10.1002/adfm.20180 4458

232. P. Kumar, K.-H. Kim, V. Bansal, P. Kumar, Nanostructured materials: a progressive assessment and future direction for energy device applications. Coord. Chem. Rev. 353, 113-141 (2017). https://doi.org/10.1016/j.ccr.2017.10.005 
233. A. Manthiram, A. VadivelMurugan, A. Sarkar, T. Muraliganth, Nanostructured electrode materials for electrochemical energy storage and conversion. Energy Environ. Sci. 1(6), 621-638 (2008). https://doi.org/10.1039/B811802G

234. J. Hongjun, H. Ling, W. Yunhong, W. Boya, W. Hao et al., Bio-derived hierarchical multicore-shell $\mathrm{Fe}_{2} \mathrm{~N}$-nanoparticle-impregnated $\mathrm{N}$-doped carbon nanofiber bundles: a host material for lithium-/potassium-ion storage. Nano-Micro Lett. 11, 56 (2019). https://doi.org/10.1007/ s40820-019-0290-0

235. J. Mao, T. Zhou, Y. Zheng, H. Gao, H.K. Liu et al., Twodimensional nanostructures for sodium-ion battery anodes. J. Mater. Chem. A 6(8), 3284-3303 (2018). https://doi. org/10.1039/C7TA10500B

236. H. Hou, G. Shao, W. Yang, W.-Y. Wong, One-dimensional mesoporous inorganic nanostructures and their applications in energy, sensor, catalysis and adsorption. Prog. Mater Sci. 113, 100671 (2020). https://doi.org/10.1016/j.pmats ci.2020.100671

237. L. Mai, J. Sheng, L. Xu, S. Tan, J. Meng, One-dimensional hetero-nanostructures for rechargeable batteries. Acc. Chem. Res. 51(4), 950-959 (2018). https://doi.org/10.1021/acs. accounts. 8 b00031

238. W. Zhang, Y. Liu, Z. Guo, Approaching high-performance potassium-ion batteries via advanced design strategies and engineering. Sci. Adv. 5(5), 7412 (2019). https://doi. org/10.1126/sciadv.aav7412

239. Y. Wu, Y. Yu, 2D material as anode for sodium ion batteries: recent progress and perspectives. Energy Storage Mater. 16, 323-343 (2019). https://doi.org/10.1016/j.ensm.2018.05.026

240. X. Chen, C. Li, M. Grätzel, R. Kostecki, S.S. Mao, Nanomaterials for renewable energy production and storage. Chem. Soc. Rev. 41(23), 7909-7937 (2012). https://doi.org/10.1039/ C2CS35230C

241. I. Hasa, J. Hassoun, S. Passerini, Nanostructured Na-ion and Li-ion anodes for battery application: a comparative overview. Nano Res. 10(12), 3942-3969 (2017). https://doi. org/10.1007/s12274-017-1513-7

242. G. Chen, L. Yan, H. Luo, S. Guo, Nanoscale engineering of heterostructured anode materials for boosting lithium-ion storage. Adv. Mater. 28(35), 7580-7602 (2016). https://doi. org/10.1002/adma.201600164

243. X. Chang, X. Zhou, X. Ou, C.-S. Lee, J. Zhou et al., Ultrahigh nitrogen doping of carbon nanosheets for high capacity and long cycling potassium ion storage. Adv. Energy Mater. 9(47), 1902672 (2019). https://doi.org/10.1002/aenm.20190 2672

244. P. Trogadas, V. Ramani, P. Strasser, T.F. Fuller, M.-O. Coppens, Hierarchically structured nanomaterials for electrochemical energy conversion. Angew. Chem. Int. Ed. 55(1), 122-148 (2016). https://doi.org/10.1002/anie.201506394

245. Y. Lu, L. Yu, X.W. Lou, Nanostructured conversion-type anode materials for advanced lithium-ion batteries. Chem 4(5), 972-996 (2018). https://doi.org/10.1016/j.chemp r.2018.01.003
246. N.-W. Li, Y.-X. Yin, S. Xin, J.-Y. Li, Y.-G. Guo, Methods for the stabilization of nanostructured electrode materials for advanced rechargeable batteries. Small Methods 1(6), 1700094 (2017). https://doi.org/10.1002/smtd.201700094

247. Y. Wang, Z. Wang, Y. Chen, H. Zhang, M. Yousaf et al., Hyperporous sponge interconnected by hierarchical carbon nanotubes as a high-performance potassium-ion battery anode. Adv. Mater. 30(32), 1802074 (2018). https://doi. org/10.1002/adma.201802074

248. J. Li, W. Qin, J. Xie, H. Lei, Y. Zhu et al., Sulphur-doped reduced graphene oxide sponges as high-performance freestanding anodes for K-ion storage. Nano Energy 53, 415-424 (2018). https://doi.org/10.1016/j.nanoen.2018.08.075

249. A. Yu, Q. Pan, M. Zhang, D. Xie, Y. Tang, Fast rate and long life potassium-ion based dual-ion battery through $3 \mathrm{~d}$ porous organic negative electrode. Adv. Funct. Mater. 30(24), 2001440 (2020). https://doi.org/10.1002/adfm.202001440

250. J. Wu, Q. Zhang, S. Liu, J. Long, Z. Wu et al., Synergy of binders and electrolytes in enabling microsized alloy anodes for high performance potassium-ion batteries. Nano Energy 77, 105118 (2020). https://doi.org/10.1016/j.nanoe n.2020.105118

251. Y. Ai, Z. Han, X. Jiang, H. Luo, J. Cui et al., General construction of 2D ordered mesoporous iron-based metalorganic nanomeshes. Small (2020). https://doi.org/10.1002/ smll.202002701

252. Z. Han, Y. Ai, X. Jiang, Y. You, F. Wei et al., Pre-polymerization enables controllable synthesis of nanosheet-based porphyrin polymers towards high-performance li-ion batteries. Chem. Eur. J. 26(46), 10433-10438 (2020). https://doi. org/10.1002/chem.202001943

253. G. Chang, Y. Zhao, L. Dong, D.P. Wilkinson, L. Zhang et al., A review of phosphorus and phosphides as anode materials for advanced sodium-ion batteries. J. Mater. Chem. A 8(10), 4996-5048 (2020). https://doi.org/10.1039/C9TA12169B

254. H. Huang, R. Xu, Y. Feng, S. Zeng, Y. Jiang et al., Sodium/ potassium-ion batteries: boosting the rate capability and cycle life by combining morphology, defect and structure engineering. Adv. Mater. 32(8), 1904320 (2020). https://doi. org/10.1002/adma.201904320

255. Q. Zhang, J. Mao, W.K. Pang, T. Zheng, V. Sencadas et al., Boosting the potassium storage performance of alloy-based anode materials via electrolyte salt chemistry. Adv. Energy Mater. 8(15), 1703288 (2018). https://doi.org/10.1002/ aenm. 201703288

256. H. Li, S. Gan, D. Han, W. Ma, B. Cai et al., High performance Pd nanocrystals supported on $\mathrm{SnO}_{2}$-decorated graphene for aromatic nitro compound reduction. J. Mater. Chem. A 2(10), 3461-3467 (2014). https://doi.org/10.1039/C3TA14506A

257. J. Cai, R. Cai, Z. Sun, X. Wang, N. Wei et al., Confining $\mathrm{TiO}_{2}$ nanotubes in pecvd-enabled graphene capsules toward ultrafast K-Ion storage: in situ TEM/XRD study and DFT analysis. Nano-Micro Lett. 12(1), 123 (2020). https://doi.org/10.1007/ s40820-020-00460-y 